\title{
Title: Political repression motivates antigovernment violence
}

Authors: Henrikas Bartusevičius ${ }^{1 *}$, Florian van Leeuwen ${ }^{2}$, Michael Bang Petersen ${ }^{3}$

${ }^{1}$ Peace Research Institute Oslo.

${ }^{2}$ Department of Social Psychology, Tilburg University.

${ }^{3}$ Department of Political Science, Aarhus University.

*Correspondence to: henrikas@prio.org

Note: This manuscript has not yet been peer-reviewed. 
Abstract: Political repression is a ubiquitous phenomenon; yet how it affects human psychology is not well understood. We examined whether repression deters citizens from engaging in antigovernment behavior (its intended goal), or in fact motivates it. Analyses of 101 nationally representative samples from three continents $(\mathrm{N}=139,266)$ revealed a positive association between perceived levels of repression and intentions to engage in antigovernment violence. Additional analyses of fine-grained data from three countries characterized by widespread repression and antigovernment violence $(\mathrm{N}=2,960)$ identified a positive association between personal experience with repression and intentions to engage in antigovernment violence. Randomized experiments revealed that memories about repression also motivate participation in antigovernment violence. These results suggest that political repression, aside from being normatively abhorrent, creates psychological conditions for political violence. 
The majority of the world's population faces threats to their basic human rights ${ }^{1}$, and levels of political repression currently show an upward trend ${ }^{2}$, reflecting an overall global decline in democracy ${ }^{3}$. These global trends suggest an urgent need to understand how political repression affects ordinary citizens. Political repression can range from surveillance and harassment of ordinary citizens to torture and "disappearances" of opposition activists. The goal of repression is to quell the opposition that is contesting power and to prevent citizens from engaging in antigovernment activities or having antigovernment views ${ }^{4}$. But how do people react to such coercion?

Political repression enforces social hierarchies and group-based discrimination ${ }^{5}$, and perceptions of discrimination are associated with lower well-being ${ }^{6}$. Political repression also undermines people's sense of power, and lack of power intensifies negative emotions, weakens positive ones $^{7-10}$, strengthens behavioral inhibitions ${ }^{11}$, and impedes goal pursuit ${ }^{12,13}$. Political repression - particularly if violent — also generates severe psychological distress, often leading to depression and/or post-traumatic stress disorder ${ }^{14,15}$, which in turn are associated with apathy and inactivity. Hence, research on the psychological consequences of repression (or other variables associated with repression) suggests that political repression deters antigovernment behavior.

However, only a handful of studies have directly analyzed how repression affects people's motivations to engage in collective actions against the repressors. Some studies have analyzed covert or individual behaviors, such as redefining one's identity, using humor, or other forms of psychological resistance to repression ${ }^{16-18}$. Other studies have examined collective actions in repressive contexts; yet this research has focused on the psychological antecedents of participation in collective actions, such as risk perceptions, not on repression as the driving cause $^{19,20}$. The few existing studies that have analyzed repression as the driving cause relied on single-country samples and analyzed dissent as an aggregate category, without distinguishing 
between non-violent and violent forms ${ }^{21,22}$. The larger literature on collective action has typically focused on injustice (or its associated emotion, anger) as an aggregate category, rather than political repression as $\operatorname{such}^{23}$. In addition, most research on collective action has relied on samples from Western democracies and analyzed non-violent collective actions, such as protests or strikes $^{24}$. Taken together, it remains unclear how political repression affects people's motivations to engage in collective actions against the repressors, particularly when it involves non-Western populations and antigovernment violence - the most destabilizing form of dissent.

The question of whether repression deters or motivates antigovernment violence has also been a subject of extensive research within political science, sociology, and economics ${ }^{4,25-27}$. This research has typically examined the repression-violence link at a higher level of aggregation, for example, by averaging the incidence of repression events over some periods (e.g., years) and political or geographic units (e.g., countries), and then correlating it with similarly aggregated incidence of antigovernment violence. The findings of the macro research are inconsistent: By far the most long-standing and stable influence on state repression concerns political conflict... [But] when the causal arrow is reversed and one considers research that investigates the influence of repressive behavior on dissent...the results are highly inconsistent. Sometimes the impact of repression on dissent is negative...sometimes it is positive...sometimes it is represented by an inverted $\mathrm{U}$-shape...sometimes it is alternatively negative or positive....and sometimes it is nonexistent...Both findings viewed together [are referred] to as the "Punishment Puzzle."

Arguably, the "Punishment puzzle" cannot be solved until we address the elemental question of how people, themselves, react to repression. This question remains underexplored in the voluminous macro literature, partly because the "data at the individual level are not easily available, particularly in the contexts of severe repression" 27 . 
A holistic account of the repression-dissent link must explain how repressed individuals are mobilized for collective action against the repressors, the tactical choices available to dissidents and repressors, and many other processes and variables ${ }^{4,25,27}$. However, the complex path from repression to organized antigovernment violence always starts with people's psychological reactions to repression. Hence, a micro-level, psychological account is crucial to address the "Punishment puzzle". If micro evidence shows that repression motivates antigovernment violence, then this provides a plausible explanation for the macro finding that repression sometimes quells dissent: despite causing motivations for violence, repression also undermines the mobilization of the repressed (e.g., repressors often detain opposition leaders who are instrumental in mobilization processes). By contrast, if micro evidence suggests that repression deters antigovernment violence, then this suggests a principal mechanism through which repression "works": repression deters the repressed themselves (e.g., by undermining people's sense of power, as suggested by the psychological research reviewed above).

Whether repression deters or motivates antigovernment violence also epitomizes a more basic debate across the social sciences. Research shows that cost imposition ("punishment') is generally an effective deterrent ${ }^{28}$. However, research also shows that cost imposition, if deemed unfair, elicits strong feelings of revenge, which are then pursued even at additional $\operatorname{costs}^{29}$.

Corresponding to these debates, we examined whether political repression (unjust cost imposition) motivates people to engage in antigovernment violence (costly and risky collective action). To advance research on collective actions, we enlisted large multinational survey data from non-Western samples. Furthermore, we conducted randomized experiments. Our analyses thus aimed to maximize external and ecological validity, while at the same time addressing characteristic threats to internal validity: reverse causality and omitted variable bias. 
The analyses proceed in three steps. We started with an extensive search and analysis of existing survey data that included questions about political repression and antigovernment violence. These analyses relied on questions about repression available in the multinational datasets, largely reflecting moderate repression forms (e.g., restrictions of civil liberties). In the second step, we collected and analyzed original data on a wide range of repression and violence measures by interviewing individuals from countries with widespread repression: Belarus, Venezuela, and Nicaragua. In the final step, we analyzed random-assignment experiments that were embedded in our original surveys in the three countries. 


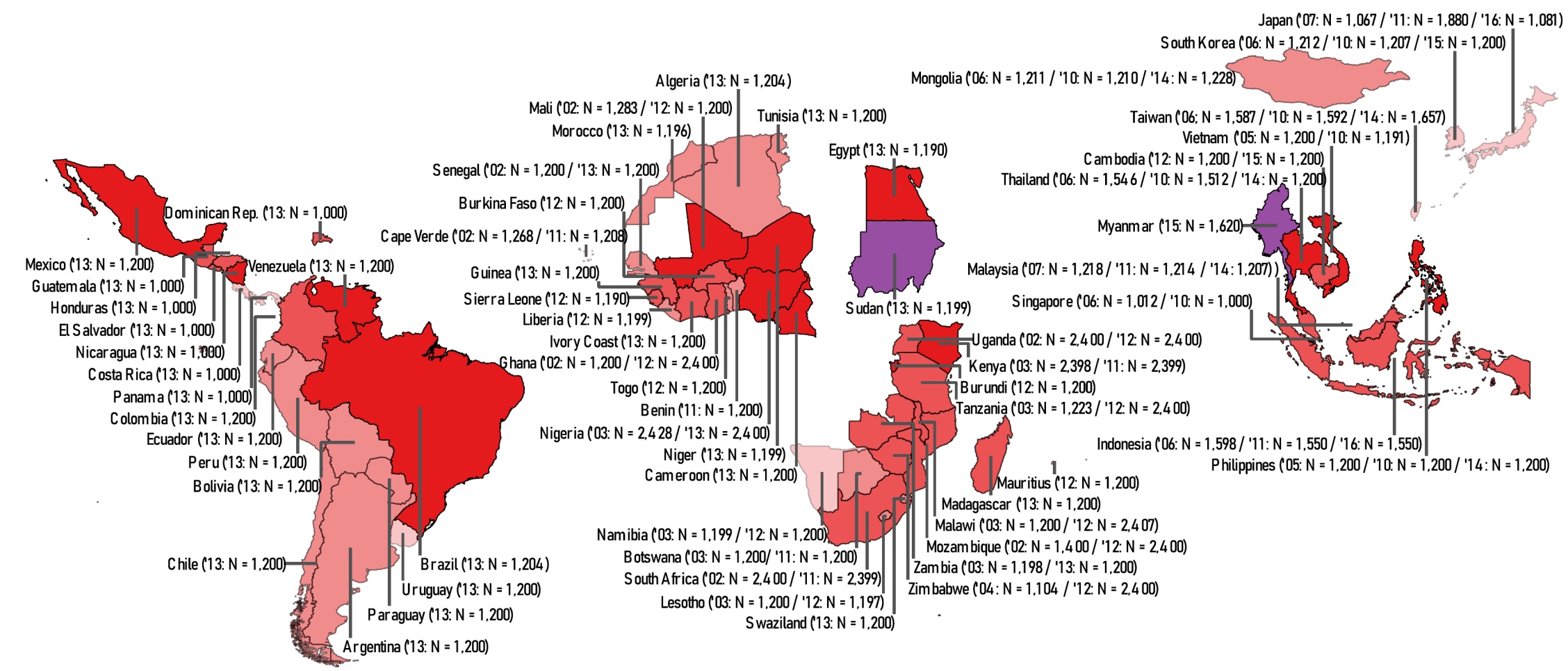

Political Terror Scale (US State Department scores)

$\square$ 1: Countries under a secure rule of law, people are not imprisoned for their views, and torture is rare or exceptional. Political murders are extremely rare.

2: There is a limited amount of imprisonment for nonviolent political activity. However, few persons are affected, torture and beatings are exceptional. Political murder is rare.

3: There is extensive political imprisonment, or a recent history of such imprisonment. Execution or other political murders and brutality may be common. Unlimited detention, with or without a trial, for political views is accepted.

4: Civil and political rights violations have expanded to large numbers of the population. Murders, disappearances, and torture are a common part of life. In spite of its generality, on this level terror affects those who interest themselves in politics or ideas.

5: Terror has expanded to the whole population. The leaders of these societies place no limits on the means or thoroughness with which they pursue personal or ideological goals.

Fig. 1. Countries (with survey years and sample sizes in parentheses) included in the multinational analyses. Color-coding represents The Political Terror Scale ${ }^{2}$. 


\section{Results}

Multinational analyses. We identified six multinational datasets that included questions about political repression and antigovernment violence: Afrobarometer Round 2, Afrobarometer Round 5, Latinobarómetro 2013, Asianbarometer Round 2, Asianbarometer Round 3, and Asianbarometer Round $4^{30-32}$. Combined, these datasets span the 65 countries shown in Figure 1 (101 independent samples; $\mathrm{N}=139,266$ ). The questions about antigovernment violence (Table 1) and repression (Table 2) are equivalent but not identical in all six datasets; therefore, we did not merge them into one. As the main outcome measures, we used binary-coded indicators of behavioral intentions to engage in political violence at the time of interview ${ }^{33}$. Behavioral intentions predict—and causally relate to — actual behavior ${ }^{33,34}$, including participation in costly collective actions $^{23}$. Even among frontline combatants in civil wars, stated and actual behaviors (e.g., sacrifices on the frontline) converge ${ }^{35}$. These measures also allow for assessing motivations for violence independent of opportunities: people who have not participated in violence might have taken part in it if they had opportunities, and such opportunities may be limited for reasons be-

15 yond our scope (e.g., sickness). We also analyzed binary-coded behavioral self-reports of actual participation in violence (reporting issues are addressed in Discussion). As the main predictor, we derived a perceived repression scale (PRS) using a factor analysis of available items in the datasets. Higher PRS scores indicate higher levels of repression as subjectively assessed by interviewees. 
Table 1. Overview of the questions used to measure the outcome variables

\begin{tabular}{|c|c|}
\hline Multinational surveys & $\begin{array}{l}\text { Measures of behavioral intentions to participate in antigovernment violence and } \\
\text { self-reported participation }\end{array}$ \\
\hline Afrobarometer Round 5 & $\begin{array}{l}\text { Here is a list of actions that people sometimes take as citizens. For each of these, please tell me } \\
\text { whether you, personally, have done any of these things during the past year. If not, would you do } \\
\text { this if you had the chance... Used force or violence for a political cause. } \\
\text { Answer options: No, would never do this; No, but would do if had the chance; Yes, once or twice; } \\
\text { Yes, several times; Yes, often; Don't know. } \\
\text { PVINTENTIONS was a binary indicator reflecting a subset of the reply options: } 0=\text { No, would } \\
\text { never do this; } 1=\text { No, but would do if had the chance. } \\
\text { PVPARTICIPATION was a binary indicator: } 0=\text { No, would never do this and No, but would do } \\
\text { if had the chance; } 1 \text {-Yes, once or twice; Yes, several times; and Yes, often. }\end{array}$ \\
\hline Afrobarometer Round 2 & Same as in Afrobarometer Round 5 \\
\hline Latinobarómetro 2013 & $\begin{array}{l}\text { Here is a list of actions that people sometimes take as citizens. For each of these, please tell me } \\
\text { whether you, personally, have never, once, or more than once done any of these things during } \\
\text { the past three years... Used force or violence for a political cause. } \\
\text { - PVINTENTIONS: Not measured in Latinobarómetro } 2013 \text {. } \\
\text { - PVPARTICIPATION was a binary indicator: } 0=\text { never; } 1=\text { once and more than once. }\end{array}$ \\
\hline Asianbarometer Round 4 & $\begin{array}{l}\text { Here is a list of actions that people sometimes take as citizens. For each of these, please tell me } \\
\text { whether you personally, have never, once, or more than once done any of these things during the } \\
\text { past three years... Used force or violence for a political cause. } \\
\text { - PVINTENTIONS: } 0=\text { I have not done this and I would not do it regardless of the situation; } 1 \\
\text { = I have not done this, but might do if something important happens in the future. } \\
\text { PVPARTICIPATION: } 0=I \text { have not done this and I would not do it regardless of the situation } \\
\text { and I have not done this, but might do if something important happens in the future; } 1= \\
\text { once and more than once. }\end{array}$ \\
\hline Asianbarometer Round 3 & $\begin{array}{l}\text { PVINTENTIONS: Not measured in Asianbarometer Round } 3 . \\
\text { PVPARTICIPATION: Same as in Latinobarómetro } 2013 .\end{array}$ \\
\hline Asianbarometer Round 2 & $\begin{array}{l}\text { PVINTENTIONS: Not measured in Asianbarometer Round } 2 . \\
\text { PVPARTICIPATION: Same as in Latinobarómetro } 2013 .\end{array}$ \\
\hline \multicolumn{2}{|l|}{ Original surveys } \\
\hline Belarus/EHU & $\begin{array}{l}\text { Here is a list of actions in which people might participate. Please tell me how likely it is that you } \\
\text { would do any of these things, where } 0 \text { means that you would never do this, and } 6 \text { means that you } \\
\text { would certainly do this if you had the chance. } \\
\text { [1] Tell a friend that, in some circumstances, it is justified to use violence for a political cause. } \\
\text { [2] Use force or violence for a political cause. } \\
\text { - PVINTENTIONS was the average score of these two items. } \\
\text { - PVPARTICIPATION: Not measured in this sample. } \\
\text { - We also measured support for violence, using a double list experiment with the sensitive } \\
\text { item It is justifiable to use violence against the government of Belarus (see Methods). }\end{array}$ \\
\hline Venezuela & $\begin{array}{l}\text { - } \\
\text { - } \quad \text { PVINTENTIONS: Same as in Afrobarometer Rounds } 2 \text { and } 5 . \\
\text { - } \quad \text { Radicalism Intention Scale (RIS) consisting of four items (e.g., I would participate in a } \\
\text { public protest against oppression of my group even if I thought the protest might turn vio- } \\
\text { lent). Answer options ranged from } 0=\text { Very unlikely to } 6=\text { Very likely. } \\
\text { - } \quad \text { Double list experiment similar to Belarus/EHU (see Methods). } \\
\text { Additional 4-item measure of PVINTENTIONS was included after the vignette experiment } \\
\text { (see Methods). }\end{array}$ \\
\hline & e \\
\hline
\end{tabular}




\begin{tabular}{|c|c|}
\hline Multinational surveys & Measures of perceived repression \\
\hline Afrobarometer Round 5 & $\begin{array}{l}\text { Perceived Repression Scale (PRS) of three items: } \\
\text { In this county, how free are you: } \\
\text { [1] To say what you think. } \\
\text { [2] To join any political organization you want. } \\
\text { [3] To choose who to vote for without feeling pressured. } \\
\text { Answer options ranged from } 0=\text { Completely free to } 3=\text { Not at all free. }\end{array}$ \\
\hline Afrobarometer Round 2 & $\begin{array}{l}\text { PRS of three items: } \\
\text { We are going to compare our new government under [...] with the former government under [...]. } \\
\text { Please tell me if the following things are worse or better now than they used to be or about the } \\
\text { same: } \\
\text { [1] Freedom to say what you think. } \\
\text { [2] Freedom to join any political organization you want. } \\
\text { [3] Freedom to choose who to vote for without feeling pressured. } \\
\text { Answer options ranged from } 0=\text { Much better to } 4=\text { Much worse. }\end{array}$ \\
\hline Latinobarómetro 2013 & $\begin{array}{l}\text { PRS of two items: } \\
\text { How would you evaluate the current government's performance... } \\
\text { [1] regarding individual freedom of expression, very good, good, poor, or very poor? } \\
\text { And [2] regarding press freedom? } \\
\text { Answer options ranged from } 0=\text { Very good to } 3=\text { Very poor. }\end{array}$ \\
\hline Asianbarometer Round 4 & $\begin{array}{l}\text { PRS of two items: } \\
\text { Now I am going to read to you a list of statements that describe how people often feel about the } \\
\text { state of affairs in [country name]. Please tell me whether you strongly agree, somewhat agree, } \\
\text { somewhat disagree, or strongly disagree with each of these statements... } \\
\text { [1] People are free to speak what they think without fear. } \\
\text { [2] People can join any organization they like without fear. } \\
\text { Answer options ranged from } 0=\text { Strongly agree to } 3 \text { = Strongly disagree. }\end{array}$ \\
\hline Asianbarometer Round 3 & As in Asianbarometer Round 4 \\
\hline Asianbarometer Round 2 & As in Asianbarometer Round 4 \\
\hline Original surveys & Measures of perceived and experienced repression \\
\hline Belarus/EHU & $\begin{array}{l}\text { In some countries, the government (or people working for government) might use intimidation or } \\
\text { violence against citizens. The government (or people working for the government) might use in- } \\
\text { timidation or violence to stop people from participating in certain activities or having certain } \\
\text { political views. Below are several things that may or may not happen to a person. Please indicate } \\
\text { how often a typical person in Belarus would experience the things below (0 =never, } 1=\text { rarely, } 2 \\
\text { = sometimes, } 3=\text { often). } \\
\text { The list included } 13 \text { events (e.g., "Imprisonment without fair trial"; see Figure } 2 \text { for others). } \\
\text { Subsequently, interviewees were asked to answer the same } 13 \text { questions considering their friends } \\
\text { and family, and then for themselves } \\
\text { Please indicate how often people you care about (your friends and family) have experienced the } \\
\text { things below. } \\
\text { Please indicate how often you personally have experienced the things below. }\end{array}$ \\
\hline Venezuela & Same as in Belarus/EHU. \\
\hline Nicaragua & Same as in Belarus/EHU. \\
\hline
\end{tabular}


Hierarchical modeling identified significant and positive associations between PRS and all outcomes in all datasets. Table 3 below reports estimated average marginal effects of PRS on the probabilities of intentions to participate in violence and self-reported participation (Tables S10-S13 in Supplementary Information provide detailed estimates). According to the estimates based on Afrobarometer Round 5 (for example), a highly repressed individual (PRS=1), compared to a non-repressed $(\mathrm{PRS}=0)$, is approximately 3 percentage points more likely to report participation in violence, and 4 percentage points more likely to report intentions to do so. For comparison, men (compared to women) are 1 percentage point more likely to report participation in violence $(\mathrm{p}<0.001)$ and 2 percentage points more likely to report intentions to do so ( $\mathrm{p}<$ 0.001). Gender is an established predictor of violence and aggression ${ }^{36}$.

We focused on antigovernment violence; however, we also explored how repression affects motivations to participate in non-violent collective actions, namely, protests and demonstrations. We identified significant and positive associations between PRS and intentions to participate in protests/demonstrations and self-reported participation in the samples of Afrobarometer Round 5 and Asianbarometers Round 2-4, but not in the samples of Afrobarometer Round 2 and Latinobarómetro 2013 (Tables S14-S17 provide detailed estimates). 
Table 3. Intentions to participate in antigovernment violence and self-reported participation as a function of the perceived repression scale (PRS). The table reports average marginal effects (with corresponding 95\% CIs and p-values) of the PRS on the probabilities of intentions to participate antigovernment violence and self-report participation. Latinobarómetro 2013 and Asianbarometer Rounds 2 and 3 lack measures of intentions to engage in violence. Asianbarometer Rounds 2-4 contain identical questions on participation in violence and repression; therefore, these datasets were combined into one for the analysis of participation. Tables S10-S13 in Supplemental Materials provide detailed estimates. For modeling choices and robustness tests, see Methods below.

\begin{tabular}{|c|c|c|c|}
\hline & & $\begin{array}{l}\text { Behavioral intentions } \\
\text { to participate in } \\
\text { antigovernment violence }\end{array}$ & $\begin{array}{l}\text { Behavioral self-reports } \\
\text { of participation in } \\
\text { antigovernment violence }\end{array}$ \\
\hline Afrobarometer Round 5 & 34 samples, $\mathrm{N}=51,587$ & $\begin{array}{c}\mathbf{4 . 1 \%} \\
95 \% \mathrm{CI}=[2.9,5.1] \\
\mathrm{p}<0.001 \\
\end{array}$ & $\begin{array}{c}\mathbf{3 . 3 \%} \\
95 \% \mathrm{CI}=[2.3,4.2] \\
\mathrm{p}<0.001 \\
\end{array}$ \\
\hline Afrobarometer Round 2 & 16 samples, $\mathrm{N}=24,301$ & $\begin{array}{c}\mathbf{5 . 8 \%} \\
95 \% \mathrm{CI}=[3.7,8.0] \\
\mathrm{p}<0.001 \\
\end{array}$ & $\begin{array}{c}\mathbf{4 . 1 \%} \\
95 \% \mathrm{CI}=[2.6,5.6] \\
\mathrm{p}<0.001 \\
\end{array}$ \\
\hline Latinobarómetro 2013 & 18 samples, $\mathrm{N}=20,204$ & - & $\begin{array}{c}\mathbf{1 . 6 \%} \\
95 \% \mathrm{CI}=[0.2,2.9] \\
\mathrm{p}<0.001 \\
\end{array}$ \\
\hline Asianbarometer Round 4 & 11 samples, $\mathrm{N}=14,360$ & $\begin{array}{c}\mathbf{3 . 9 \%} \\
95 \% \mathrm{CI}=[1.1,6.6] \\
\mathrm{p}=0.006\end{array}$ & \\
\hline Asianbarometer Round 3 & 12 samples, $\mathrm{N}=15,963$ & - & $\begin{array}{c}\mathbf{0 . 7 \%} \\
95 \% \mathrm{CI}=[0.2,1.3] \\
\mathrm{p}=0.013\end{array}$ \\
\hline Asianbarometer Round 2 & 10 samples, $\mathrm{N}=12,851$ & - & \\
\hline
\end{tabular}


Analyses of original data from Belarus, Venezuela, and Nicaragua. We first conducted a pilot survey of citizens of Belarus, a state with a robust security apparatus. We assumed that citizens of Belarus would have a realistic grasp of risks involved in violence against a repressive regime, and hence report realistic behavioral intentions. Following our discussions with area experts, we concluded that conducting a survey about repression and antigovernment violence would be unfeasible in Belarus. Therefore, utilizing an unusual situation, we interviewed Belarussians in Lithuania, which hosts the European Humanities University (EHU), relocated from Belarus after a forced closure by the regime. The interviewees $(\mathrm{N}=386)$ were students who either reside in Belarus and visit EHU for exams or reside in Lithuania for the whole study period. Hence, the EHU sample provided a unique opportunity to pilot and develop our survey instrument in close contact with those who have first-hand experience with repression.

We then searched for opportunities to collect large probability samples via online surveys in countries experiencing both repression and antigovernment violence. We assumed that interviewees from these countries would also report realistic behavioral intentions. In addition, we expected such samples to contain actual participants in violence. We first interviewed citizens of Venezuela $(\mathrm{N}=1,000)$, which experienced antigovernment protests during the survey period (September 2017), with hundreds of deaths and thousands injured. Five months prior to our survey, up to six million people ( $1 / 5$ of the population) reportedly participated in the nationwide Mother of all Marches ${ }^{37}$. Our surveyed sample thus likely contained individuals who participated in antigovernment protests, or at least observed such protests in their immediate environments. We then conducted a pre-registered (link to the pre-registration at OSF) replication study in Nicaragua $(\mathrm{N}=1,574)$, which also experienced violent large-scale protests prior to and during the survey period (October 2018). 
At EHU, we included a continuous scale of intentions to engage in antigovernment violence (Table 1). In Venezuela and Nicaragua, we used two binary outcomes analogous to those in the multinational analyses. We also obtained the Radicalism Intention Scale (RIS) ${ }^{38}$, an established multi-item measure of intentions to engage in violence. To assess whether interviewees underreport their true intentions (e.g., due to fears of reprisals), we also measured behavioral intentions via list experiments ${ }^{39}$. We found little evidence of such underreporting (see Discussion); hence, our main analyses relied on the standard measures.

Repression was measured with a 39-item instrument that we developed based on existing literature and on our pilot study, following multiple rounds of discussions with EHU staff and students (Table 2). We subdivided the items into (i) beliefs about the repression of typical people, (ii) experience of repression among friends and family, and (iii) personal experience of repression. Figure 2 provides all items. All samples reported widespread repression. For example, roughly every eighth (11.97\%) EHU student reported property confiscation by police and nearly half $(44.77 \%)$ reported such confiscation among friends and family. Every third to fourth in Venezuela $(34.56 \%)$ and Nicaragua $(28.03 \%)$ reported having been physically beaten by police or other people working for the government. 

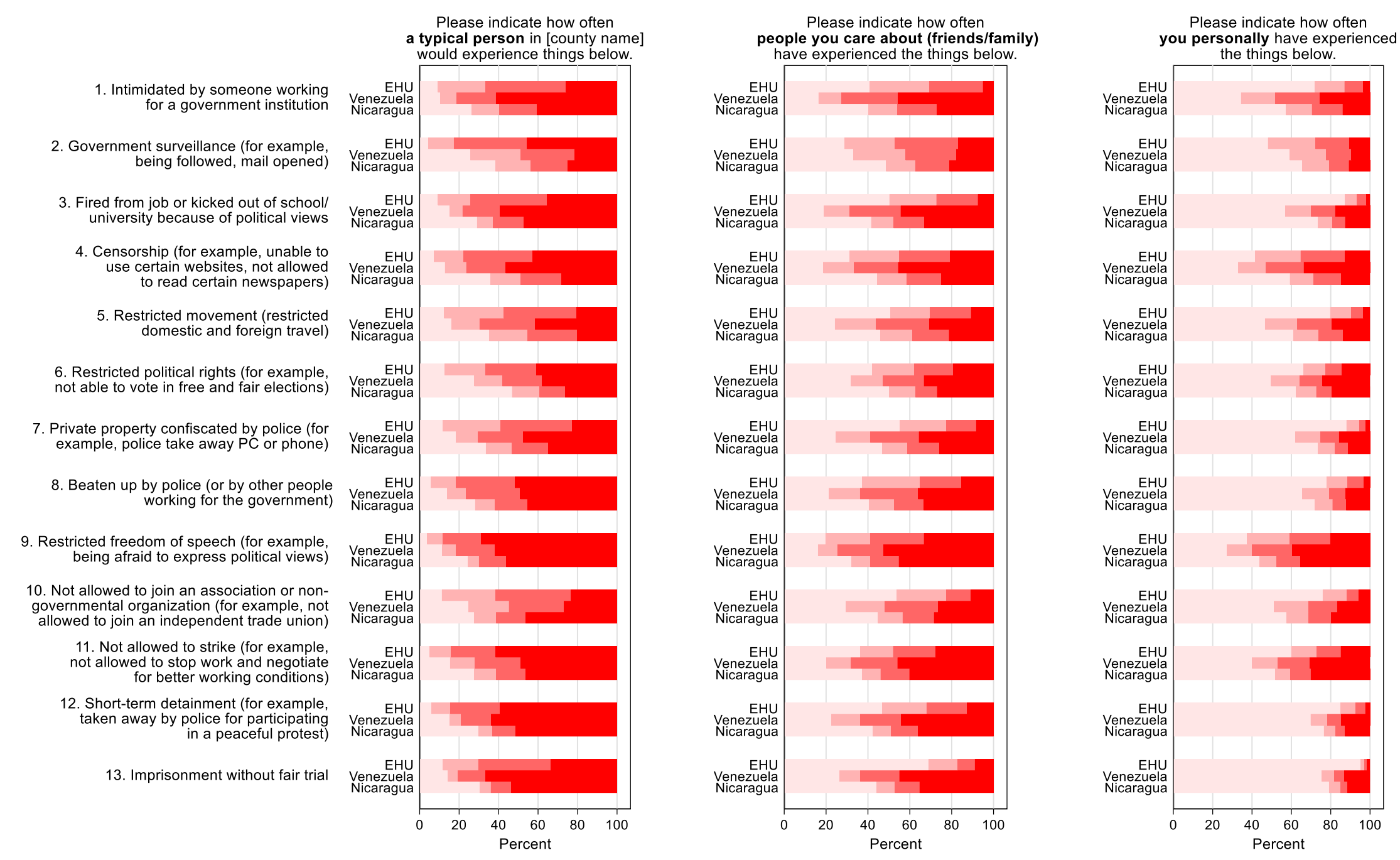

\begin{tabular}{|l|l|l|l|}
\hline Never & Rarely & Sometimes & Often \\
\hline
\end{tabular}

Fig. 2. Political repression in EHU, Venezuela, and Nicaragua. 
Repression significantly varied with intentions to engage in violence and self-reported participation. Figure 3 reports the main results (all variables are normalized to range from 0 to 1 ) (Tables S26-S31, S34, S35, S38-S41, S44, S45 provide detailed estimates). An aggregate 39item repression scale (RS) significantly and positively predicted all outcomes in all samples. The sub-types of repression by the target of repression also significantly predicted all outcomes in all samples, save for RS (typical people) at EHU. We also analyzed high-intensity repression (violence/intimidation; Items 1, 8, 12, and 13; see Figure 2) and low-intensity repression (restrictions of civil liberties; all other items). Both significantly predicted all outcomes in all samples. The analyses also revealed substantial effect sizes. For example, a highly repressed citizen of Nicaragua $(\mathrm{RS}=1)$ compared to a non-repressed citizen $(\mathrm{RS}=0)$ was roughly 15 times more likely to report participation in violence, $0.44 \%$ vs. $6.85 \%$, and six times more likely to report intentions to participate in violence, $3.03 \%$ vs. $18.18 \%$. Analogous probabilities for Venezuela were even higher: $0.46 \%$ vs. $14.74 \%$ and $5.27 \%$ vs. $39.64 \%$.

Repression also significantly varied with motivations to engage in non-violent collective actions. The aggregate repression scale (RS), and all the repression sub-scales (typical people, friends/family, self, high intensity, and low intensity), significantly and positively predicted intentions to engage in protests/demonstrations and self-reported participation in Venezuela (Tables S32, S33, S36, S37) and Nicaragua (Tables S42, S43, S46, S47) (in EHU, we only measured violent outcomes). 

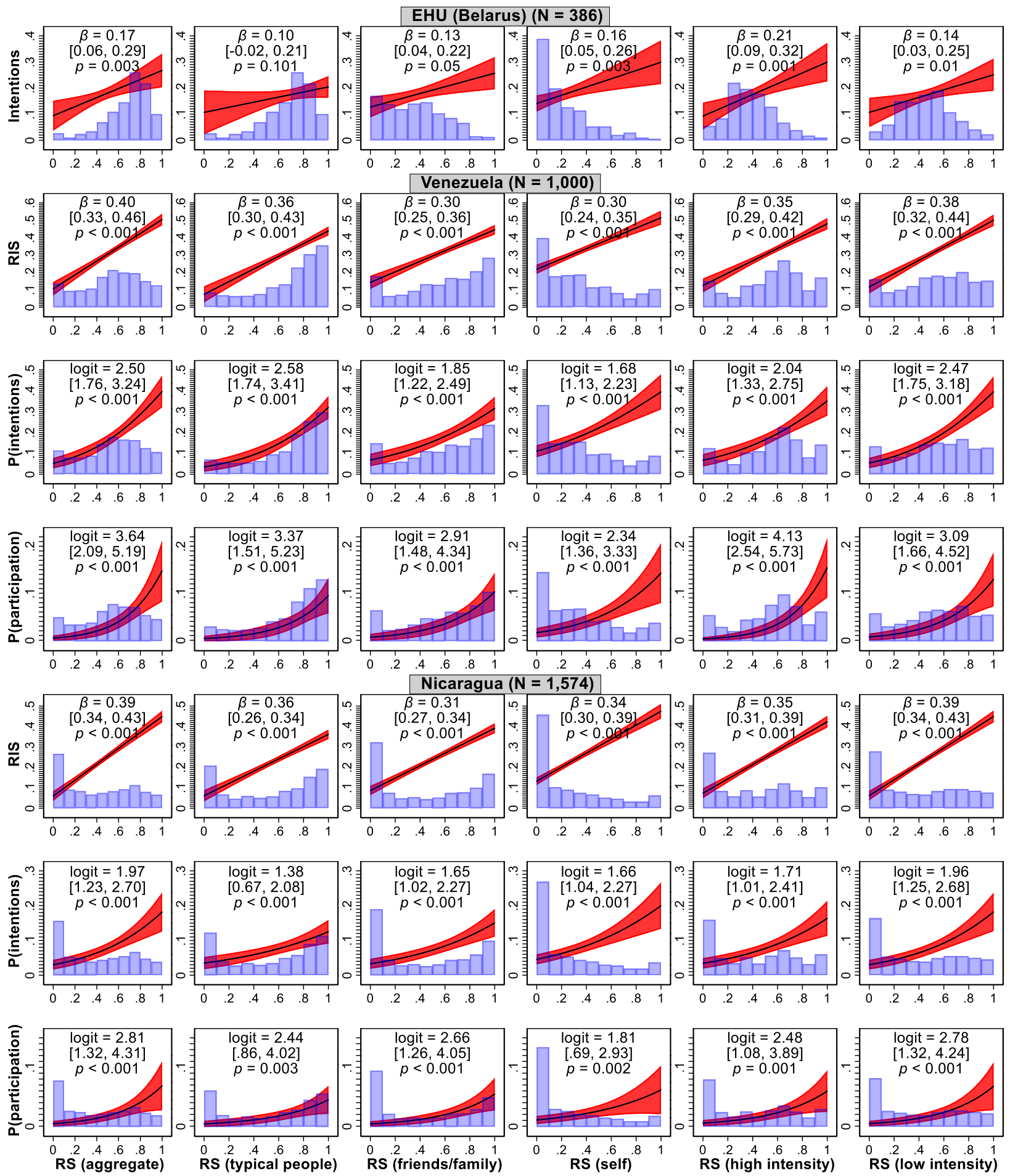

Fig. 3. Predicted values and probabilities (with 95\% CIs) of radicalism intentions (RIS), intentions to participate in political violence, and self-reported participation in political violence as a function of repression scales (RS). Predictors and outcomes are 0-1 normalized. 
Random-assignment experiments. Repression cannot be experimentally administered;

therefore, drawing on established experimental paradigms ${ }^{40,41}$, we developed designs to manipulate thoughts or memories about repression. We assumed that memories about repression evoke psychological responses that resemble those evoked by the actual experience. These experiments also tap into familiar real-world scenarios, for example, where opposition leaders refer to repression (e.g., in a public speech) to mobilize opposition. In the pilot study at EHU, we asked interviewees to write down their thoughts about repression events. However, half of the interviewees left the description boxes blank. Therefore, for Venezuela and Nicaragua we developed an alternative questions-as-treatments design, which used questions about repression themselves as a manipulation instrument. Replying to 39 questions, as listed in Figure 2, naturally induces thoughts and memories of repression. Thus, we randomly assigned half of the interviewees to answer the questions about repression before they answered the questions about violence, while the other half immediately answered questions about violence. In Venezuela, considering repression increased intentions to participate in violence from $15.6 \%$ to $21.8 \%(\mathrm{p}=0.017)$ and radicalism intentions from 0.289 to $0.348(\mathrm{p}=0.001$ ). Estimates in Nicaragua were $5.27 \%$ vs. $9.89 \%$ (p $<0.001)$ and 0.200 vs. $0.243(\mathrm{p}=0.003)$, respectively.

We also assessed a corollary prediction that remedying repression reduces violent intentions. Specifically, we embedded vignette experiments in Venezuelan and Nicaraguan surveys, describing a familiar (hypothetical) event: in the context of antigovernment protests, a video circulates online showing a police officer beating a non-armed protester, who reportedly eventually died. The vignette continues with the president stating that "he will not tolerate police brutality and that there would be a comprehensive investigation of the event" (experimental condition), or that "the authenticity of the video could not be established and that there would be no further 
investigation of the event". Interviewees then completed a 4-item scale of intentions to engage in violence. In Venezuela, remedial actions by state authorities reduced intentions to engage in violence by approximately $18 \%$ (from 0.197 to 0.161$)(\mathrm{p}=0.039)$; and in Nicaragua, by approximately $36 \%$ (from 0.104 to .066$)(\mathrm{p}<0.001)$.

It is possible that some of our interviewees did not realistically assess the risks involved in antigovernment violence, despite observing protester-government clashes in their natural settings. Therefore, using an additional manipulation, we asked a random half of Nicaraguan interviewees to explicitly consider risks of "injury, capture, and imprisonment" prior to reporting violence intentions - and found that such priming did not influence the reported intentions for antigovernment violence, $b=0.01, \mathrm{SE}=0.01, \mathrm{t}(1488)=0.69, \mathrm{p}=.492$. This suggests that even without an explicit reminder of the risks, interviewees considered the risks involved in violence while reporting behavioral intentions.

\section{Discussion}

State authorities use repression to subdue political opposition. Our studies find, however, that such coercion creates psychological conditions for antigovernment violence. Whether violence indeed breaks out depends on multiple other processes, some of which are also influenced by repression. Aside from citizen's motivations, repression influences the opposition's opportunities for mobilization. Jailing opposition activists, for example, can cause anger among citizens but, at the same time, undermine their ability to mobilize for a collective action against the repressors.

20 These group- or state-level processes have been extensively examined within sociology and political science ${ }^{25}$, and are beyond our study's scope. We focused on a more elemental, micro-level question of whether repression decreases or increases citizens' motivations for violence. We 
found that repression strongly motivates antigovernment violence. This implies that if such violence does not occur, then this is likely due to undermined mobilization opportunities. Hence, repressive tactics may quell the opposition in the short term, but at the cost of alienating ordinary citizens, who_-given the opportunity—will more likely resort to violence.

Corroborating this, research has documented a relationship between popular support for political violence and actual events of such violence. Using Afrobarometer data, Linke et al. ${ }^{42}$ tested whether average levels of people's endorsement of political violence in administrative units at certain periods predicted political violence events in those units at subsequent periods, finding a positive association. Linke et al. focused on attitudinal support for/endorsement of political violence. Attitudinal support for violence is not synonymous with intentions to engage in violence (i.e., what we measured), but the two are closely related. In standard collective action models in social psychology, attitudinal support for/endorsement of collective action is considered as the first step, preceding motivations or intentions, in the processes leading to participa$\operatorname{tion}^{23,43}$. In these models, analogously to other models of attitude-behavior relations ${ }^{34,44}$, intentions to engage in collective actions are considered as closer proxies of actual participation, compared to mere attitudes. Hence, if attitudes toward violence predict actual incidence of violence - as shown by Linke et al.- - then intentions should do so stronger. Whether this is indeed true is an interesting empirical question but beyond the scope of our research, which centers on people's motivations.

More generally, our findings corroborate the emerging literature across the behavioral sciences on the psychology operating behind the feelings of revenge ${ }^{29}$. Repression - as unjust cost imposition - motivates retaliation, despite risks and costs. Theoretical accounts conceptualize revenge (or retaliatory aggression) as a negotiation tool designed to up-regulate the weight of 
the retaliator's welfare in the social decisions of others ${ }^{29,45}$. By imposing costs on individuals who put too little weight on the retaliator's welfare, revenge serves as an incentive for targets and bystanders to place more weight on the welfare of the agent. Over evolutionary history, organisms that could not defend their fitness interests in this way faced significant costs; therefore, today we observe revenge behavior not only among humans but virtually across all social spe$\operatorname{cies}^{45}$. As such, the psychology regulating revenge is deep-seated and exerts powerful influence on behavior ${ }^{46}$.

Our findings also concur with recent research on collective actions in repressive contexts, showing that perceived risks of government sanctions increase-not decrease-motivations to engage in collective actions ${ }^{19,20}$. In particular, Ayanian et al. ${ }^{20}$ surveyed protesters in Russia, Ukraine, Hong Kong, and Turkey. The authors examined how intentions to participate in future non-violent protests were influenced by perceived risks and several mediating variables. The results showed that perceiving more risk was associated with stronger intentions to the participate in future protests, and that this relation was mediated by outrage, efficacy, and several other variables. The measure of perceived risk that Ayanian et al. used likely also captured perceptions of being repressed (e.g., estimates of the likelihood that protesting leads to being detained). Hence, this research suggests that perceptions of potential repression increase motivations to participate in future protests, at least among individuals who already participated in protest. Our studies show consistent results. Using other measures of repression (which focus on experience of repression, not potential) and intentions to engage in both non-violent and violent dissent, as well as broader samples and experimental manipulations, we also found that repression motivates antigovernment dissent. 
Generally, extant research hitherto has analyzed non-violent forms of collective actions and relied on relatively small samples from a limited set of countries. Here, using large and nationally representative samples from $1 / 3$ of all world's countries, we present evidence that repression motivates both non-violent and violent collective actions. Our studies show that political repression less reliably predicts participation in non-violent collective actions than in antigovernment violence. This implies that political repression may provoke particularly destabilizing forms of resistance, thereby increasing the risk of direct confrontation with the repressors and large-scale political violence.

Limitations. Research on political repression and violence faces several design constrains. First, we cannot experimentally administer the key predictor of interest (i.e., experience of repression). To address this challenge, we developed designs that aimed to manipulate thoughts or memories about repression. These designs draw on established experimental paradigms and invoke the assumption that memories about repression induce responses resembling those evoked by the actual experience. However, we did not assess this assumption empirically. Compared to the actual experience, memories about repression may evoke weaker fear; in such a scenario, our analyses would overestimate the effects of repression on violence. However, memories about repression may also evoke weaker anger; in this scenario, our analyses would underestimate the effects of repression on violence. We are not aware of any approaches to assess these scenarios empirically, as we cannot experimentally manipulate experience of repression. Note, however, that thoughts or memories about repression is an important research subject in its own right. Mobilization processes often involve public discourse about injustices citizens experienced in the past. Our experiments tap into scenarios where opposition leaders refer to past repression events while mobilizing citizens for antigovernment action. Our studies suggest that 
such mobilization discourse, emphasizing repression, can strongly resonate with citizens and holds potential to initiate antigovernment violence. Finally, although the results of the experiments support a causal effect in one direction (repression causing motivations for violence), this does not imply the absence of a causal path in the opposite direction (motivations for violence causing perceptions of repression). Future work may examine whether the relation between violent collective action and repression is bi-directional.

Second, naturalistic observation of the key outcome of interest (i.e., participation in violence) is very difficult. We can measure changes in attitudes and intentions toward violence following an experiment, but we can hardly observe whether interviewees subsequently engage in real-world violence. To address this challenge, we relied on measures of behavioral intentions. The use of such measures as proxies of behavior is standard in psychology $y^{33,34}$. However, although studies suggest that behavioral intentions predict participation in non-violent collective actions (e.g., protests) ${ }^{23}$, the evidence is more limited when it comes to collective violence. Instead of using intentions as proxies of behavior, some studies used interviews of frontline combatants about their behavior in armed conflicts ${ }^{35}$. Such interviews may generate more valid evidence than surveys of behavioral intentions. However, interviewing combatants in armed conflicts faces major logistical, security, and ethical challenges, limiting such research to particular countries and small samples. Multinational studies suggest that predictors of participation in political violence vary greatly across countries ${ }^{47}$; hence, research based on single-country samples may be confounded or moderated by country-specific characteristics. Importantly, combatant interviews confirm that stated behavioral intentions converge with actual behavior, providing a rare piece of evidence on the validity of behavioral intentional measures in the study of political violence $^{35}$. Measures of behavioral intentions also allow assessing people's motivations to take 
part in violence independent of opportunities: people who have not participated in violence could have taken part in it if they had an opportunity to do so. In addition, given that intentions to partake in violence does not constitute actual violence, such measures may also suffer less from reporting bias, compared, for example, to behavioral self-reports. In addition to behavioral intentions or behavioral self-reports, scholars have recently started developing virtual simulations of combat, using professional soldiers as participants ${ }^{48}$. However, at present, all types of evidence on participation in political violence remain scarce, and hence constitute prospective avenues for future research.

Third, given the sensitive nature of our research subject, we potentially faced nonresponse problems. To address this issue, we (a) took a priori measures to prevent non-response bias; and (b) analyzed list experiments, non-response rates, and non-responders, which provided little evidence of such bias. We estimate that non-response bias, if present, has likely generated conservative estimates in our case (for details see Supplementary Methods S2.6).

Finally, state authorities in repressive regimes may not allow surveying citizens about repression and antigovernment violence. Some research therefore relies on convenience samples (e.g., students) and vignettes with hypothetical scenarios or economic games simulating some aspect of political violence. However, individuals exposed to such simulations rarely have firsthand experience with repression or political violence and hence a limited grasp of real-world injustices, risks, and costs involved in violence against repressive regimes. To address this challenge, we searched for opportunities to interview individuals from repressive regimes experiencing widespread violence. EHU, a university relocated to a democratic country, provided us with a unique opportunity to pilot and develop our survey instrument in close contact with those who had fist-hand experience with repression. Subsequently, we searched for opportunities to collect 
larger surveys in countries experiencing repression and political violence. Our surveyed samples likely contained substantial numbers of individuals who directly engaged in antigovernment protests or at least observed them in their immediate environments. We assumed that such interviewees would provide realistic behavioral intentions regarding participation in violence. Still, while replying to survey questionnaires, interviewees may evaluate risks and costs differently compared to when they deliberate actual engagement in antigovernment behavior. To address this challenge, we designed an additional experiment that explicitly asked interviewees to consider risks and costs involved in antigovernment violence. We found that such priming did not influence interviewee's replies, substantiating our measures of behavioral intentions. However, whether interviewees consider risks similarly while stating behavioral intentions in survey questionnaires and while considering actual engagement in violence is another important subject for future research.

Conclusion. Political repression involves abuse of basic human rights and hence is normatively undesirable. This notwithstanding, state authorities, across the globe (Figure 1), continue to utilize repression, expecting to maintain their political power. However, our studies suggests that state authorities underestimate the strength of revenge motivations among citizens they repress. Hence, in addition to normative considerations, our research provides a strategic rationale for governments to halt repression and, instead, use democratic means to address opposition. Reducing repression likely enhances—not undermines—-political stability, and hence may be in the long-term interest of governments.

\section{Methods}

\section{Multinational surveys.}


Samples. We identified six datasets that contain relevant questions about political repression and antigovernment violence: Afrobarometer Round 2 (16 countries with Ns from 1,198 to 2,428; total $\mathrm{N}=24,301$ ), Afrobarometer Round 5 (34 countries with Ns from 1,197 to 2,407; total $\mathrm{N}=$ 51,587), Latinobarómetro 2013 (18 countries with Ns from 1,000 to 2,459; total $\mathrm{N}=22,663$ ), Asianbarometer Round 2 (13 countries with Ns from 849 to 5,098; total N = 19,798), Asianbarometer Round 3 (13 countries with Ns from 1,000 to 3,473; total N = 19,436), and Asianbarometer Round 4 (14 countries with Ns from 1,081 to 4,068; total $\mathrm{N}=19,798)^{30-32}$. Combined, these datasets span 109 independent samples from 67 countries. Due to limited data on some variables, our final analyses spanned 101 independent samples from 65 countries. S1.1 in Supplementary Methods provide further details about the multinational datasets.

Outcome variables. We used two types of outcome measures: behavioral intentional measures, reflecting intentions to participate in antigovernment violence at the time of interview and prospectively (hereafter PVINTENTIONS); and behavioral self-reports of actual participation in antigovernment violence (PVPARTICIPATION). Both measures were binary indicators derived from questions about the use of "force or violence for a political cause" (see Table 1). In robustness tests, we also analyzed original, ordinal versions of this variable (S1.6). Furthermore, we measured PDPARTICIPATION and PDINTENTIONS, which reflect interviewees' motivations to participate and self-reported participation in non-violent protests or demonstration. For complete formulations of the questions used to derive outcome variables, reporting and endogeneity concerns, summary statistics, and histograms, see S1.2 in Supplementary Methods. 
Measures of repression. We derived a perceived repression scale (PRS) based on a factor analysis of items in Afrobarometer Round 5 (see S1.3 in Supplementary Methods). We computed each interviewee's score on the PRS as the mean score over three items: "In this county, how free are you: [1] To say what you think; [2] To join any political organization you want; [3] To choose who to vote for without feeling pressured" (reply options: $0=$ "Completely free", $3=$ "Not at all free", Cronbach's $\alpha=.78)$. The other surveys included two or three similar items. For complete formulations of the questions used to derive PRS, summary statistics, and histograms, see S1.3 in Supplementary Methods.

Control variables. We also analyzed a set of individual-level control variables. Because posttreatment bias is a key concern for analysis of observational data, we limited control variables to a basic set: gender, age, education, subjective socio-economic status (SES), and democratic values. In robustness tests, we controlled for variables related to political activism, mobilization, government support, group-based injustice, contempt toward state authorities, political effica$\mathrm{cy}^{24}$, dishonest responding, and question comprehension. For complete formulations of the questions used to derive controls, summary statistics, and histograms, see S1.4 in Supplementary Methods. Furthermore, drawing on the idea that the amount of selection on the observed controls in a model provides a guide to the amount of selection on unobservables, we estimated the risk of omitted-variable bias and bias-adjusted effects (see S1.6). In addition, we included a number of country-level control variables: national-level repression, political instability, violent crime, violent protests, national economic status, conflict history, and national population size (see S1.4 for details). We also used fixed-effects estimators, as well as several types of multi-level models, to account for country-level confounding (see Modeling below). 
Modeling. We first analyzed Afrobarometer Round 5, which has the largest coverage and the widest range of other items allowing us to assess the robustness of results to a range of alternative modeling choices. The large number of level-2 and level-1 units (i.e., countries and individuals), allowed us to conduct a comprehensive multilevel analysis, accounting for countryspecific factors that potentially confound or moderate the (individual-level) associations of interest. Given binary outcomes, we used hierarchical generalized linear models with the logit link function. To aid interpretation, all covariates were normalized to range from 0 to 1 . After Afrobarometer Round 5, we analyzed Afrobarometer Round 2, Latinobarómetro 2013, and Asianbarometer Rounds 2-4 (Asianbarometers were merged into one dataset). See S1.5 in Supplementary Methods for detailed model specifications and multiple robustness tests.

\section{Original data from Belarus, Venezuela, and Nicaragua.}

Samples. The studies at EHU, Venezuela, and Nicaragua complied with all relevant ethical regulations. Specifically, the study procedures complied with [masked for peer review] University's Code of Conduct as well as the Committee Act of the [masked for peer review] National Committee of Health Research Ethics, which states that "Surveys using questionnaires and interviews that do not involve human biological material (section 14(2) of the Committee Act)" are exempted from approval. Informed consent was obtained from all interviewees.

We administered the EHU survey in Russian in February and March 2017 and collected 386 fully or partly completed questionnaires (nearly half of all EHU students). We then interviewed citizens of Venezuela $(\mathrm{N}=1,000)$ in September 2017. In the Venezuelan sample, 52.7\% of interviewees $(527$ of 1,000) reported participation in protests, and $4.5 \%$ (45) in violence, over 
the last year. Subsequently, we interviewed citizens of Nicaragua $(\mathrm{N}=1,574)$ in October 2018. In this sample, $29.1 \%$ of interviewees $(458$ of 1,574$)$ reported participation in protests and $1.8 \%$ (28) reported participation in violence. Both surveys were administered in Spanish via YouGov, and quota-sampled for age, gender, and geography to obtain nationally representative samples of online populations. See S2.1 in Supplementary Methods for detailed description of data collection procedures.

Outcome variables. The surveys included multiple measures of intentions to participate in antigovernment violence and self-reports of participation in antigovernment violence (Table 1). To assess whether interviewees underreported their true intentions (e.g., due to fears of reprisals), we also measured intentions with an indirect measure (i.e., a double list experiment ${ }^{39}$, see below). Since we found no evidence of such underreporting (see S2.6 Supplementary Methods), our main analyses relied on the standard measures.

The survey at EHU only measured PVINTENTIONS, because there were no salient events of antigovernment violence in Belarus during or prior to the survey. PVINTENTIONS was measured with a 2-item scale ("Tell a friend that, in some circumstances, it is justified to use violence for a political cause", "Use force or violence for a political cause", answered on a 7-point Likert-type scale from $0=$ "would never do this" to $6=$ "would certainly do this", Cronbach's $\alpha=$ $0.79)$.

The EHU questionnaire included an indirect measure of support for violence against the actual government of Belarus, derived from a double list experiment ${ }^{39}$, an item-count technique $^{49}$. A list experiment allows estimating agreement with statements about sensitive topics without asking individual interviewees to explicitly indicate agreement with specific statements, 
which decreases the risk of dishonest or socially desirable responding. The double list experiment is a simple extension of the standard list experiment aimed at increasing estimate accuracy, by having each participant complete two list experiments (lists A and B; see Supplementary Methods S2.2).

In Venezuela and Nicaragua, we measured both PVINTENTIONS and PVPARTICIPATION (as well as PDINTENTIONS and PDPARTICPATION), since these populations experienced large-scale (and violent) antigovernment protests during the survey period. For comparability with multinational analyses, we measured PVINTENTIONS and PVPARTICIPATION using identical questions as in Afrobarometer Rounds 2 and 5. In addition, we obtained an alternative, validated measure of PVINTENTIONS, the Radicalism Intention Scale (RIS) ${ }^{38}$. This scale consists of four items (e.g., " $I$ would participate in a public protest against oppression of my group even if I thought the protest might turn violent"”; 0 = "very unlikely", 6 = "very likely"). The surveys in Venezuela and Nicaragua also included a double list experiment to measure PVINTENTIONS, and another 4-item scale measuring intentions to participate in violence after an experimental vignette (see below).

Measures of repression. In the samples from Belarus, Venezuela, and Nicaragua we measured interviewees' experiences with and perceptions of political repression. We first presented an explanation of what we considered political repression: "In some countries, the government (or people working for government) might use intimidation or violence against citizens. The government (or people working for the government) might use intimidation or violence to stop people from participating in certain activities or having certain political views". The survey then asked 39 questions, subdivided into (1) beliefs about the repression of typical people, (2) experience of repression among friends and family, and (3) personal experience of repression. 
First followed a list of 13 events for which we asked the following question: "Below are several things that may or may not happen to a person. Please indicate how often a typical perSon in Belarus would experience the things below" ( 0 = "never", 1 = "rarely", 2 = "sometimes", $3=$ "often"). The 13 events were based on the definition and examples of repression presented in existing work ${ }^{4,25}$. We also consulted with area experts, including the EHU staff, to include examples of repression that might have happened to individuals in the sample populations. The items are shown in Figure 2 (see also Supplementary Methods 2.3). Subsequently, the interviewees were asked to answer the same 13 items considering their friends and family ("Please indicate how often people you care about (your friends and family) have experienced the things below"), and themselves personally ("Please indicate how often you personally have experienced the things below").

We computed six repression variables (Table S7 and Figure S14 provide summary statistics and histograms): (1) An aggregate repression scale (RS), the average response over all 39 items $(\alpha=.94)$; (2) Repression of typical people ( $\mathrm{RS}-\mathrm{T})$, the average response over the 13 items about a typical person $(\alpha=.91)$; (3) Repression of friends and family (RS-F), the average response over the 13 items about friends and family ( $\alpha=.90)$; (4) Repression of the self (RS-S), the average response over the 13 items about interviewees own experience of repression $(\alpha=$ .86); (5) High-intensity repression (RS-H), the average of the four high-intensity repression items (i.e., intimidated by someone working for the government, beaten-up by police, short-term detainment, imprisonment without fair trial) across typical people, friends and family, and self (12 items, $\alpha=.84$ ); (6) Low-intensity repression (RS-L), the average of the remaining nine lowintensity repression items across typical people, friends and family, and self (27 items, $\alpha=.92$ ). 
We used the same questions to measure repression in the surveys in Venezuela (all $\alpha>$ .91 ) and Nicaragua (all $\alpha>.94$ ). Tables S8 and S9 and Figures S16 and S18 provide summary statistics and histograms. The surveys in Venezuela and Nicaragua also asked about experience of torture. For comparability with the EHU study, we excluded the torture item from the RS scales in the Venezuelan and Nicaraguan samples. The results remained substantively the same when the torture item was included in the scales.

Control variables. We obtained the same basic set of control variables in Belarus, Venezuela, and Nicaragua: gender, age, education (not measured in EHU), SES, and democratic values (see Supplementary Methods S2.4). We did not control for any additional variables in the three countries; we addressed potential confounding via random-assignment experiments.

Modeling. We analyzed continuous outcomes (Radicalism Intention Scale, RIS, in all samples and PVINTENTIONS in EHU) using standard OLS regressions, and binary outcomes (PVINTENTIONS and PVPARTICIPATION in the Venezuelan and Nicaraguan samples) using standard logit regressions. We analyzed each sample separately. The results reported in Figure 3 were produced while conditioning on the basic set of controls. Detailed estimates are reported in Tables S26S31, S34, S35, S38-S41, S44, S45. The random-assignment experiments were analyzed with simple regressions (i.e., without conditioning on any controls).

Random-assignment experiments. The EHU survey included a guided recall task that asked interviewees to think of Belarusian political situation and that varied the recall instructions between interviewees. Unfortunately, this task suffered from non-compliance (see Supplementary 
Methods 2.5). Therefore, we developed an alternative design for the surveys in Venezuela and Nicaragua. Specifically, we used the set of 39 repression items itself as a manipulation instrument to induce thoughts or memories about repression. Answering these questions about experienced repression in the past (or observed in a given country) should naturally induce thoughts or memories about repression. This experimental procedure built on existing questions-as-treatment designs, where treatment questions are formulated and located immediately before outcome items to increase the saliency of particular thoughts or memories (e.g., "How close do you feel to your ethnic or racial group?" to manipulate saliency of ethnic identity $)^{41,50-53}$.

In the surveys in Venezuela and Nicaragua half of the interviewees first received the repression items (experimental condition), immediately followed by the questions measuring intentions for antigovernment violence (ns $=492$ and 771 in Venezuela and Nicaragua, respectively). The other half of the interviewees started the survey with the questions about antigovernment violence (ns $=508$ and 803 in Venezuela and Nicaragua, respectively).

The surveys in Venezuela and Nicaragua also included experiments to measure the effect of governments' conciliatory gestures on citizens' intentions to participate in violence. Both surveys included vignettes describing a hypothetical, but realistic situation familiar to our interviewees: a conflict between a newly elected government and opposition, during which a protester was killed by police. Half of the interviewees received a text with a conciliatory gesture (ns = 497 and 774 in Venezuela and in Nicaragua, respectively).

Imagine that there were presidential elections in Venezuela [Nicaragua] last week and the candidate that you oppose has claimed to be the new president of Venezuela [Nicaragua]. All week there were big protests in the large cities by people like you. People like you-who oppose the new president - think that the elections were not fair and do not accept the new president. During one of the protests, a protester was killed by the police. Videos that circulate on the internet show a police officer hitting the protestor multiple times with a stick. The protestor was lying on the ground and did not have any weapons. Today the new president issued a statement that he will not tolerate police brutality and that there would be a comprehensive investigation of the event. 
For the other half of the interviewees (ns = 503 and 800 in Venezuela and in Nicaragua, respectively) the last sentence of the vignette was different so that it did not include a conciliatory gesture (i.e., "Today the new president issued a statement that the authenticity of the video could not be established and that there would be no further investigation of the event").

In Venezuela, the vignette was followed by two questions that served as manipulation checks, the first measuring perceived concern for wellbeing of citizens, the second measuring anger about the event (see Supplementary Methods 2.5). Responses to these questions showed that the conciliatory gesture significantly increased perceived concern for wellbeing of citizens, $b$ $=1.94, \mathrm{SE}=0.12, \mathrm{t}(938)=15.78, \mathrm{p}<.001$, but did not significantly influence anger about the killing, $b=0.14, \mathrm{SE}=0.08, \mathrm{t}(959)=1.68, \mathrm{p}=.093$.

Then there followed four items measuring PVINTENTIONS. The interviewees were asked to indicate intentions to respond to the killing in four ways: "Tell a friend that it is justified to use violence to oppose the new president"; "help members of a violent political movement that opposes the new president"; "join a violent political movement that opposes the new president"; "use force or violence as part of fighting the new president" (answered on a 7-point scale from 0 = "would never do this", $6=$ "would certainly do this").

In the Nicaragua survey, the vignette was followed by the question about concern for wellbeing of citizens and the conciliatory gesture increased perceived concern for the wellbeing of citizens, $b=1.90, \mathrm{SE}=0.11, \mathrm{t}(1362)=16.61, \mathrm{p}<.001$ (the item about anger was not included). The survey then included the same four items measuring PVINTENTIONS, with one additional variation in the instructions. 
It is possible that interviewees, while reporting their intentions in a survey questionnaire, may not seriously consider risks involved in actual political violence. Therefore, the vignette experiment included another manipulation. Half of the interviewees were given the same instructions as in the Venezuela survey. For the other half $(\mathrm{n}=808)$, the instruction (before PVINTENTIONS) contained an additional sentence, which read: "Please consider the risks involved in the

indicated activities, for example, injury, capture, or imprisonment". This additional manipulation enabled a test of whether consideration of risks associated with antigovernment violence influenced interviewees reported intentions. For further details on experimental designs, see S2.5 in Supplementary Methods.

\section{Data availability}

The data used in the multinational analyses are secondary and available via http://www.afrobarometer.org/ (may require subscription), https://www.latinobarometro.org/ (does not require subscription), and http://www.asianbarometer.org/ (requires subscription) (we do not provide specific links to the datasets, as they can change; therefore, please use the parent

15 links and navigate to the relevant datasets). The original data from EHU (Belarus), Venezuela, and Nicaragua are available at a public repository (Open Science Framework): https://osf.io/nyx7u/?view_only=fc455c002af543f6a7e8d1bb5283c373

\section{Code availability}

The code script for all analyses is available at a public repository (Open Science Framework): https://osf.io/nyx7u/?view_only=fc455c002af543f6a7e8d1bb5283c373 


\section{References and Notes}

1. Haschke, P. 2019 PTS Release. The Political Terror Scale https://www.politicalterrorscale.org/archive/Release2019/.

2. Gibney, M. et al. The Political Terror Scale. The Political Terror Scale 1976-2020 http://www.politicalterrorscale.org/ (2021).

3. Diamond, L. Facing Up to the Democratic Recession. J. Democr. 26, 141-155 (2015).

4. We draw on an established conceptualization of political repression as "the actual or threatened use of physical sanctions against an individual or organization, within the territorial jurisdiction of the state, for the purpose of imposing a cost on the target as well as deterring specific activities and/or beliefs perceived to be challenging to government personnel, practices or institutions", see Davenport, C. State Repression and Political Order. Annu. Rev. Polit. Sci. 10, 1-23 (2007).

5. Pratto, F., Sidanius, J. \& Levin, S. Social dominance theory and the dynamics of intergroup relations: Taking stock and looking forward. Eur. Rev. Soc. Psychol. 17, 271-320 (2006).

15 6. Schmitt, M. T., Branscombe, N. R., Postmes, T. \& Garcia, A. The consequences of perceived discrimination for psychological well-being: a meta-analytic review. Psychol. Bull. 140, 921-948 (2014).

7. Keltner, D., Gruenfeld, D. H. \& Anderson, C. Power, approach, and inhibition. Psychol. Rev. 110, 265-284 (2003).

8. Berdahl, J. L. \& Martorana, P. Effects of power on emotion and expression during a controversial group discussion. Eur. J. Soc. Psychol. 36, 497-509 (2006).

9. Sherman, G. D. et al. Leadership is associated with lower levels of stress. Proc. Natl. Acad. Sci. 109, 17903-17907 (2012). 
10. van Kleef, G. A. \& Lange, J. How hierarchy shapes our emotional lives: effects of power and status on emotional experience, expression, and responsiveness. Curr. Opin. Psychol. 33, 148-153 (2020).

11. Anderson, C. \& Berdahl, J. L. The experience of power: Examining the effects of power on approach and inhibition tendencies. J. Pers. Soc. Psychol. 83, 1362-1377 (2002).

12. Guinote, A. How Power Affects People: Activating, Wanting, and Goal Seeking. Annu. Rev. Psychol. 68, 353-381 (2017).

13. Pike, B. E. \& Galinsky, A. D. Power leads to action because it releases the psychological brakes on action. Curr. Opin. Psychol. 33, 91-94 (2020).

14. Johnson, H. \& Thompson, A. The development and maintenance of post-traumatic stress disorder (PTSD) in civilian adult survivors of war trauma and torture: a review. Clin. Psychol. Rev. 28, 36-47 (2008).

15. Canetti, D. et al. Exposure to prolonged socio-political conflict and the risk of PTSD and depression among Palestinians. Psychiatry 73, 219-231 (2010).

16. Vollhardt, J. R., Okuyan, M. \& Ünal, H. Resistance to collective victimization and oppression. Curr. Opin. Psychol. 35, 92-97 (2020).

17. Haslam, S. A. \& Reicher, S. D. When Prisoners Take Over the Prison: A Social Psychology of Resistance. Personal. Soc. Psychol. Rev. 16, 154-179 (2012).

18. Leach, C. W. \& Livingstone, A. G. Contesting the Meaning of Intergroup Disadvantage: Towards a Psychology of Resistance: Meaning of Disadvantage. J. Soc. Issues 71, 614632 (2015). 
19. Ayanian, A. H. \& Tausch, N. How risk perception shapes collective action intentions in repressive contexts: A study of Egyptian activists during the 2013 post-coup uprising. $B r$. J. Soc. Psychol. 55, 700-721 (2016).

20. Ayanian, A. H. et al. Resistance in repressive contexts: A comprehensive test of psychological predictors. J. Pers. Soc. Psychol. 120, 912-939 (2021).

21. Sullivan, C. M. \& Davenport, C. The Rebel Alliance Strikes Back: Understanding the Politics of Backlash Mobilization. Mobilization Int. Q. 22, 39-56 (2017).

22. Young, L. E. The Psychology of State Repression: Fear and Dissent Decisions in Zimbabwe. Am. Polit. Sci. Rev. 113, 140-155 (2019).

23. van Zomeren, M., Postmes, T. \& Spears, R. Toward an integrative social identity model of collective action: a quantitative research synthesis of three socio-psychological perspectives. Psychol. Bull. 134, 504-535 (2008).

24. Becker, J. C. \& Tausch, N. A dynamic model of engagement in normative and nonnormative collective action: Psychological antecedents, consequences, and barriers. Eur. Rev. Soc. Psychol. 26, 43-92 (2015).

25. deMeritt, J. H. R. The Strategic Use of State Repression and Political Violence. in Oxford Research Encyclopedia of Politics (Oxford University Press, 2016). doi:10.1093/acrefore/9780190228637.013.32.

26. Hafez, M. M. Why Muslims rebel: repression and resistance in the Islamic world. (Lynne Rienner publ, 2003).

27. Honari, A. From 'the effect of repression' toward 'the response to repression'. Curr. Sociol. 66, 950-973 (2018). 
28. Fehr, E. \& Gächter, S. Cooperation and Punishment in Public Goods Experiments. Am. Econ. Rev. 90, 980-994 (2000).

29. McCullough, M. E., Kurzban, R. \& Tabak, B. A. Cognitive systems for revenge and forgiveness. Behav. Brain Sci. 36, 1-15 (2013).

30. Afrobarometer. https://afrobarometer.org/.

31. Latinobarometro. https://www.latinobarometro.org.

32. Asianbarometer. Asian Barometer http://asianbarometer.org/.

33. We follow Sheeran's (2002, p. 2) definition of behavioral intentions, as “...people’s decisions to perform particular actions. Intentions can be inferred from participants' responses that have the form, 'I intend to do X', 'I plan to do X', or 'I will do X'. In psychological terms, a behavioral intention indexes a person's motivation to perform a behavior. That is, behavioral intentions encompass both the direction (to do $\mathrm{X}$ vs. not to do $\mathrm{X}$ ) and the intensity (e.g., how much time and effort the person is prepared to expend in order to do X) of a decision", see Sheeran, P. Intention-Behavior Relations: A Conceptual and Empirical Review. Eur. Rev. Soc. Psychol. 12, 1-36 (2002).

34. Webb, T. L. \& Sheeran, P. Does changing behavioral intentions engender behavior change? A meta-analysis of the experimental evidence. Psychol. Bull. 132, 249-268 (2006).

35. Gómez, Á. et al. The devoted actor's will to fight and the spiritual dimension of human conflict. Nat. Hum. Behav. 1, 673-679 (2017).

36. Archer, J. Does sexual selection explain human sex differences in aggression? Behav. Brain Sci. 32, 249-266; discussion 266-311 (2009). 
37. Gleditsch, K. S. Advances in Data on Conflict and Dissent. in Computational Conflict Research (eds. Deutschmann, E., Lorenz, J., Nardin, L. G., Natalini, D. \& Wilhelm, A. F. X.) 23-41 (Springer International Publishing, 2020). doi:10.1007/978-3-030-29333-8_2.

38. Moskalenko, S. \& McCauley, C. Measuring Political Mobilization: The Distinction Between Activism and Radicalism. Terror. Polit. Violence 21, 239-260 (2009).

39. Glynn, A. N. What Can We Learn with Statistical Truth Serum? Public Opin. Q. 77, 159172 (2013).

40. Lerner, J. S., Gonzalez, R. M., Small, D. A. \& Fischhoff, B. Effects of fear and anger on perceived risks of terrorism: a national field experiment. Psychol. Sci. 14, 144-150 (2003).

41. Ben-Nun Bloom, P., Arikan, G. \& Courtemanche, M. Religious Social Identity, Religious Belief, and Anti-Immigration Sentiment. Am. Polit. Sci. Rev. 109, 203-221 (2015).

42. Linke, A. M., Schutte, S. \& Buhaug, H. Population Attitudes and the Spread of Political Violence in Sub-Saharan Africa. Int. Stud. Rev. 17, 26-45 (2015).

43. van Stekelenburg, J. \& Klandermans, B. The social psychology of protest. Curr. Sociol. 61, 886-905 (2013).

44. Ajzen, I. The theory of planned behavior. Organ. Behav. Hum. Decis. Process. 50, 179211 (1991).

45. Clutton-Brock, T. H. \& Parker, G. A. Punishment in animal societies. Nature 373, 209-216 (1995).

46. de Quervain, D. J.-F. et al. The neural basis of altruistic punishment. Science 305, 1254 1258 (2004). 
47. Bartusevičius, H., van Leeuwen, F. \& Petersen, M. B. Dominance-Driven Autocratic Political Orientations Predict Political Violence in Western, Educated, Industrialized, Rich, and Democratic (WEIRD) and Non-WEIRD Samples. Psychol. Sci. 31, 1511-1530 (2020).

48. Donadio, B. T. et al. Simulating Combat to Explore Motivations Behind Why Military Members Make Costly Sacrifices. in 2020 Systems and Information Engineering Design Symposium (SIEDS) 1-6 (2020). doi:10.1109/SIEDS49339.2020.9106644.

49. Tourangeau, R. \& Yan, T. Sensitive questions in surveys. Psychol. Bull. 133, 859-883 (2007).

50. Transue, J. E. Identity Salience, Identity Acceptance, and Racial Policy Attitudes: American National Identity as a Uniting Force. Am. J. Polit. Sci. 51, 78-91 (2007).

51. Laurin, K., Shariff, A. F., Henrich, J. \& Kay, A. C. Outsourcing punishment to God: beliefs in divine control reduce earthly punishment. Proc. R. Soc. B Biol. Sci. 279, 3272$3281(2012)$.

52. Chong, D., Citrin, J. \& Conley, P. When Self-Interest Matters. Polit. Psychol. 22, 541-570 (2001).

53. McFarland, S. G. Effects of Question Order on Survey Responses. Public Opin. Q. 45, 208 (1981).

\section{Author contributions}

All authors contributed to developing the study concept, designing research, collecting the data, analyzing the data, and drafting the manuscript, and all approved the final manuscript for submission.

\section{Competing interests}

Authors declare no competing interests. 


\title{
Supplementary Materials for
}

Political repression motivates antigovernment violence

\author{
Authors
}

Correspondence to: masked for peer review

This file includes:

Supplementary Methods S1 to S3

Figs. S1 to S18

Tables S1 to S52 


\section{Contents}

S1: Supplementary methods for multinational analyses ................................................ 4

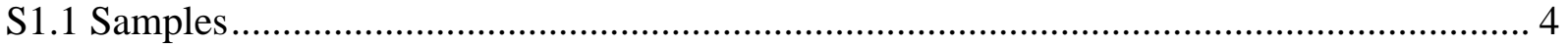

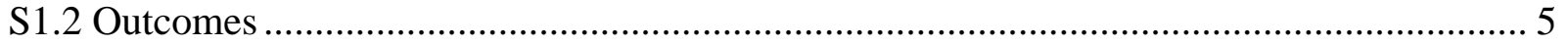

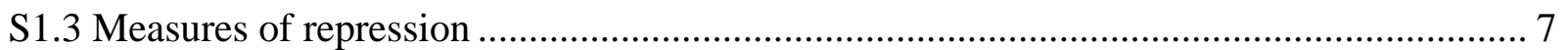

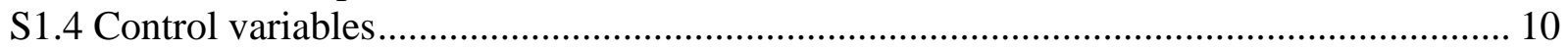

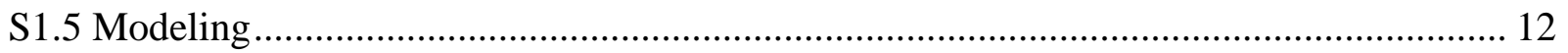

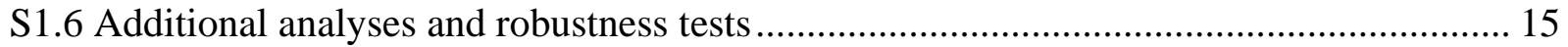

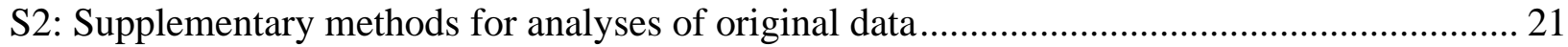

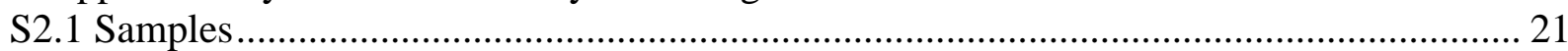

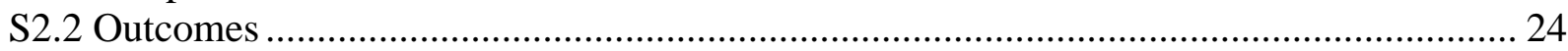

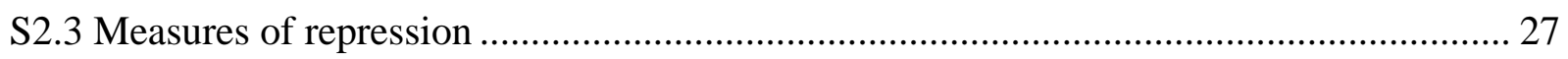

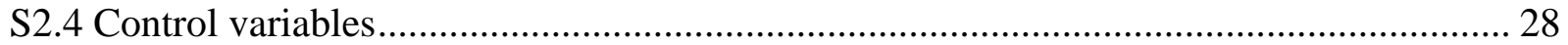

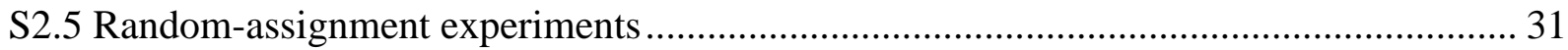

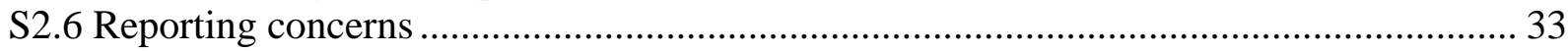

S3: References for supplementary methods....................................................................... 40

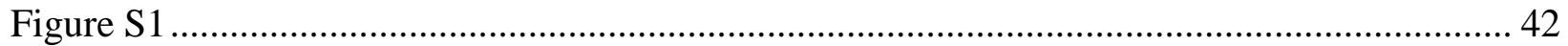

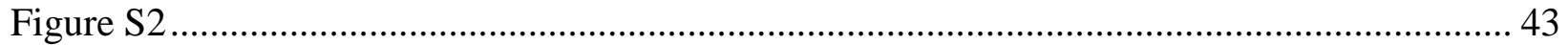

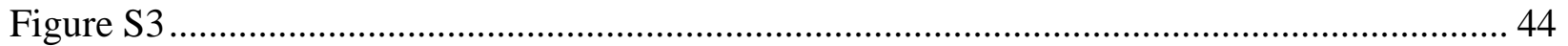

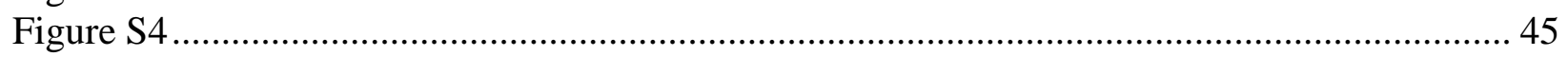

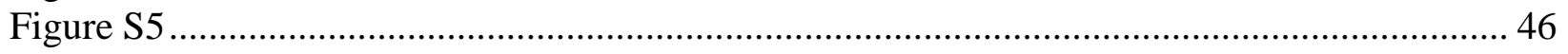

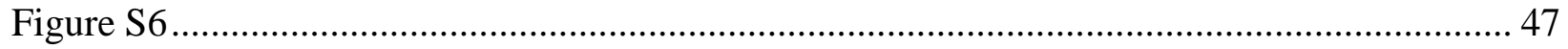

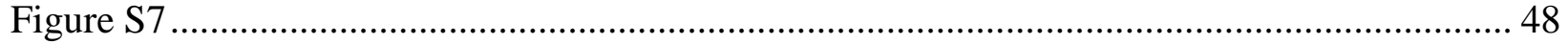

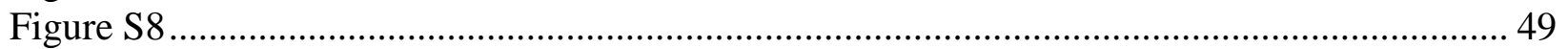

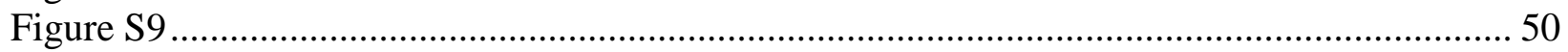

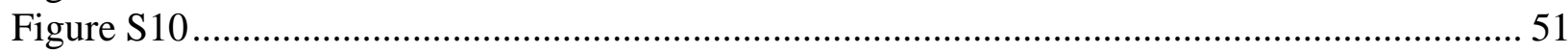

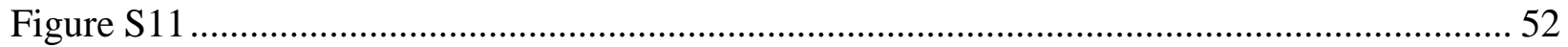

Figure S12

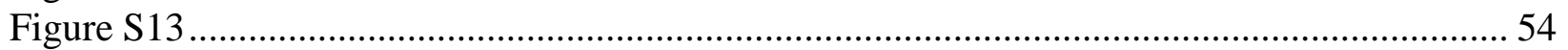

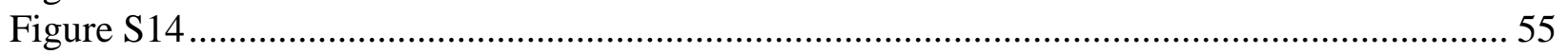

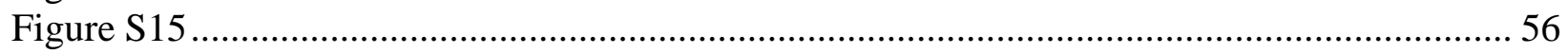

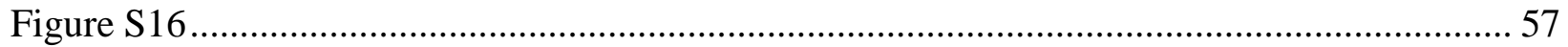

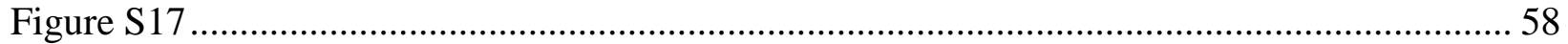

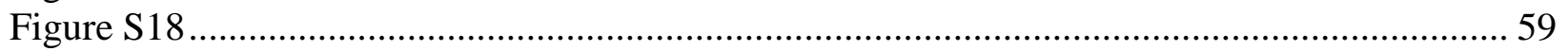

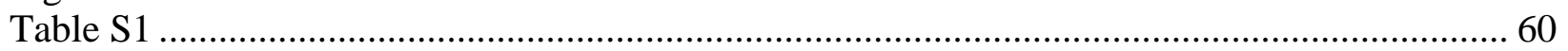

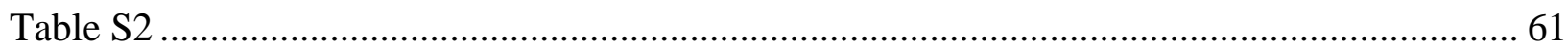

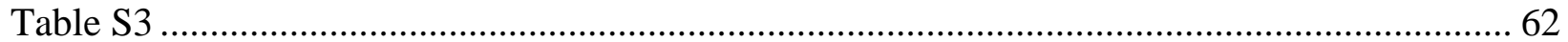

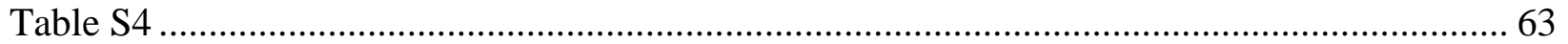

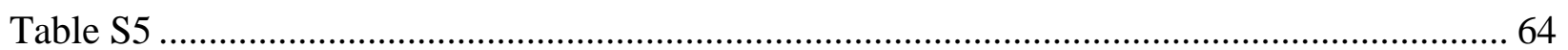

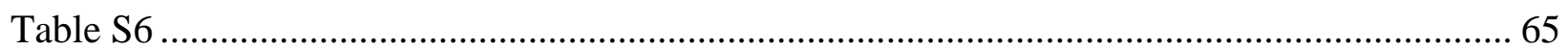

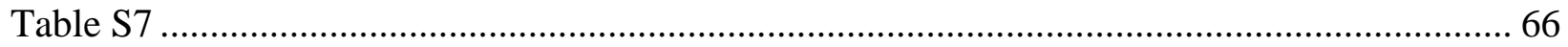

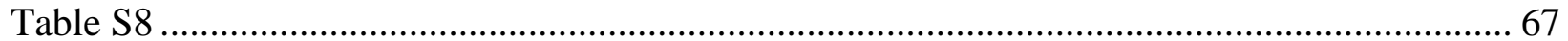

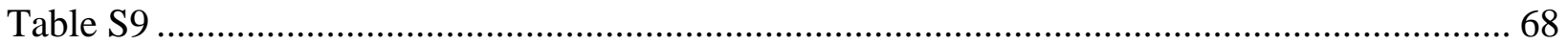

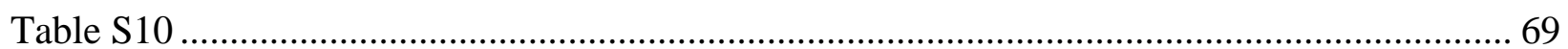

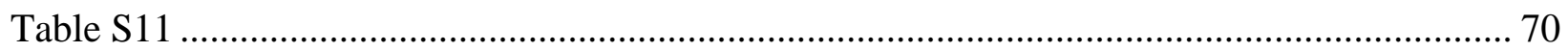

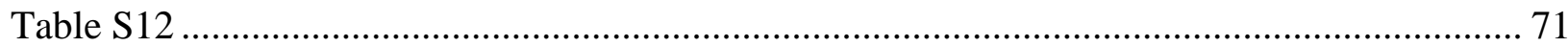




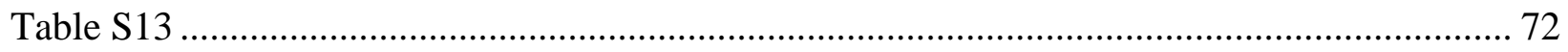

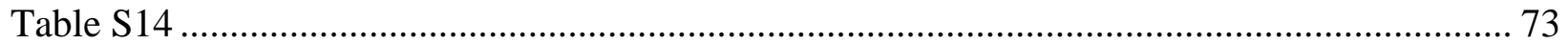

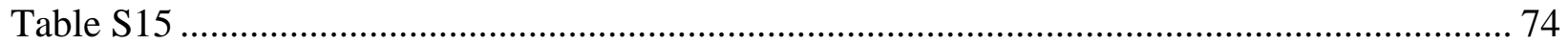

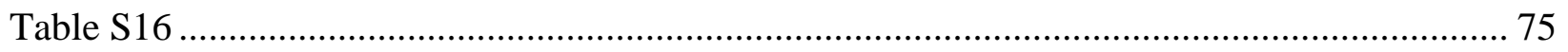

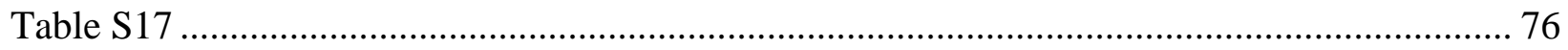

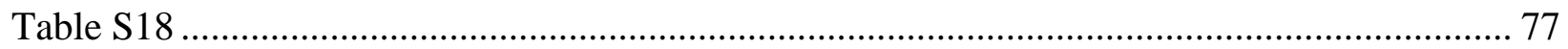

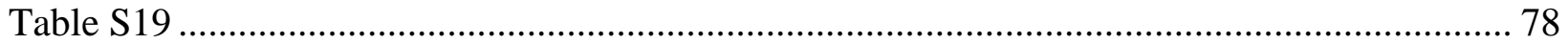

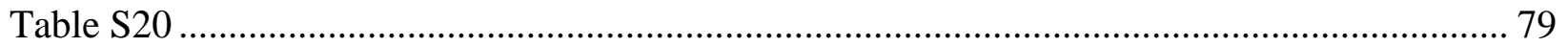

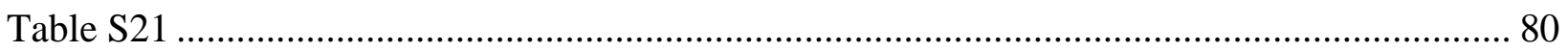

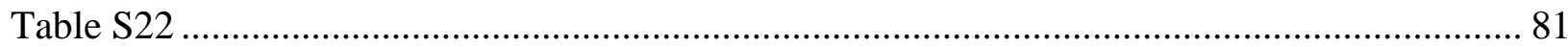

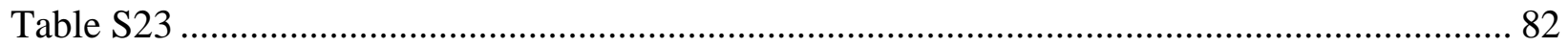

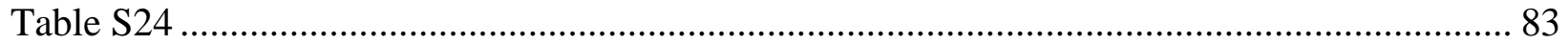

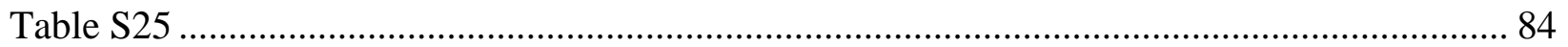

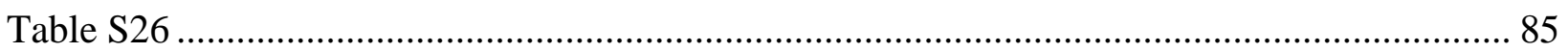

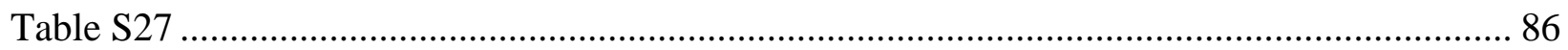

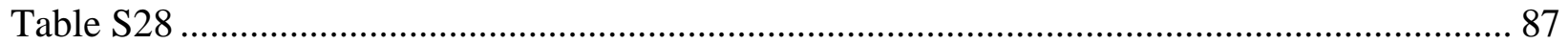

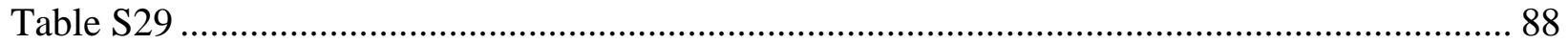

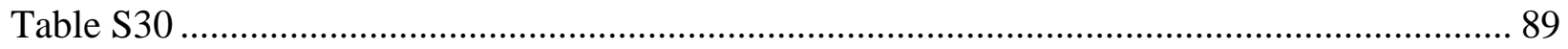

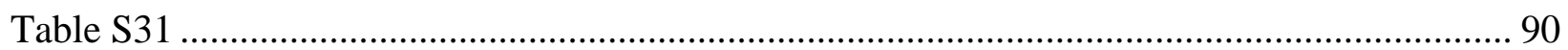

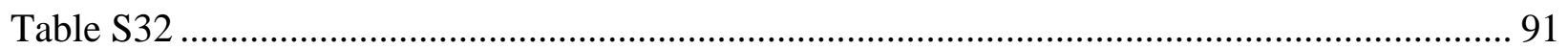

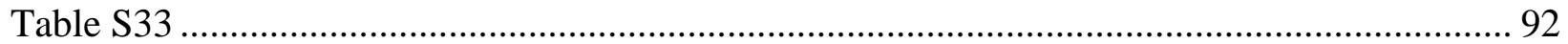

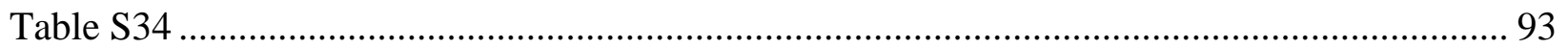

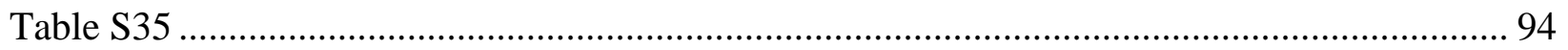

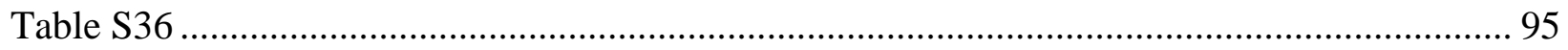

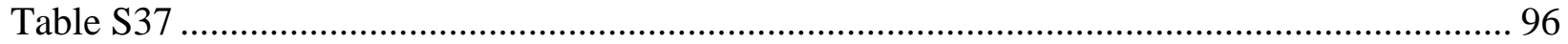

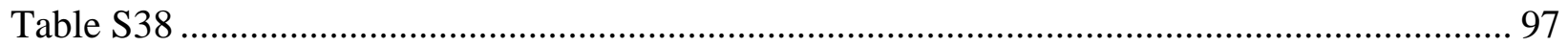

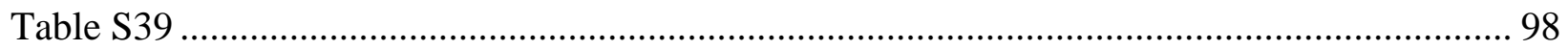

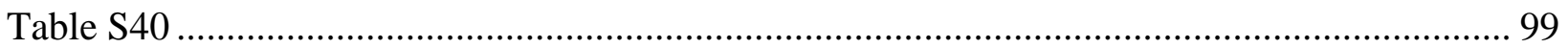

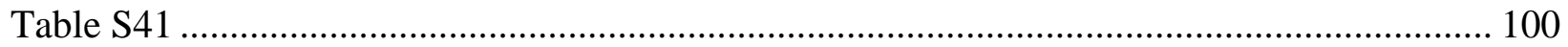

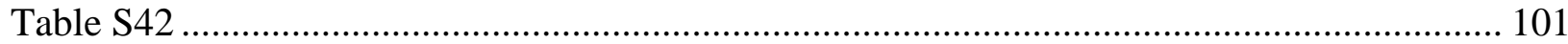

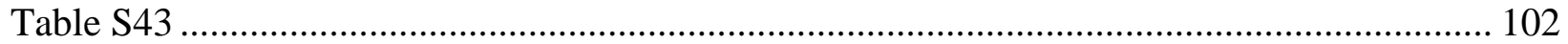

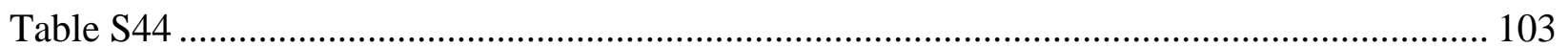

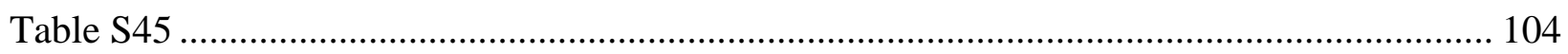

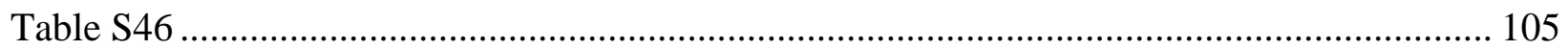

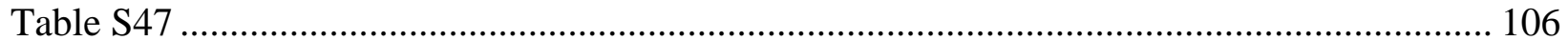

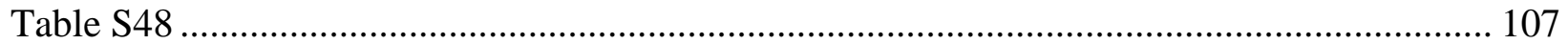

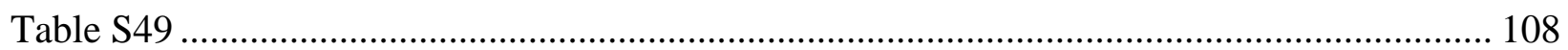

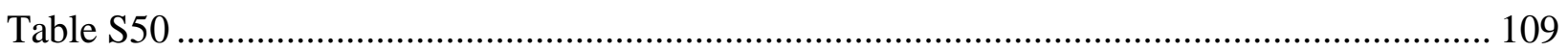

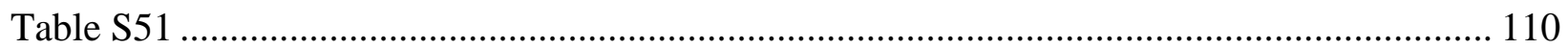

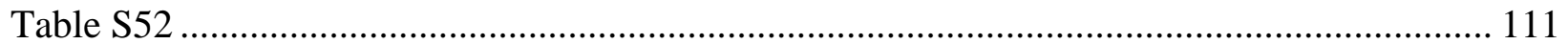




\section{S1: Supplementary methods for multinational analyses}

\section{S1.1 Samples}

We conducted a comprehensive search of multinational survey data among the Global Barometer Surveys (GBS). GBS is a network of regional barometers in Africa, Asia, Latin America, the Middle East, and the former Soviet Union. The GBS network covers $70 \%$ of the world's population. All regional barometers use a common GBS survey protocol. Sampling, questionnaires, training of interviewers, conduct of interviews, quality control, etc., follow analogous (but not identical) procedures across the barometers. All barometers aim to generate nationally representative samples of citizens of voting age, rely on multi-stage probability sampling, and collect data via face-to-face interviews. For details on survey methods, see: https://www.globalbaro-meter.net/.

The questions about political repression and antigovernment violence across the six datasets are equivalent but not identical. Therefore, to avoid confounding by method effects, we did not merge all the datasets into one. We started multinational analyses with Afrobarometer Round 5. We then analyzed Afrobarometer Round 2, containing identical items on violence but slightly different items on repression. Subsequently, we analyzed Latinobarómetro 2013, where both repression and violence items are different (but equivalent) from those in the Afrobarometers. Finally, we analyzed Asianbarometer Rounds 2-4 in a combined analysis, since these datasets contain identical items on violence and repression (but which are different from those of Afrobarometers and Latinobarómetro 2013).

For method details of Afrobarometer, see https://www.afrobarometer.org/surveys-andmethods. The Latinobarómetro 2013 spans 19 countries. The Latinobarómetro includes Spain. 
However, the questions about violence were not asked in Spain. Therefore, our analysis of Latinobarómetro included 18 countries. For method details, see http://www.Latinobarómetro.org/lat.jsp. In the Asianbarometer, the questions about violence were not asked in Cambodia (Round 2), China (Rounds 2-4), Hong Kong (Round 2), Singapore (Round 4), and Vietnam (Round 4). Therefore, the analysis of Asianbarometers spanned 33 samples (from 13 countries). For method details, see http://www.asianbarometer.org/survey/survey-methods.

\section{S1.2 Outcomes}

Afrobarometer Round 5 contains the following question: "Here is a list of actions that people sometimes take as citizens. For each of these, please tell me whether you, personally, have done any of these things during the past year. If not, would you do this if you had the chance?" The list of actions included "Used force or violence for a political cause". (The list also included the actions "attended a community meeting", "got together with others to raise an issue", "refused to pay a tax or fee to government", and "attended a demonstration or a protest march". Hence, the item about violence refers to participation in a protest-like antigovernment action characterized by violence.) The interviewees could choose from among "no, would never do this", "no, but would do if had the chance", "yes, once or twice", "yes, several times", "yes, often", and "don't know". PVINTENTIONS was a binary indicator reflecting a subset of the reply options, 0 = "no, would never do this"; 1 = "no, but would do if had the chance". PVPARTICIPATION was also a binary indicator with the first two reply options coded 0 and the last three coded 1. We dropped "don't know" from both variables. We also analyzed an ordinal version, coding the five reply options with integer values 0-4 (PVPARTICIPATION04), and an alternative version, with the first two categories combined, representing a more general response "no" (coded 0) (PVPARTICIPATION03). Table S1 and Figure S1 provide summary statistics and histograms. 
Afrobarometer Round 2 contains questions on violence identical to those of Round 5. Accordingly, we derived identical measures of PVINTENTIONS and PVPARTICIPATION. Table S2 and Figure S3 provide summary statistics and histograms.

Latinobarómetro 2013 contains a question on participation in violence analogous, but not identical, to that of Afrobarometers. Specifically, Latinobarómetro 2013 asked about participation in violence over the last three years (whereas Afrobarometers asked about participation in violence over the last year), and did not contain a question about intentions to engage in violence: "Here is a list of actions that people sometimes take as citizens. For each of these, please tell me whether you, personally, have never, once, or more than once done any of these things during the past three years. Hence, we derived analogous (binary) indicator of PVPARTICIPATION. Table S3 and Figure S5 provide summary statistics and histograms.

Asianbarometer Rounds 2-4 contain questions on participation in violence identical to those of Latinobarómetro 2013. Hence, we derived an identical binary indicator of PVPARTICIPATION. Asianbarometer Round 4 contains an additional question on intentions to participate in violence analogous, but not identical, to that of Afrobarometers "Here is a list of actions that people sometimes take as citizens. For each of these, please tell me whether you personally, have never, once, or more than once done any of these things during the past three years: Used force or violence for a political cause" $(0=$ "I have not done this and I would not do it regardless of the situation", 1 = "I have not done this, but might do if something important happens in the future). Tables S4-S6 and Figures S7, S9, and S11 provide summary statistics and histograms.

The questions used to measure PVPARTICIPATION asked about participation in violence over the last year or over the last three years. This raises endogeneity concerns, specifically, over reverse causation. Individuals who engaged in violence in the past may perceive higher levels of 
repression. Our analyses of PVPARTICIPATION, therefore, may partly capture the effects of past participation in violence on perceived repression. PVINTENTIONS, by contrast, refers to intentions to engage in violence at the time of interview and prospectively. Hence, analyzes of PVINTENTIONS are unlikely to suffer from such endogeneity concerns. If individuals participated in violence in the past, this could influence their perceptions of repression and their current motivations to engage in violence. Yet, by design, PVINTENTIONS excludes those who reported participation in violence in the past.

As noted in the main text, we also explored how repression affects motivations to participate in non-violent collective actions. We obtained two additional outcomes, PDPARTICIPATION and PDINTENTIONS, which reflect interviewees' motivations to participate and self-reported participation in protests or demonstration. The two indicators are identical to the indicators of PVPARTICIPATION and PVINTENTIONS described above but focus on whether interviewees attended non-violent protests or demonstrations.

\section{S1.3 Measures of repression}

To measure repression, we derived a perceived repression scale (PRS), following a factor analysis of available items in Afrobarometer Round 5. We identified seven items in the Afrobarometer questionnaire that reflect perceptions of political repression in a given country:

- Q17A: "In this country, how free are you: To say what you think?"

- Q17B: "In this country, how free are you: To join any political organization you want?" Q17C: "In this country, how free are you: To choose who to vote for without feeling pressured?"

- Q52D: "In your opinion, how often, in this country: Are opposition parties or their supporters silenced by the government?" 
- Q54: "During election campaigns in this country, how much do you personally fear becoming a victim of political intimidation or violence?"

- Q55: "How likely do you think it is that powerful people can find out how you voted, even though there is supposed to be a secret ballot in this country?"

- Q56A: "In your opinion, how often, in this country: do people have to be careful of what they say about politics?"

To select the items that best capture variability in perceptions of repression, we performed an exploratory factor analysis. We examined whether responses to the seven items reflected one or more dimensions. Responses to all items were coded to range from 0 to 3 with higher values reflecting more perceived repression. The analysis revealed one factor with Eigenvalue > 1 (1.85; overall Kaiser-Meyer-Olkin measure of sampling adequacy $=0.74 ; \mathrm{N}=39,413$ ). The scree plot also indicated to retain one factor. The first factor explained $26.4 \%$ of variance, while the second factor explained only 4.5\%. Three items had loadings > .40 (Q17A: .67, Q17B: .77, and Q17C: .71), and only 1 other item had a loading > .30 (item Q52D loaded .32). No item had a loading > .40 on the second factor. Neither orthogonal varimax or oblique oblimin rotation revealed a second factor with multiple high-loading items. After either rotation, only one item had a loading > .40 on the second factor (Q54: loading after orthogonal rotation .41, loading after oblique rotation .45). In summary, the items Q17A, Q17B, and Q17C loaded highly on the first factor, while the other items did not have high loadings on either the first or second factor. Based on these results, we concluded that of the seven items pertaining to political repression, the three items Q17A, Q17B, and Q17C appear most strongly related to an underlying factor. Therefore, we computed each interviewee's score on PRS as the mean score over these three items: "In this 
county, how free are you: [1] To say what you think; [2] To join any political organization you want; [3] To choose who to vote for without feeling pressured" (reply options: $0=$ "Completely free", 3 = "Not at all free"). Estimated across 34 countries, Cronbach's $\alpha=.78$. Table S1 and Figure S2 provide summary statistics and histograms.

In Afrobarometer Round 2, we derived an analogous three-item PRS. The formulations are slightly different from those of Round 5: "We are going to compare our new government under $[\ldots]$ with the former government under [...]. Please tell me if the following things are worse or better now than they used to be or about the same: [1] Freedom to say what you think; [2] Freedom to join any political organization you want; [3] Freedom to choose who to vote for without feeling pressured" ( $0=$ "Much better", 4 = "Much worse"). Estimated across 16 countries, $\alpha=.83$. Table S2 and Figure S4 provide summary statistics and histograms.

In Latinobarómetro 2013, we derived a two-item PRS. Latinobarómetro contains two items comparable to those used to derive PRS in studies above: "How would you evaluate the current government's performance [1] regarding individual freedom of expression, very good, good, poor, or very poor? And [2] regarding press freedom?" Estimated across 19 countries, $\alpha=$ .87. Table S3 and Figure S6 provide summary statistics and histograms.

In Asianbarometer Rounds 2-4, we derived a two-item perceived repression scale (PRS). Asianbarometers contain two items comparable to those used to derive PRS in studies above: "Now I am going to read to you a list of statements that describe how people often feel about the state of affairs in [country name]. Please tell me whether you strongly agree, somewhat agree, somewhat disagree, or strongly disagree with each of these statements: [...] [1] People are free to speak what they think without fear; [2] People can join any organization they like without 
fear". In Round 2, estimated across 13 countries, $\alpha=.74$. In Round 3, estimated across 13 countries, $\alpha=.75$. In Round 4, estimated across 14 countries, $\alpha=.75$. Tables S4-S6 and Figures S8, S10, S12 provide summary statistics and histograms.

\section{S1.4 Control variables}

For the main analyses, we limited control variables to a basic set: gender $(0=$ male, $1=$ female $)$, age, education ( $0=$ "No formal schooling", 9 = "Post-graduate"), subjective socio-economic status (SES) ("Let's discuss economic conditions. In general, how would you describe your own present living conditions?" 0 = "Very bad", 4 = "Very good"), and democratic values ("Which of these three statements is closest to your own opinion?" "Democracy is preferable to any other kind of government" = 1, "In some circumstances, a non-democratic government can be preferable" $=0$, "For someone like me, it doesn't matter what kind of government we have" =0). For education, SES, and democratic values, item formulations slightly vary across the barometers. The question formulations presented here are from Afrobarometer Round 5.

In robustness tests, we explored a range of other controls. First, we analyzed variables related to political activism and mobilization. Specifically, we controlled for whether interviewees were active supporters of a political party ("Thinking about the last national elections in [year], did you: Work for a candidate or party?" $0=$ "No", 1 = "Yes"), "active members" of a "voluntary association or a community group" ( $0=$ "No", $1=$ "Yes"), and "attended a demonstration or a protest march" (analogous to PVPARTICIPATION). Politically active or mobilized people may be better aware of repression, and concurrently have increased opportunities to engage in violence.

Second, we analyzed variables related to government support. Specifically, we controlled for whether interviewees "trust" state leaders (presidents or prime ministers) and parliaments (0 $=$ "Not at all", $3=$ "A lot"), and whether they "approve" of the way state leaders (presidents and 
prime ministers) "performed their jobs over the past twelve months" ( 0 = "Strongly disapprove", $4=$ "Strongly approve"). People who distrust or disapprove of their governments may see higher levels of repression and concurrently may be motivated to engage in antigovernment violence.

Third, we analyzed variables highlighted in psychological literature on political violence: group-based injustice, contempt toward state authorities, and political efficacy (to influence politics in a given country) ${ }^{1}$. Group-based injustice was proxied with "How often is [interviewee's ethnic group] treated unfairly by the government?" ( $0=$ "Never", 3 = "Always"). Contempt was proxied with refusal to vote, which (as contrasted to other reasons, e.g., lack of time) is an expression of disaffection with state authorities ${ }^{1}$. We coded voting in the most recent national elections $(1=$ "Decided not to vote", $0=$ all other replies). Political efficacy was measured with "How much of the time do you think...members of parliament...try their best to listen to what people like you have to say?" ( 0 = "Never", 3 = "Always").

Finally, we controlled for whether interviewees' answers were deemed by interviewers to have been influenced by third parties and whether interviewees appeared suspicious or dishonest: "Do you think anyone influenced the respondent's answers during the interview?" $(0=$ "No", $1=$ "Yes"); "What was the respondent's attitude towards you during the interview? E. Was he or she at ease, in between, suspicious?" (1 = "At ease", 2 = "In between", 3 = "Suspicious"); "What was the respondent's attitude towards you during the interview? F. Was he or she honest, in between, misleading?" (1 = "Honest", 2 = "In between", 3 = "Misleading"). We also controlled for whether interviewees correctly understood the questions: "What proportion of the questions do you feel the respondent had difficulty answering?" ( 0 = "None", 1 = "Few", 2 = "Some", 3 = "Most", 4 = "All”). 
In addition, we included a number of country-level variables: national-level repression, indexed by the Political Terror $\mathrm{Scale}^{2}$; political instability, proxied by the proportion of interviewees indicating "political instability/ethnic tensions" among the three "most important problems facing [country]"; violent crime, measured by intentional homicide rate per $100,000^{3}$; violent protests, proxied by the count of events coded in the Social Conflict Analysis Database (SCAD) in the year before the surveys (adjusted to population; per 1,000,000 people) ${ }^{4}$; national economic status, measured with GDP/cap. (constant 2010 US\$) ${ }^{3}$; conflict history, measured with peace years since the last internal armed conflict coded in the UCDP/PRIO Armed Conflict Dataset $^{5,6}$; and national population $\operatorname{size}^{3}$.

\section{S1.5 Modeling}

To identify an appropriate multilevel specification, we followed the strategy by Hox, Moerbeek, and van de Schoot ${ }^{7}$. First, we estimated an intercept-only model, finding significant intraclass correlation in both PVPARTICIPATION $(\rho=.14)$ and PVINTENTIONS $(\rho=.10)$. We therefore modeled random intercepts. Second, we added level-1 predictors with between-country variance of slopes fixed at zero. PRS was a significant predictor of both PVPARTICIPATION $(\operatorname{logit}=$ 1.171, $\mathrm{p}<0.001$ ) and PVINTENTIONS (logit $=.636, \mathrm{p}<0.001)$. Third, we added level-2 predictors. PRS remained a significant predictor of both PVPARTICIPATION $(\operatorname{logit}=1.167, \mathrm{p}<0.001)$ and PVINTENTIONS (logit $=.605, \mathrm{p}<0.001)$. Fourth, we modeled randomly varying slopes for each level-1 predictor (i.e., PRS, gender, age, education, SES, and democratic values). Likelihood ratio tests indicated that modeling random slopes for PRS, age, education, SES, and democratic values significantly improved the model fit in the analysis of PVPARTICIPATION; and that modeling random slopes for PRS, gender, education, SES, and democratic values significantly improved the model fit in the analysis of PVINTENTIONS. Subsequently, we included randomly 
varying slopes for all predictors with significant between-country variance simultaneously. Modeling multiple random slopes simultaneously is computationally intensive. We used Stata's melogit, which calls maximum likelihood estimation with numerical integration. Stata allows for choosing between three numerical integration methods, with the mode-curvature adaptive GaussHermite quadrature being the fastest in our setup (this method produces nearly indistinguishable coefficients from mean-variance adaptive Gauss-Hermite quadrature, Stata's default option). We also changed the number of integration points. There is a tradeoff between computation time and bias in parameter estimates, with every additional integration point typically slightly reducing bias, but considerably increasing processing time. We set $\mathrm{N}$ of integration points to 4 , which produced estimates, for most level-1 parameters, identical to the third significant figure to those produced with 5 integration points, but decreased processing time up to five times. Analyses were conducted with parallel-processing Stata/MP (15 version) on an 8-core computer. Fifth, we tested cross-level interactions of PRS with each level-2 variable, i.e., national-level repression (PTS), political instability, violent crime, violent protests, economic status, economic growth, conflict history, and population size (see S1.4). None of the interactions were statistically significant. Therefore, our final multilevel specification did not include cross-level interactions.

We found that the (level-2) Political Terror Scale (PTS) significantly correlated with the (level-1) perceived repression scale (PRS), $r=0.21(p<0.001)$. PTS did not significantly predict PVINTENTIONS or PVPARTICIPATION. Note, that PTS may use repression of particular groups in a given country to assign the score for the whole country. Hence, countries where ethnic majorities (who constitute majorities of surveyed samples) de facto experience little to no repression, but where ethnic minorities experience severe repression, may receive highest PTS scores. The 
cross-level interaction of PRS with PTS in the models of PVPARTICIPATION and PVINTENTIONS were, respectively, logit $=1.531(p=0.170)$ and $-.594(p=0.453)$.

In the main text (Table 1), we report results of analyses that do not model randomly varying slopes. This is because the number of level-2 units in all barometers, except Afrobarometer Round 5, is too small for modelling randomly varying slopes and cross-level interactions. In addition, our primary interest was in individual-level associations. Therefore, for comparability of estimates across different barometers, instead of analyzing level-2 variables, we removed their influence on level-1 associations by including level-2 means of all level-1 variables as controls in a multilevel specification with random intercepts (the combined analysis of Asianbarometer Rounds 2-4 also included a dummy-coded year variable, controlling for the effects of time trends). This is the Mundlak specification ${ }^{8}$, which removes observed and unobserved confounding by level- 2 characteristics ${ }^{9}$. Note that although Mundlak specification fully accounts for confounding by level-2 characteristics in linear models, in generalized linear models it may not reliably partition between-level-2 effects from within-level-2 effects. Simulations show that this can introduce some bias in the estimates of level-1 coefficients; however, under most conditions, the remaining bias in level-1 coefficients due to level- 2 confounding is negligible ${ }^{10}$. We have crosschecked our analyses with fixed-effects estimators (which reliably partition between-level-2 effects from within-level-2 via conditional maximum likelihood) and found nearly identical results. The average marginal effects on the probabilities reported in Table 3 were estimated using Stata's margins post-estimation command. Tables S10-S13 provide detailed estimates. We fitted a number of alternative models on Afrobarometer Round 5, including models with randomly varying slopes (see "Additional analyses and robustness tests" below). 


\section{S1.6 Additional analyses and robustness tests}

Table 1 in the main text reports results of multilevel analyses specified following the approach suggested by Mundlak ${ }^{8}$. In what follows, we report a range of alternative specifications. Here, we utilize Afrobarometer Round 5, which (due to coverage and a large number of other items) allows us to conduct the widest range of robustness tests.

We first conducted a multilevel analysis with 1) randomly varying slopes for all predictors with significant between-county variance, and 2) all level-2 predictors (i.e., the fully-fledged hierarchical specification, excluding cross-level interactions). As shown in Table S18, the results remain substantively the same, with PRS positively and significantly predicting the two outcomes.

Subsequently, we analyzed ordinal versions of PVPARTICIPATION (i.e., PVPARTICIPATION04 and PVPARTICIPATION03) using alternative estimators, including hierarchical models with the cumulative logit link function and the identity link function. As shown in Table S19, the substantive results remain the same.

The analyses above included a number of level-2 predictors; however, $\operatorname{var}($ constant) remained above zero, indicating that some remaining unmeasured country-level characteristics might confound the individual-level relationships of interest. We used several techniques to account for such unobserved level-2 variables. As discussed above, our main analyses relied on Mundlak specification, which accounts for level-2 confounding. Here, we also explored alternative techniques: country-mean centering and fixed effects estimators (conditional maximum likelihood) $)^{9,10}$. Table S20 shows that results remain virtually the same.

Country-mean centering and fixed effects models eliminate higher-level omitted variable bias. However, our analyses remain vulnerable to lower-level omitted variable bias. Therefore, 
we conducted a number of additional tests, controlling for the 14 individual-level control variables. Due to additional randomly varying slopes, these analyzes are computationally intensive, and may be prohibitively slow on general purpose computers/software. This poses a problem for reproducing our analysis. Therefore, we recommend to replicate these analyses with some randomly varying slopes removed. Our code script is annotated with our comments throughout, describing how to replicate the analyses. As shown in Tables S21-S23, the substantive results remain virtually the same. The coefficient of PRS in the model for PVINTENTIONS that controls for trust in president/PM is above the 5\% significance level $(p=0.054)$. The coefficients of PRS in both PVINTENTIONS and PVPARTICIPATION models that control for ethnic discrimination are also above the 5\% significance levels ( $p=0.098$ and 0.088 , respectively). Note that the number of observations in the models that control for ethnic discrimination is considerably reduced (the question about ethnic discrimination was not asked in Algeria, Egypt, Morocco, Sudan, and Tunisia). Also note that perceived repression and ethnic discrimination potentially capture the same construct (i.e., a perception that one's ethnic group is treated unfairly by the government may be due to repression of members of the ethnic group). In the linear probability models that include all 14 controls combined (see below), the PRS coefficient is significant at $p<0.001$.

Although we conditioned on a large set of potential confounders, we cannot entirely rule out the possibility of unobserved individual-level characteristics confounding our main results. However, we can evaluate the influence such confounders would need to have to change our main conclusions. Here, we draw on research within applied economics, suggesting that the amount of confounding by the observed controls in a model provides a guide to the amount of confounding by the unobserved variables ${ }^{11-14}$. 
Coefficient stability across models with and without controls is considered as evidence against omitted variable bias ${ }^{14}$. The robustness of PRS to inclusion of 14 theoretically relevant controls is a first piece of evidence against omitted confounders driving our results. We now present a more formal evaluation of sensitivity to unobserved confounding, following the approach introduced by Altonji, Elder, \& Taber ${ }^{11}$ and extended by Oster ${ }^{12}$.

Analyses of sensitivity to unobserved confounding are not yet applicable to hierarchical models (assessing sensitivity to unobserved confounding requires $R$-squared or analogous measures of explained variance, which are difficult to derive from hierarchical models ${ }^{15}$ ). Therefore, for this exercise, we shift to linear probability models (LPMs) with country-level fixed effects. The coefficient from an LPM that regresses PVPARTICIPATION on PRS, with no controls, is $b_{n c}=.0479754$. An analogous estimate in the model of PVINTENTIONS is $b_{n c}=.0429212$. The coefficient estimated in an LPM that regresses PVPARTICIPATION on PRS with all 14 controls (gender, age, education, SES, democratic values, active support for political party, active membership in a voluntary association/community group, past participation in demonstration/protest, trust in president/PM, trust in parliaments, approval of state leaders, group-based injustice, contempt toward state authorities, and political efficacy) is $b_{c}=.0387031$ (uncontrolled and controlled models were estimated on the same data; we removed missing observations in the controlled model from the uncontrolled model). An analogous estimate in the model of PVINTENTIONS is $b_{n c}=$ .0284379. Hence, in the model of PVPARTICIPATION the observed level-1 controls attenuate the effect of PRS by $b_{n c}-b_{c}=.0479754-.0387031=0.0092723$. An analogous attenuation in the model of PVINTENTIONS is $b_{n c}-b_{c}=.0429212-.0284379=0.0144833$. To reduce the coefficient to zero, confounding by unobservables would therefore have to be roughly four times 
stronger in the model of PVPARTICIPATION, and two times stronger in the model of PVINTENTIONS, than the confounding by the 14 observed controls combined. Given this, and because we have considered a large set of theory-informed confounders, as contrasted to a random set (the relationship between the unobserved confounders and the outcome is likely to be weaker than the relationship between the observed controls and the outcome, because the observed controls were selected with the aim of reducing bias, not at $\operatorname{random}^{11}$ ), we see it as unlikely that the bias due to unknown variables would explain away the entire effects of PRS.

This initial exercise assumed that the observed and unobserved confounders have equal variances. If these variances are unequal, coefficient stability across models with and without observed controls may fail to detect existing confounding. Accordingly, we have to account for the variance in the outcome due to observed controls. Oster suggests scaling coefficient movements by the change in $R$-squared when controls are included, using the following formula: $b^{*}=b_{c}-$ $\left(b_{n c}-b_{c}\right) \times\left(R_{\max }-R_{c}\right) /\left(R_{c}-R_{n c}\right)$, where $b_{c}$ and $R_{c}$ are from the model including observed controls, and $b_{n c}$ and $R_{n c}$ are from the model with no controls ${ }^{12} \cdot R_{\max }$ represents $R$-squared from a model with all observable and unobservable controls; hence, it is an unknown parameter. If observables and unobservables have the same explanatory power in the outcome, the above formula is a consistent estimator of the bias-adjusted treatment effect. All coefficients, besides $R_{\max }$, can be estimated from regressions with and without controls. For $R_{\max }$, however, we can only derive some plausible bounds. $R_{c}$ is, naturally, a lower bound on $R_{\max }$, and 1 is a hypothetical upper bound on $R_{\max }$. However, given the likely measurement error, $R_{\max }=1$ is highly unrealistic ${ }^{14}$. Based on randomized experiments as empirical reference, Oster suggests the upper bound of $R_{\max }$ $=1.3 R_{c}$, above which we can consider results robust. If we set $R_{\max }$ to $1.3 R_{c}$ the bias-adjusted effects (if the above proportionality assumption holds) of PRS on PVPARTICIPATION is $b^{*}=.03570$, 
and in the model of PVINTENTIONS $b^{*}=.02566$. If we use a more conservative value of $R_{\max }=$ $2.2 R_{c}$, suggested by Oster in her earlier work, the effect drops to $b^{*}=.02597$ in the model of PVPARTICIPATION and to $b^{*}=.01681$ in the model of PVINTENTIONS.

We also calculated the upper bound of $R_{\max }$ under which the effect would be 0 (assuming that confounding by unobservables is at least as strong as confounding by observables), which is 0.66 in the case of PVPARTICIPATION and 0.52 in the case of PVINTENTIONS. We also report values of another sensitivity parameter, $\delta$, the relative degree of selection on observed and unobserved variables, under which the effect would be 0 . If $R_{\max }=1.3 R_{c}$, then this value is $\delta=$ 10.41736 in the model of PVPARTICIPATION and $\delta=8.86825$ in the model of PVINTENTIONS. If $R_{\max }=2.2 R_{c}$, then the values are $\delta=2.66579$ and $\delta=2.24240$ respectively. Hence, to reduce the effect to zero, confounding by unobservables would have to be several times stronger than the confounding by the observed controls. Altogether, these analyses provide evidence against omitted variables driving our main results.

Empirical results can be given causal interpretation under the so-called conditional ignorability assumption ${ }^{16}$. For example, the above identified association between PRS and PVPARTICIPATION can be given causal interpretation under the assumption that PRS is randomly assigned given the observed controls (i.e., if we assume that there is no confounding of the PRS-PVPARTICIPATION association, after controlling for observed controls). However, we did not randomize PRS, and it is unlikely that PRS was naturalistically randomly assigned. Hence, the ignorability assumption is unlikely to hold in our case. The quantities estimated above, such as the values of $\delta$, can be understood as estimates of the robustness of the observed results to the departures from 
this assumption. That is, these estimates indicate how sensitive the observed results are to the violation of the ignorability assumption. The large $\delta$ values indicate that our main results are robust to large departures from the assumption.

Finally, we controlled for whether interviewees appeared to interviewers to have been influenced by third parties, suspicious, and dishonest. We also controlled for whether interviewees correctly understood the questions. As shown in Tables S24 and S25, the substantive results remain the same. 


\section{S2: Supplementary methods for analyses of original data}

\section{S2.1 Samples}

The studies at EHU, Venezuela, and Nicaragua complied with all relevant ethical regulations. Specifically, the study procedures complied with [masked for peer review] University’s Code of Conduct as well as the Committee Act of the [masked for peer review] National Committee of Health Research Ethics, which states that "Surveys using questionnaires and interviews that do not involve human biological material (section 14(2) of the Committee Act)" are exempted from approval. Informed consent was obtained from all interviewees.

We first conducted a pilot study that interviewed citizens of Belarus, an autocratic state with a robust security apparatus. Open antigovernment opposition in Belarus is typically crushed without concessions. We thus interviewed individuals aware of risks involved in violent opposition against a strong repressive regime. Following our discussions with area experts, we concluded that conducting a survey about repression and antigovernment violence was unfeasible in Belarus (the regime would likely be unwilling to allow such a survey in Belarus). Therefore, we surveyed Belarusians in neighboring Lithuania. Lithuania hosts the European Humanities University (EHU), relocated from Belarus after a forced closure by the regime in 2004.

The interviewees were students who either permanently reside in Belarus and visit EHU twice a year for exams or reside in Lithuania for the whole study period. Note, therefore, that the EHU sample over-represents those who are young, educated, and have anti-regime views. Typical to humanities programs in Eastern Europe, the sample also over-represents females.

We administered the survey in Russian in February and March 2017. The questionnaire was translated by a professional translator and then proofread by a native Russian speaker. 
Translation issues were resolved in consultation with area experts that were fluent in both English and Russian. The questionnaire was also proofread by members of the EHU staff. Finally, we conducted a trial survey with 10 EHU students, followed by a discussion, to identify any remaining issues that our interviewees may encounter while completing the final survey.

The questionnaires were distributed by four research assistants during lectures. The research assistants were recruited from among the EHU students. Interviewees completed the questionnaires at the start or end of lectures or during breaks. We informed interviewees that they could cease participation in the survey at any time without negative consequences. It took approximately 15-25 minutes to complete the survey. Interviewees were compensated for completing the survey with a gift card (value equivalent to 10 EUR) for a local department store.

Fully or partly completed surveys were returned by 386 interviewees. Responses and comments written on the questionnaires were translated to English by the EHU research assistants. Responses to the survey questions were entered in MS Excel by a research assistant at Aarhus University who was unaware of the hypotheses of the research. We coded ambiguous responses prior to analysis. When a participant had marked more than one answer option (e.g., marked both answer options 2 and 4), this was coded as the lowest number (in this case 2).

To ensure anonymity, we opted for pen-and-paper questionnaires. Despite this, and other anonymity precautions (see below, section 2.6 Reporting concerns), interviewees may still be reluctant to disclose information pertaining to repression and violence. However, personal communication at the EHU study site spoke against this. Due to resentment over experienced repression, we were told, the EHU students might actually be eager to report such experiences and intentions. As shown in Figure 2, the interviewees in fact reported high levels of repression. Still, we acknowledge that the actual levels of repression may be even higher than those reported (the 
question of whether such underreporting drives our results is addressed in section 2.6 Reporting concerns).

Our subsequent studies collected data online, allowing us to access larger samples and sampling from countries experiencing antigovernment violence (there were no major protest/violence events in Belarus during or prior to the survey). The online surveys were collected by YouGov, a major international survey company, who ensured anonymity via their established procedures.

We conducted the first online survey in Venezuela, a non-democratic country experiencing a large-scale popular uprising. Five months prior to our survey, which was conducted in September 2017, up to six million people reportedly participated in a nationwide antigovernment protest ("The Mother of All Marches"). This and subsequent protests resulted in hundreds of deaths and thousands injured, with victims on both sides, i.e., the government and the protest$\operatorname{ers}^{17}$. Our surveyed sample thus highly likely contained people with direct experience of participation in antigovernment protests. Given this, we assumed that Venezuelans would report realistic behavioral intentions pertaining to antigovernment violence. We also expected the Venezuelan sample to contain individuals who actually engaged in violence during these protests. The survey was administered in Spanish via YouGov, and was quota-sampled for age, gender, and geography to obtain an approximately nationally representative sample of online population. $52.7 \%$ of interviewees $(527$ of 1,000$)$ reported participation in protests, and $4.5 \%$ (45) in violence, over the last year.

Subsequently, we conducted a pre-registered (link to the pre-registration at OSF) replication study in Nicaragua, which also experienced a popular uprising prior to and during our survey (conducted in October 2018), with several hundred thousands of participants, hundreds of 
deaths, and thousands injured. The survey was administered in Spanish via YouGov, and was quota-sampled for age, gender, and geography to obtain an approximately nationally representative sample of online population. $29.1 \%$ of interviewees $(458$ of 1,574$)$ reported participation in protests and $1.8 \%(28)$ reported participation in violence.

\section{S2.2 Outcomes}

At EHU, we only measured PVINTENTIONS, because there were no salient events of antigovernment violence in Belarus during or prior to the survey. PVINTENTIONS was measured with a 2-item scale ("Tell a friend that, in some circumstances, it is justified to use violence for a political cause", "Use force or violence for a political cause", answered on a 7-point Likert-type scale from $0=$ "would never do this" to $6=$ "would certainly do this", Cronbach's $\alpha=0.79)$. Table S7 and Figure S13 provide summary statistics and histograms. These two items do not specify the target or goal of violence. We did not specify this, because we anticipated that interviewees would be unwilling to answer such specific questions (e.g., "Would you use force or violence to help overthrow the current government of Belarus?"). To make interviewees interpret these questions as asking about violence against the government of Belarus (rather than another country, e.g., Lithuania), we included a guided recall task immediately before these questions.

A guided recall task is a standard method in psychological research to activate particular thoughts or emotions and typically consists of asking interviewees to think back of a particular situation (e.g., a situation in which they had no control) and write down in a few sentences what

happened and how this made them fee ${ }^{18}$. We used a guided recall task that asked interviewees to think of the government of Belarus or some aspect of Belarusian politics and write down a brief description (we varied the recall instructions across interviewees; see below). The inclusion of this recall task immediately before PVINTENTIONS makes it likely that interviewees interpreted 
"violence for a political cause" as violence against the government of Belarus, rather than another country.

The EHU questionnaire also included an indirect measure of support for violence against the actual government of Belarus, derived from a double list experiment ${ }^{19}$, an item-count technique $^{20}$. In a list experiment, interviewees are not asked to indicate how much they agree or disagree with a particular statement, but are presented with a number of statements (e.g., four) and are asked to indicate with how many statements they agree. By giving half of the interviewees a list with one additional item (the sensitive item, also called the treatment item) the list experiment allows for estimating the proportion of interviewees that agrees with the sensitive item. The benefit of the list experiment is that it allows generating estimates of agreement with statements about sensitive topics without asking individual interviewees to explicitly indicate agreement with specific statements, which decreases the risk of dishonest or socially desirable responding.

The double list experiment is a simple extension of the standard list experiment aimed at increasing estimate accuracy, by having each participant complete two list experiments (list A and B), with randomly receiving the baseline list for one, while receiving the treatment list for the other. We followed the recommendations of Glynn when selecting the baseline items ${ }^{19}$. That is, we aimed for both baseline lists to have one high frequency item, one low frequency item, and two negatively correlated items, and a positive correlation between the baseline items of list A and B). The baseline items of list A were: (1) "I enjoy listening to music"; (2) "Schools should teach more science"; (3) "Schools should teach more religion"; (4) "I would like to work as a cleaner". The baseline items of list B were: (1) "I enjoy watching movies"; (2) "Schools should teach more biology"; (3) "Schools should teach more Christian values"; (4) "I would like to be a garbage collector". For both lists, the sensitive item was "It is justifiable to use violence against 
the government of Belarus". For each list, the participant was asked "How many statements do you agree with?" List A was included near the start of the survey (after the repression questions) and list B was included near the end of the survey. We estimated agreement with the sensitive item following the standard procedures described by Glynn ${ }^{19}$. The list experiment is based on the assumption that agreement with the baseline statements should (on average) be the same for those presented the baseline list and those presented the treatment list. Based on this assumption, the standard procedure for analyzing a list experiment involves estimating the proportion of interviewees that agree with the treatment item by computing the difference between the mean agreement for the treatment list and the mean agreement for the baseline list. In the double list experiment, each interviewee is presented with two separate list experiments (A and B). The double list experiment thus produces two estimates of agreement with the treatment item, and takes the average of these two.

The survey in Venezuela also included a double list experiment to measure PVINTENTIONS. The double list experiment was the same as in the EHU study, but with a different wording for the sensitive item and different negatively correlated items on the baseline list. The sensitive item was "I would use violence against a government of Venezuela that I oppose". The baseline items, for list A, items 1 and 4 were the same as in the EHU study, but items 2 and 3 were: (2) "Gay marriage should be made legal"; (3) "Abortion should remain illegal". For list B, again, items 1 and 4 were the same as in the EHU study, but items 2 and 3 were different: (2) "It should be legal for two men to get married"; (3) "Having an abortion is morally wrong".

The survey in Nicaragua also used the same double list experiment as in the Venezuela survey, with the sensitive "I would use violence against a government of Nicaragua that I oppose". 
In all three samples, we measured a number of other outcomes, including dehumaniza$\operatorname{tion}^{21}$ and several other indicators of intentions to participate in antigovernment violence. However, these other measures followed experimental vignettes that aimed to assess other research questions. Except for dehumanization, repression measures, without exceptions, predicted all these outcomes. These analyses are available upon request.

\section{S2.3 Measures of repression}

In EHU, Venezuela, and Nicaragua we measured interviewees' actual experiences with political repression. We first presented an explanation of what we considered political repression: "In some countries, the government (or people working for government) might use intimidation or violence against citizens. The government (or people working for the government) might use intimidation or violence to stop people from participating in certain activities or having certain political views". The survey then asked 39 questions, subdivided into (1) beliefs about the repression of typical people, (2) experience of repression among friends and family, and (3) personal experience of repression.

First followed a list of 13 events for which we asked the following question: "Below are several things that may or may not happen to a person. Please indicate how often a typical person in Belarus would experience the things below" ( 0 = "never", 1 = "rarely", 2 = "sometimes", $3=$ "often"). The 13 events were based on the definition and examples of repression presented in existing work ${ }^{22,23}$. We also consulted with area experts, including the EHU staff, to include examples of repression that might have happened to individuals in the sample populations. Four of the listed events involved the threat or use of violence (high-intensity repression):

a) "Intimidated by someone working for a government institution";

b) "Beaten up by police (or by other people working for the government)"; 
c) "Short-term detainment (for example, taken away by police for participating in a peaceful protest)";

d) "Imprisonment without fair trial".

The remaining nine listed events involved restriction of civil liberties (low-intensity repression):

e) "Government surveillance (for example, being followed, mail opened)";

f) "Fired from job or kicked out of school/university because of political views";

g) “Censorship (for example, unable to use certain websites, not allowed to read certain newspapers)";

h) "Restricted movement (restricted domestic and foreign travel)";

i) "Restricted political rights (for example, not able to vote in free and fair elections)";

j) "Private property confiscated by police (for example, police take away PC or phone)";

k) "Restricted freedom of speech (for example, being afraid to express political views)";

1) "Not allowed to join an association or non-governmental organization (for example, not allowed to join an independent trade union)";

m) "Not allowed to strike (for example, not allowed to stop work and negotiate for better working conditions)".

Subsequently, the interviewees were asked to answer the same 13 questions considering their friends and family ("Please indicate how often people you care about (your friends and family) have experienced the things below"), and themselves personally ("Please indicate how often you personally have experienced the things below").

\section{S2.4 Control variables}

We obtained the same basic set of control variables in EHU, Venezuela, and Nicaragua: gender $(0=$ male; $1=$ female $)$, age, education (not measured in EHU), SES, and democratic values. SES 
was measured with a verbal version of the MacArthur Scale of Subjective Social Status ${ }^{24}$. Interviewees were asked to think of a ladder with ten steps that represents where people stand in their society, where the highest step represents the people who are best off, and the lowest step represents the people who are worst off. Interviewees were then asked to indicate on which step they would place themselves.

The EHU survey included 10 items about democratic values:

1. The state must provide equal social and political rights to all citizens, regardless of religion, race or gender.

2. Open and public criticism of the government is permissible even in states of national emergency.

3. The slightest threat to the security of the state is enough to justify serious restrictions on democracy. *

4. I prefer a democratic government whose actions and views are opposed to mine over a non-democratic government with whose views I agree.

5. Every citizen has the right to take his convictions to the street if necessary.

6. Public participation of the people is not necessary if decision making is left in the hands of a few trusted leaders. *

7. I don't mind a politician's methods if he manages to get the right things done.*

8. Because demonstrations frequently become disorderly and disruptive, radical and extremist political groups shouldn't be allowed to demonstrate. *

9. Society shouldn't have to put up with the views that are fundamentally different from the views of the majority. * 
10. No matter what a person's beliefs are, he is entitled to the same legal rights and protection as anyone else.

For each statement, interviewees indicated their agreement on a 7-point scale $(0=$ "strongly disagree", 6 = "strongly agree"). Items 1-6 were adapted from Canetti-Nisim ${ }^{25}$ and items 7-10 from Miklikowska $^{26}$. Five items reflected democratic values (items 1, 2, 4, 5, 10) and five items reflected opposition to democratic values (items 3, 6, 7, 8, 9, marked with an asterisk).

We examined the underlying factor structure with an exploratory factor analysis. The scree plot indicated to retain two factors. Oblique oblimin rotation revealed that all items that reflected support for democracy $(1,2,4,5,10)$ had loadings $>.40$ on the first factor. Items 3,6 and 7 had loadings $>.40$ on the second factor. Items 8 and 9 has loadings $<.40$ on both the first and second factor. The first and second factor were negatively correlated $(r=-.24)$. Based on these results, we excluded items 8 and 9 when computing scale scores for democratic values. We computed the average of the five pro-democracy items and the remaining three oppose-democracy items (items 3, 6, 7, reverse-scored). This scale showed acceptable reliability, $\alpha=.66$.

The survey in Venezuela included the same 10 items about democratic values. We performed a confirmatory factor analysis to assess the factor structure. Based on the results of the EHU survey, we expected that the items loaded highly on two negatively correlated latent factors, one reflecting democratic values, one reflecting opposition to democratic values. We estimated two models. In Model 1, we specified one latent factor, and we estimated paths from this latent factor to all 10 items. In Model 2, we specified two latent factors that were allowed to correlate. We estimated paths from one latent factor to all items that reflected democratic values (pro-democracy items 1, 2, 4, 5, 10) and paths from the second latent factor to all items that reflected opposition to democratic values (oppose-democracy items 3, 6, 7, 8, 9). Model 1 
$(\mathrm{RMSEA}=0.113,90 \% \mathrm{CI}[0.104,0.122], \mathrm{CFI}=0.617, \mathrm{TLI}=0.508)$ did not satisfy standard criteria for good model fit. Model $2(\mathrm{RMSEA}=0.048,90 \% \mathrm{CI}[0.038,0.058], \mathrm{CFI}=0.933, \mathrm{TLI}=$ 0.911) satisfied standard criteria for good model fit. In Model 2, the paths from the latent factors to the items were all significant (all $p s<.001$ ). Unexpectedly, Model 2 indicated that the two latent factors were not correlated, $r=-.01,95 \%$ CI $[-.10, .09]$. Internal consistency was slightly higher for a scale computed over the pro-democracy items $(\alpha=.64)$ than over the oppose-democracy items $(\alpha=.59)$. Based on these results, we computed scores for democratic values as the average of the five pro-democracy items.

The survey in Nicaragua included the same 10 items about democratic values. We again performed a confirmatory factor analysis. Model 1 (RMSEA $=0.121,90 \%$ CI $[0.114,0.129]$, $\mathrm{CFI}=0.746, \mathrm{TLI}=0.673)$ did not satisfy standard criteria for good model fit. Model 2 (RMSEA $=0.051,90 \% \mathrm{CI}[0.043,0.058], \mathrm{CFI}=0.957, \mathrm{TLI}=0.943)$ performed better on all three criteria. However, Model 2 indicated that the two latent factors were positively correlated, $r=.22,95 \%$ CI $[.15, .29]$. Internal consistency was higher for a scale computed over the pro-democracy items $(\alpha=.78)$ than over the oppose-democracy items $(\alpha=.65)$. Based on these results, we computed the same scale as for the Venezuela survey; scores for democratic values were computed as the average of the five pro-democracy items.

\section{S2.5 Random-assignment experiments}

The EHU survey included a guided recall task that varied the recall instructions between interviewees. The survey included four different instructions. In the REPRESSION condition, interviewees were instructed to "Please take a moment and think about a way in which the government of Belarus has repressed people like you. Please take a few minutes to describe specific examples of such repression". In the POLITICAL INFLUENCE condition, interviewees were instructed to think 
about "how it would benefit you if you had more influence on the direction of Belarusian politics and society". In the PARITY condition, the instruction was to think about "how it would benefit everyone in Belarus if all citizens had equal influence on the direction of Belarusian politics and society". In the CONTROL condition, the instruction was to "think about the government of Belarus. Please take a few minutes to describe the House of Representatives of Belarus. (For example, how many members are in the house? From what parties are the members?)".

This pilot experiment built on established emotion-induction paradigms, commonly used in psychology to study, for example, the effects of fear on judgment ${ }^{27}$. We did not focus on any specific emotion induced by repression. The target variable we aimed to manipulate was memories or thoughts about repression. We assumed that such memories generate psychological responses that resemble those generated by the actual experience, allowing us to test, experimentally, the effects of repression without actually administering repression.

Unfortunately, only about half of the EHU interviewees (207 out of 386, 54\%) followed the instruction to provide some written description. PVINTENTIONS did not differ across the four recall conditions, $F(3,369)=0.39, p=0.761, \mathrm{~N}=370$. Note, however, that these estimates represent intent-to-treat effects (ITT), which (given such large non-compliance rate) likely poorly reflect average treatment effects (i.e., the quantity of interest). In the presence of non-compliance, scholars often estimate "complier average treatment effects" (CATE) or "local average treatment effects" (LATE). However, we were unable to estimate CATE/LATE, because our questionnaire did not allow clearly distinguishing between compliers and non-compliers. Despite providing no written descriptions, the interviewees may have actually followed the instruction to recall repression events (i.e., compliers), or they may have followed neither instruction (noncompliers), and we cannot distinguish between the two from the blank description boxes. Given 
this non-compliance issue, we developed an alternative design for the surveys in Venezuela and Nicaragua.

Both in Venezuela and Nicaragua half of the interviewees first received the repression items (experimental condition), immediately followed by questions measuring violence. The other half of the interviewees started the survey with the questions about violence.

The surveys in Venezuela and Nicaragua also included vignette experiments to measure the effect of governments' conciliatory gestures on citizens' intentions to participate in violence. In Venezuela, the vignette was followed by two questions that served as manipulation checks, the first measuring perceived concern for wellbeing of citizens, "Based on the story, do you think the new president of Venezuela cares for the wellbeing of the citizens?" $(0=$ "not at all", $6=$ "very mисh"), the second measuring anger about the event, "How angry do you feel about the killing of the protestor?" (0 = "not angry at all", 6 = "extremely angry").

\section{S2.6 Reporting concerns}

Our surveys focused on sensitive issues (i.e., political repression and antigovernment violence). Hence, a risk exists that our interviewees did not honestly report their true experiences with repression, past participation in violence, and intentions to participate in violence in the future. The reasons for such withheld or dishonest reporting are multiple, including fears of reprisals from state authorities (e.g., interviewees may believe that state authorities can intercept the surveys, reveal interviewees' identities and responses, and use repression in retaliation). The collection of questionnaires at the EHU was overseen by one of the authors. All questionnaires were successfully and anonymously collected and eventually securely archived. The online surveys in Venezuela and Nicaragua were collected following YouGov procedures that assign random numbers to interviewees, which makes identification of interviewees impossible. 
To alleviate such concerns among the interviewees, we have taken several a priori measures. First, we provided explicit options throughout the questionnaires to refuse answering questions (e.g., "prefer not to say"), which reduces dishonest responding ${ }^{28}$. Subsequently, both verbal (in EHU) and written introductions (Venezuela and Nicaragua) emphasized that interviewees could cease participating in the survey at any moment without negative consequences, which also reduces dishonest responding. Third, none of the questions about violence referred to concrete targets. These questions either left the target of violence unspecified (e.g., "violence for a political cause"), or concerned hypothetical governments or people working for governments described in experimental vignettes. Hence, although the targets of violence were implicit throughout the questionnaires (i.e., the actual governments in the surveyed countries), replies to particular questions did not contain any incriminating information that could be used against interviewees in case the surveys were intercepted by state authorities. Finally, we measured intentions to participate in violence via list experiments, ${ }^{32}$ which allowed us to assess intentions to use violence against actual, not hypothetical, governments without asking interviewees to explicitly indicate this.

Despite these a priori measures, we cannot entirely rule out the possibility that dishonest reporting influenced our results. However, we can use available data from our surveyed samples to assess whether such bias exists and to what extent it potentially drives our results. There are several entry points for potential nonresponse bias. First, the contacted would-be interviewees may decline participation in the survey (e.g., due to lack of time). Second, the contacted wouldbe interviewees may decline participation in the survey after reading (hearing) the survey intro- 
duction (e.g., that the survey is about politics). Third, interviewees may refuse answering or provide dishonest replies to particular questions (i.e., those pertaining to political repression and antigovernment violence).

Importantly, non-zero nonresponse rate to the survey (as a whole) and to particular questions do not automatically imply bias, as there is no clear relationship between response rates and nonresponse bias, and nonresponse bias varies across variables ${ }^{29}$. Nonresponse could only influence our results if the nonparticipants or dishonest interviewees were systematically differentwith respect to repression and violence-from the participants and honest interviewees. For example, nonresponse bias may drive our results if highly repressed individuals, in contrast to what we found, are in fact less prone to violence and less likely to participate in our survey or decline replying (or reply dishonestly) to violence questions.

We have no auxiliary data about the individuals who declined participation in the survey upon invitation or after reading the survey introductions. However, the overall response rates (i.e., the percent of individuals, among all invited to participate in the surveys, who eventually completed the surveys, in part or in full) were not atypical, e.g., 78.50\% in Afrobarometer Round 5 and $62.70 \%$ in Venezuela. The response rates to questions about violence, specifically, were also not atypical. Table S48 reports the percent of interviewees replying "prefer not to say" or "don't know" to the question that constitutes PVPARTICIPATION/PVINTENTIONS, compared to the preceding item asking about participation in a protest/demonstration, i.e., a question about a less sensitive subject at the same stage of the questionnaire. As shown in the table, the nonresponse rates to questions about violence were generally low, and in five samples (out of eight) were actually lower that nonresponse rates to the question about a less sensitive topic. 
As noted above, nonresponse rates per se do no imply nonresponse bias. Therefore, we assessed nonresponders with respect to measured variables. Although we do not have auxiliary data about nonresponders to the survey as a whole, we have data for individuals who did not respond to questions about violence.

Interviewees may refuse answering questions about violence by marking "prefer not to say" or "don't know". Interviewees may do so for multiple reasons; however, if these reasons do not relate to our key predictor of interest (i.e., repression), such nonresponding would not bias our estimates of the association between repression and violence. Hence, we need to assess whether nonresponders are systematically different with respect to repression.

We see no clear rationale why repressed interviewees, wary of state reprisals, would reply "prefer not to say" if they had not participated in political violence (or have no intentions to do so) rather than simply replying that they did not do so (or that they have no such intentions). In contrast, repressed interviewees, due to fears of further repression, may select "prefer not to say" when they in fact participated in violence in the past (or have intentions to do so). Hence, we only compared repression levels in the sub-samples of individuals who replied "prefer not to say" / "don't know" to those who reported participation in violence. As shown in Table S49, in four samples (Afrobarometer Round 5, Afrobarometer Round 2, Venezuela, and Nicaragua), the average repression levels, indexed with PRS or RS, among nonresponders are actually lower than among the participants (i.e., those scored PVPARTICIPATION =1). Hence, in these samples, repression does not seem to produce underreporting of violence.

In the other four samples (see Table S49) bias potentially exists, as repression levels are higher among the nonresponders that among the participants. However, if such bias indeed ex- 
ists, then our reported results are likely underestimates (rather than overestimates) of the true effects of repression on violence. If observed or experienced repression leads individuals to withhold their participation in violence, then our samples contain a number of individuals with high scores of PRS/RS and PVPARTICIPATION = 0, who would otherwise be coded PVPARTICIPATION = 1.

Likewise, our results would be underestimates of the true effects if, instead of replying "prefer not to say" / "don't know", such repressed individuals (who participated in violence in the past or have intentions to do so) replied that they have not taken part in political violence.

Under what conditions would our analyses overestimate the true repression effects? This would happen if less repressed individuals were in fact more prone to violence but who would tend to reply "prefer not to say"/ "don't know" or reply that they did not participate in violence or had no such intentions. While we see why some individuals (e.g., individuals who hold democratic values) would be reluctant to admit participation in violence, we see no clear rationale why such reluctance would correlate negatively with observed or experienced repression.

Given that the processes underlying nonresponse are unknown, the generality of these conclusions should not be overstated. We cannot rule out that more complex relationships among a larger number of variables produces nonresponse bias, which we cannot detect just by focusing on repression, reporting, and violence. However, the above discussion suggests that the most plausible scenario, where the possibility of state reprisals among repressed interviewees incentivizes underreporting of violence, has likely produced a downward, not upward, bias in our results.

Finally, we analyzed list experiments. As mentioned above, the standard procedure for analyzing data from a double list experiment yields an estimate of the proportion of interviewees in a sample that agree with the treatment item, rather than estimates of agreement for individual 
interviewees. Hence, research utilizing list experiments has typically examined associations with individual difference variables by splitting in subsamples (e.g., subsamples for high and low education $^{30}$ ). As the sample for the EHU survey was relatively small, we used a median split, while we split in tertiles for the Venezuela and Nicaragua surveys.

For the EHU survey, we estimated the proportion of respondents who agreed with the sensitive item ("It is justifiable to use violence against the government of Belarus") for interviewees that scored below the median and those who scored at or above the median on the repression scale (see Table S50). Among those with low scores on the repression scale, the difference-in-means estimator of the proportion of interviewees who agreed with the sensitive item was $0.06,95 \% \mathrm{CI}[-0.02,0.14]$. Among those with high scores on the repression scale, the estimated proportion of interviewees who agreed with the sensitive item was $0.22,95 \%$ CI [0.13, $0.30]$. The difference in estimated support for political violence was significant, $\mathrm{t}(361)=2.61, \mathrm{p}$ $=.010$.

For the Venezuela survey, we estimated the proportion of interviewees who agreed with the sensitive item for the lowest tertile, the middle tertile, and the highest tertile on the repression scale (see Table S51). Among those with low scores on the repression scale, the difference-inmeans estimator of the proportion of interviewees who agreed with the sensitive items was 0.18 , 95\% CI [0.11, 0.24]. Among those with high scores on the repression scale, the estimated proportion of interviewees who agreed with the sensitive items was $0.23,95 \% \mathrm{CI}[0.17,0.30]$. The difference in estimated support for political violence was not significant, $\mathrm{t}(658)=1.18, \mathrm{p}=.238$.

For the Nicaragua survey, we estimated the proportion of interviewees who agreed with the sensitive item for those in the lowest tertile, the middle tertile, and the highest tertile on the 
repression scale (see Table S52). Among those with low scores on the repression scale, the difference-in-means estimator of the proportion of interviewees who agreed with the sensitive items was $0.08,95 \%$ CI $[0.03,0.13]$. Among those with high scores on the repression scale, the estimated proportion of interviewees who agreed with the sensitive items was $0.16,95 \%$ CI [0.11, 0.21]. The difference in estimated support for political violence was significant, $t(1029)=2.06, p$ $=.040$.

Taken together, the analyses of the list experiments generate results consistent with the main analyses; however, the identified associations in the list experiments were weaker. Hence, the analyses of the list experiments provide no evidence that underreporting of violence drives our main results. If interviewees were afraid to reveal their true intentions while replying to direct question, the results of the list experiments would have revealed stronger, not weaker, effects. Alternatively, these weaker results potentially reflect the lower reliability of list experiments, due to the complexity of the item-count task ${ }^{30}$. 


\section{S3: References for supplementary methods}

1. Becker, J. C. \& Tausch, N. A dynamic model of engagement in normative and non-normative collective action: Psychological antecedents, consequences, and barriers. Eur. Rev. Soc. Psychol. 26, 43-92 (2015).

2. Gibney, M. et al. The Political Terror Scale. The Political Terror Scale https://www.politicalterrorscale.org/.

3. World Development Indicators. https://datacatalog.worldbank.org/search/dataset/0037712.

4. Salehyan, I. et al. Social Conflict in Africa: A New Database. Int. Interact. 38, 503-511 (2012).

5. Gleditsch, N. P., Wallensteen, P., Eriksson, M., Sollenberg, M. \& Strand, H. Armed Conflict 1946-2001: A New Dataset. J. Peace Res. 39, 615-637 (2002).

6. Pettersson, T. \& Eck, K. Organized violence, 1989-2017. J. Peace Res. 55, 535-547 (2018).

7. Hox, J. J., Moerbeek, M. \& Schoot, R. van de. Multilevel Analysis: Techniques and Applications, Third Edition. (Routledge, 2017).

8. Mundlak, Y. On the Pooling of Time Series and Cross Section Data. Econometrica 46, 69 (1978).

9. McNeish, D. \& Kelley, K. Fixed effects models versus mixed effects models for clustered data: Reviewing the approaches, disentangling the differences, and making recommendations. Psychol. Methods 24, 20-35 (2019).

10. Bell, A., Fairbrother, M. \& Jones, K. Fixed and random effects models: making an informed choice. Qual. Quant. 53, 1051-1074 (2019).

11. Altonji, J. G., Elder, T. E. \& Taber, C. R. Selection on Observed and Unobserved Variables: Assessing the Effectiveness of Catholic Schools. J. Polit. Econ. 113, 151-184 (2005).

12. Oster, E. Unobservable Selection and Coefficient Stability: Theory and Evidence. J. Bus. Econ. Stat. 37, 187-204 (2019).

13. Bellows, J. \& Miguel, E. War and local collective action in Sierra Leone. J. Public Econ. 93, $1144-1157$ (2009).

14. González, F. \& Miguel, E. War and local collective action in Sierra Leone: A comment on the use of coefficient stability approaches. J. Public Econ. 128, 30-33 (2015).

15. Rights, J. D. \& Sterba, S. K. Quantifying explained variance in multilevel models: An integrative framework for defining R-squared measures. Psychol. Methods 24, 309-338 (2019).

16. Rosenbaum, P. R. \& Rubin, D. B. Assessing Sensitivity to an Unobserved Binary Covariate in an Observational Study with Binary Outcome. J. R. Stat. Soc. Ser. B Methodol. 45, 212218 (1983).

17. Gleditsch, K. S. Advances in Data on Conflict and Dissent. in Computational Conflict Research (eds. Deutschmann, E., Lorenz, J., Nardin, L. G., Natalini, D. \& Wilhelm, A. F. X.) 23-41 (Springer International Publishing, 2020). doi:10.1007/978-3-030-29333-8_2.

18. Whitson, J. A. \& Galinsky, A. D. Lacking Control Increases Illusory Pattern Perception. Science 322, 115-117 (2008).

19. Glynn, A. N. What Can We Learn with Statistical Truth Serum? Public Opin. Q. 77, 159172 (2013).

20. Tourangeau, R. \& Yan, T. Sensitive questions in surveys. Psychol. Bull. 133, 859-883 (2007).

21. Bastian, B. \& Haslam, N. Excluded from humanity: The dehumanizing effects of social ostracism. J. Exp. Soc. Psychol. 46, 107-113 (2010). 
22. Davenport, C. State Repression and Political Order. Annu. Rev. Polit. Sci. 10, 1-23 (2007).

23. deMeritt, J. H. R. The Strategic Use of State Repression and Political Violence. in Oxford Research Encyclopedia of Politics (Oxford University Press, 2016). doi:10.1093/acrefore/9780190228637.013.32.

24. Operario, D., Adler, N. E. \& Williams, D. R. Subjective social status: reliability and predictive utility for global health. Psychol. Health 19, 237-246 (2004).

25. Canetti-Nisim, D. The Effect of Religiosity on Endorsement of Democratic Values: The Mediating Influence of Authoritarianism. Polit. Behav. 26, 377-398 (2004).

26. Miklikowska, M. Psychological underpinnings of democracy: Empathy, authoritarianism, self-esteem, interpersonal trust, normative identity style, and openness to experience as predictors of support for democratic values. Personal. Individ. Differ. 53, 603-608 (2012).

27. Lerner, J. S., Gonzalez, R. M., Small, D. A. \& Fischhoff, B. Effects of fear and anger on perceived risks of terrorism: a national field experiment. Psychol. Sci. 14, 144-150 (2003).

28. Persson, M. \& Solevid, M. Measuring Political Participation-Testing Social Desirability Bias in a Web-Survey Experiment. Int. J. Public Opin. Res. 26, 98-112 (2014).

29. Groves, R. M. Nonresponse Rates and Nonresponse Bias in Household Surveys. Public Opin. Q. 70, 646-675 (2006).

30. Kramon, E. \& Weghorst, K. (Mis)Measuring Sensitive Attitudes with the List Experiment. Public Opin. Q. 83, 236-263 (2019). 

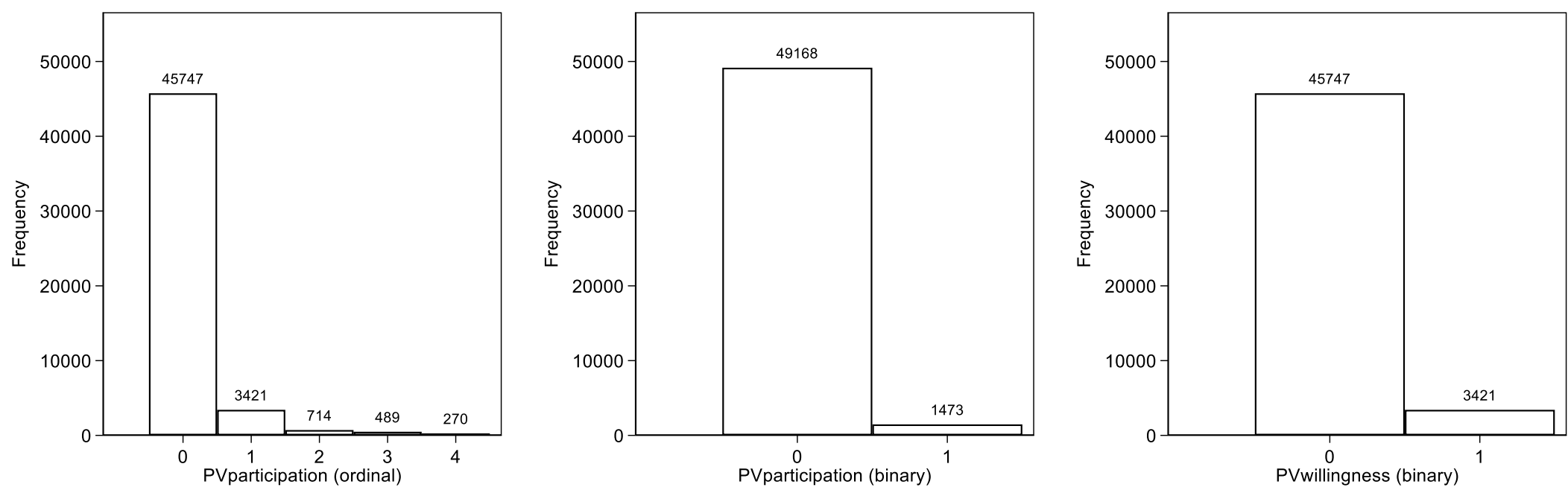

\section{Figure S1}

Histograms of outcomes (Afrobarometer Round 5). 

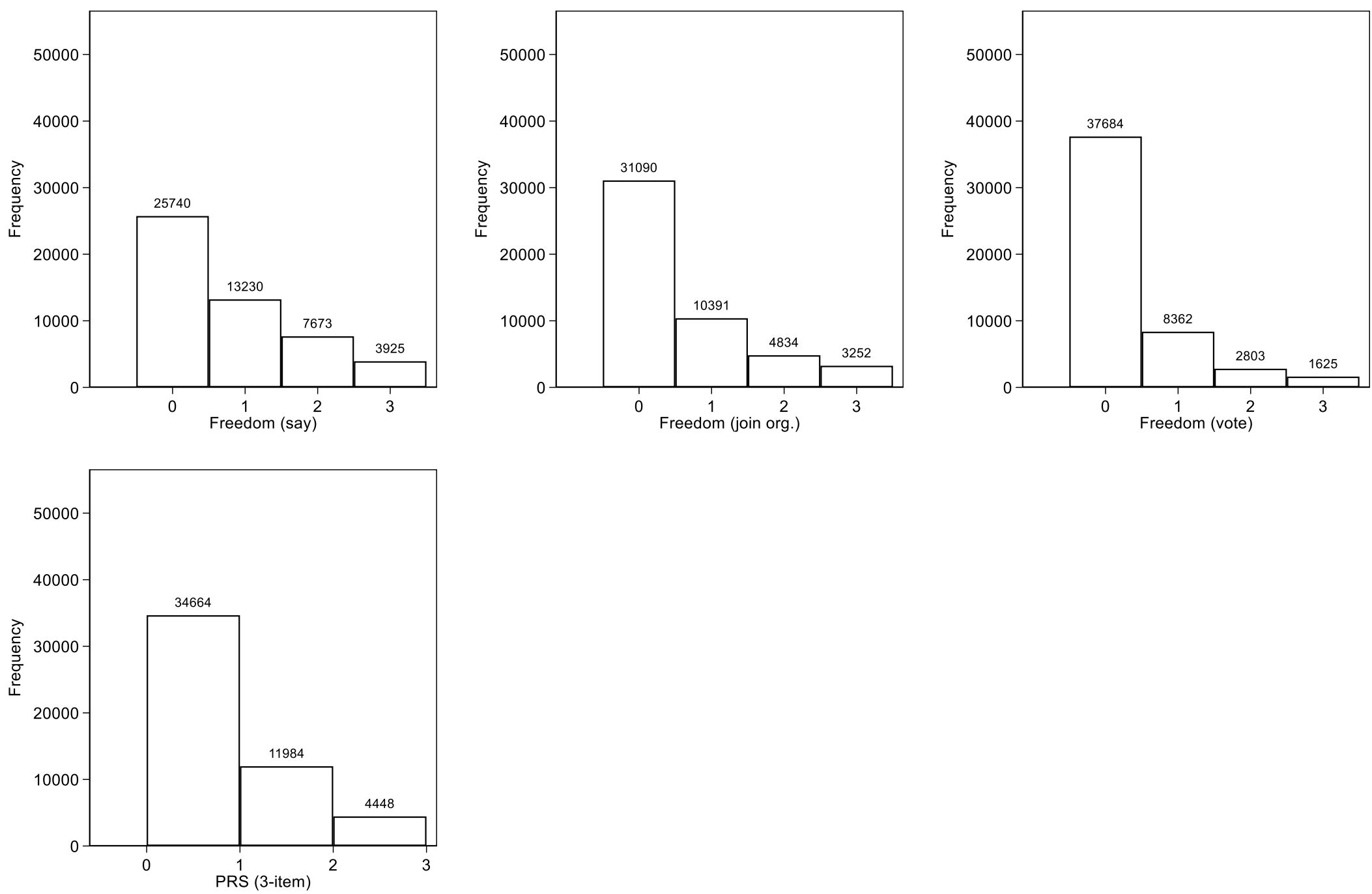

\section{Figure S2}

Histograms of items composing the perceived repression scale (PRS), and PRS (Afrobarometer Round 5). 

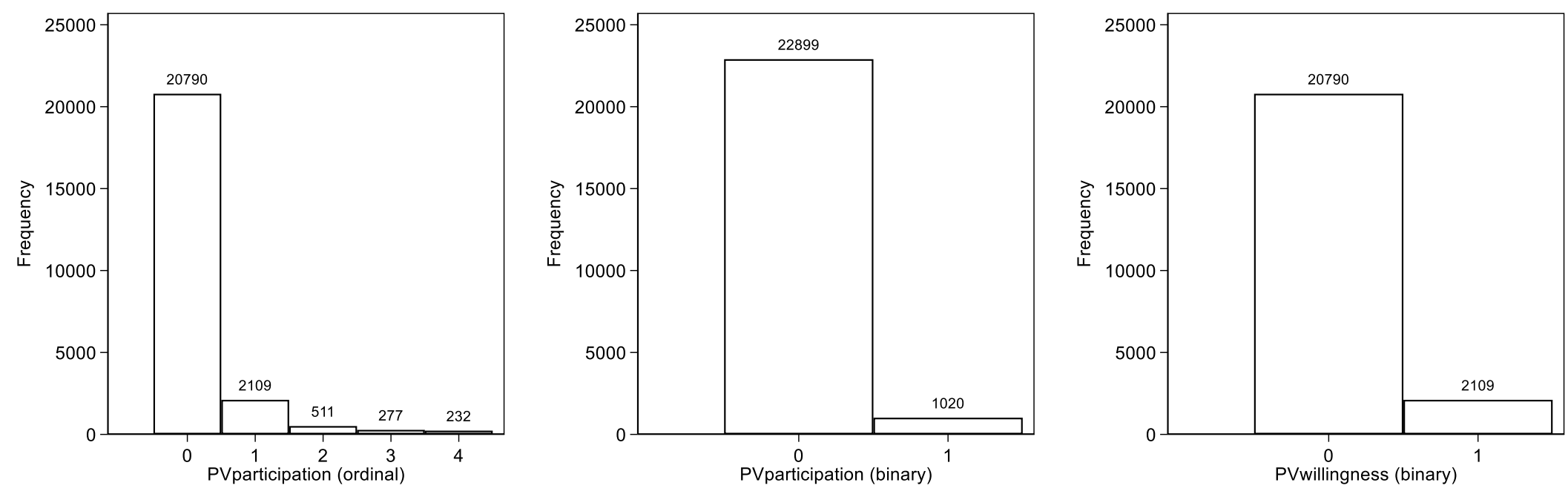

\section{Figure S3}

Histograms of outcomes (Afrobarometer Round 2). 

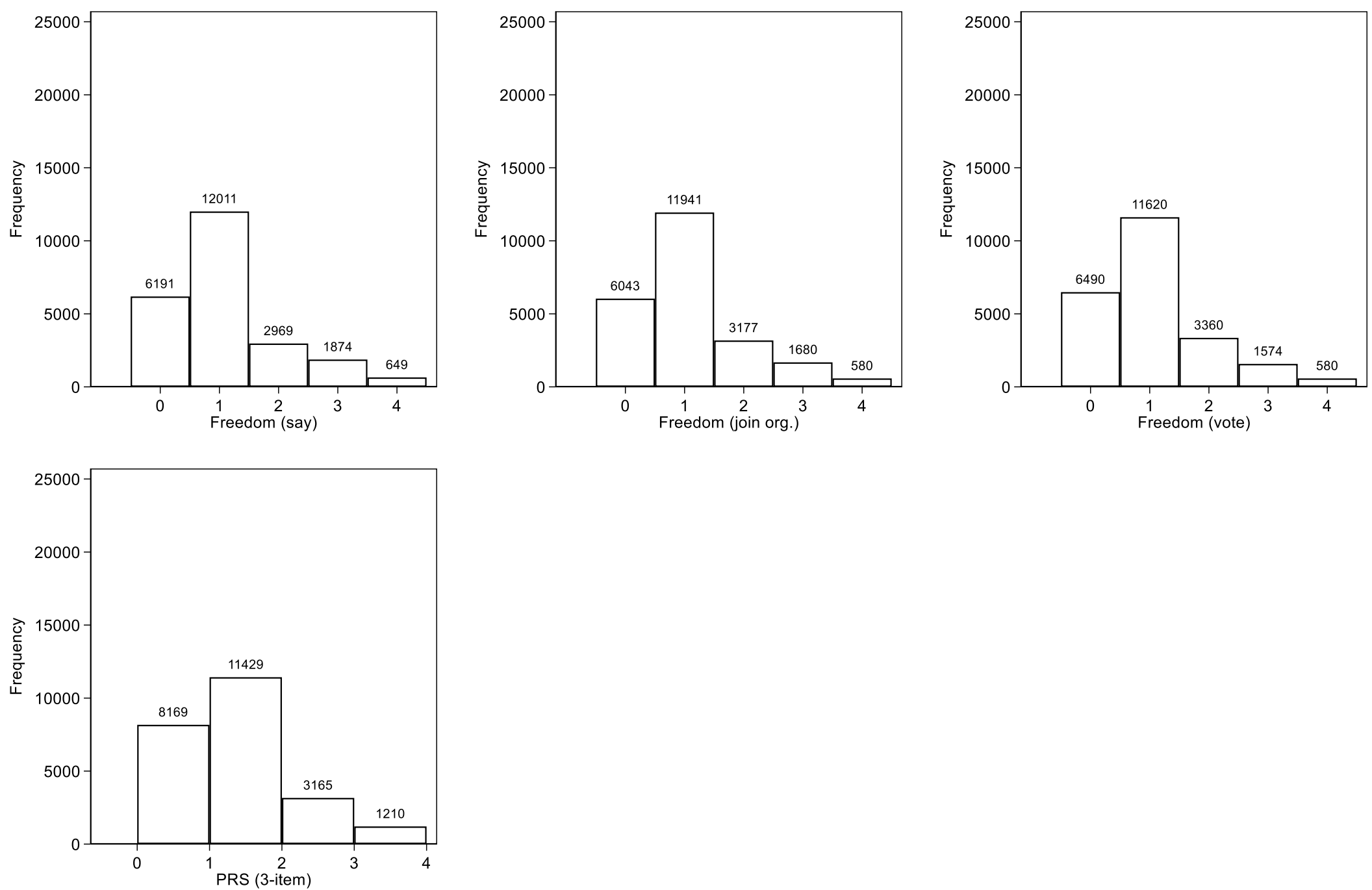

\section{Figure S4}

Histograms of items composing the perceived repression scale (PRS), and PRS (Afrobarometer Round 2). 

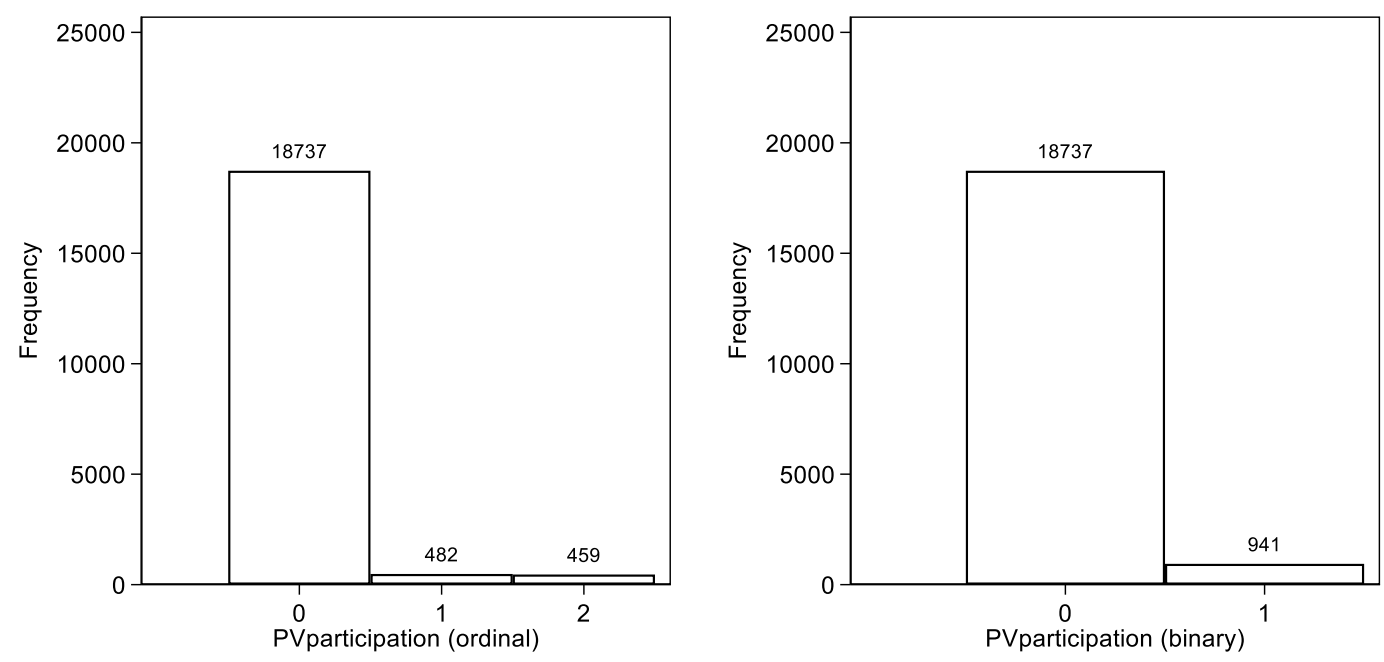

\section{Figure S5}

Histograms of outcomes (Latinobarometero 2013). 

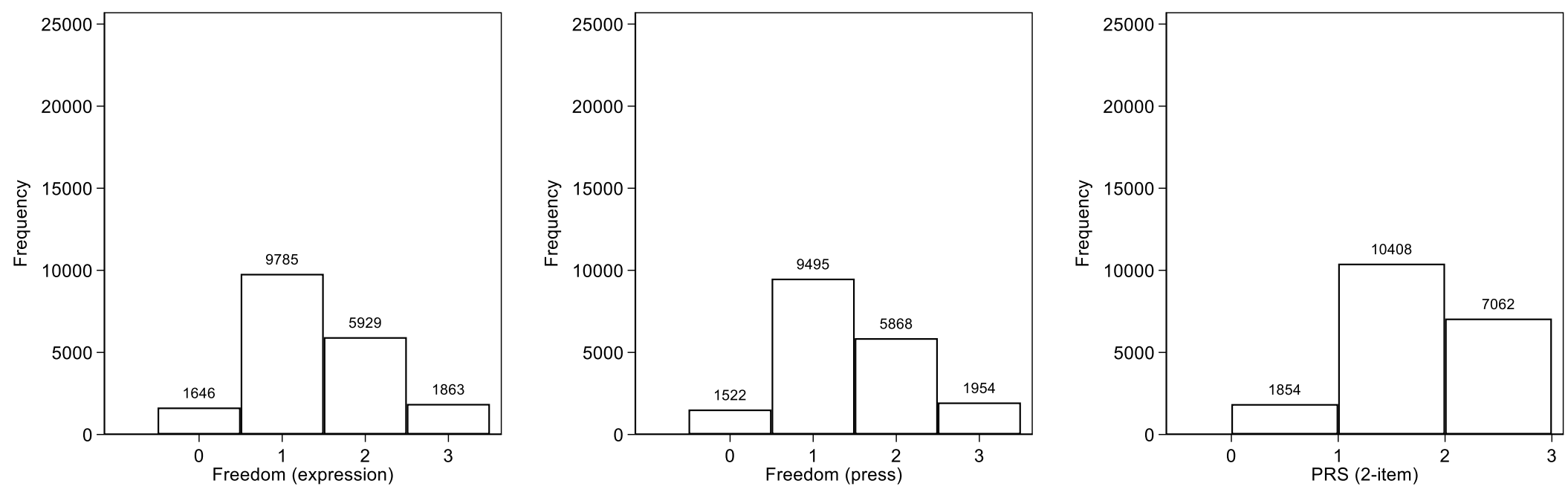

\section{Figure S6}

Histograms of items composing the perceived repression scale (PRS), and PRS (Latinobarometero 2013). 

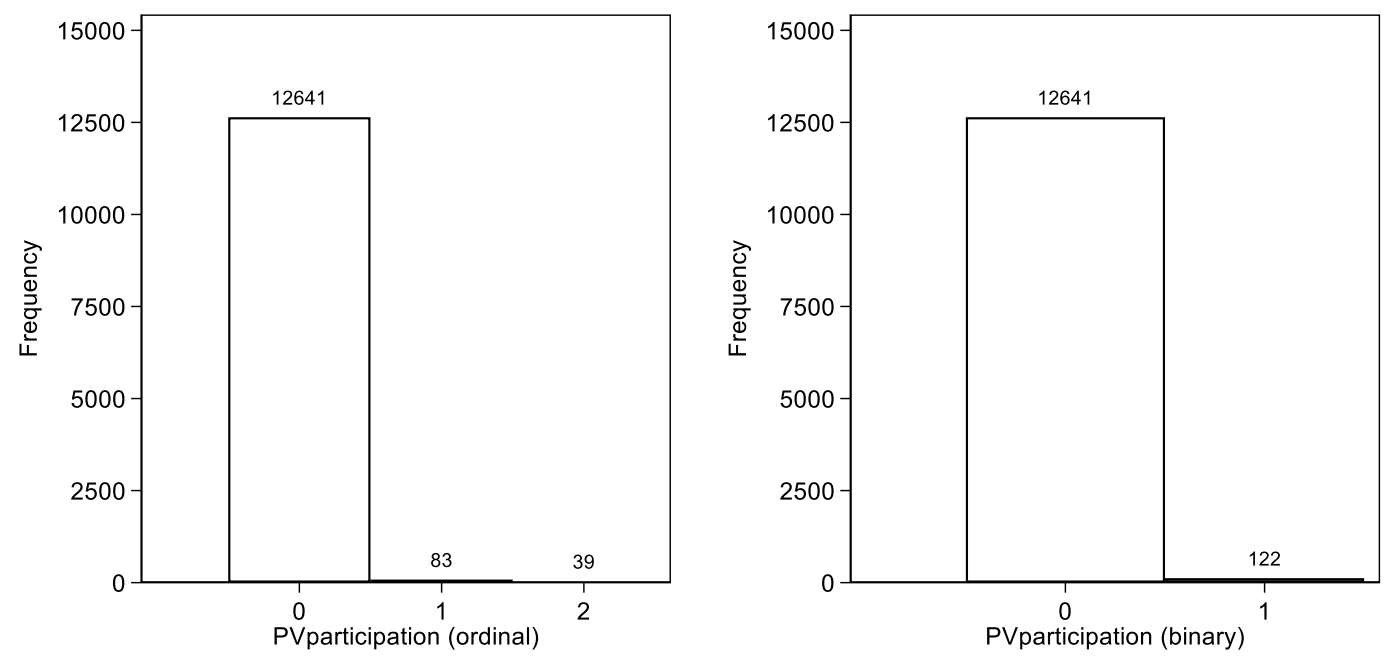

Figure S7

Histograms of outcomes (Asianbarometer Round 2). 

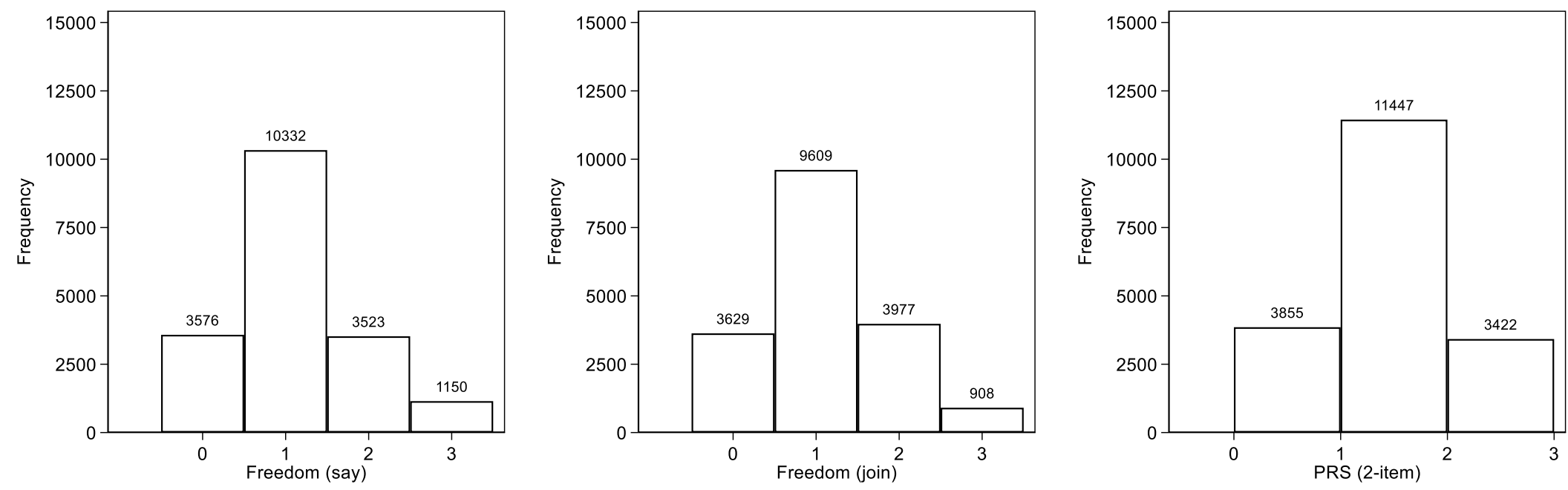

\section{Figure S8}

Histograms of items composing the perceived repression scale (PRS), and PRS (Asianbarometer Round 2). 

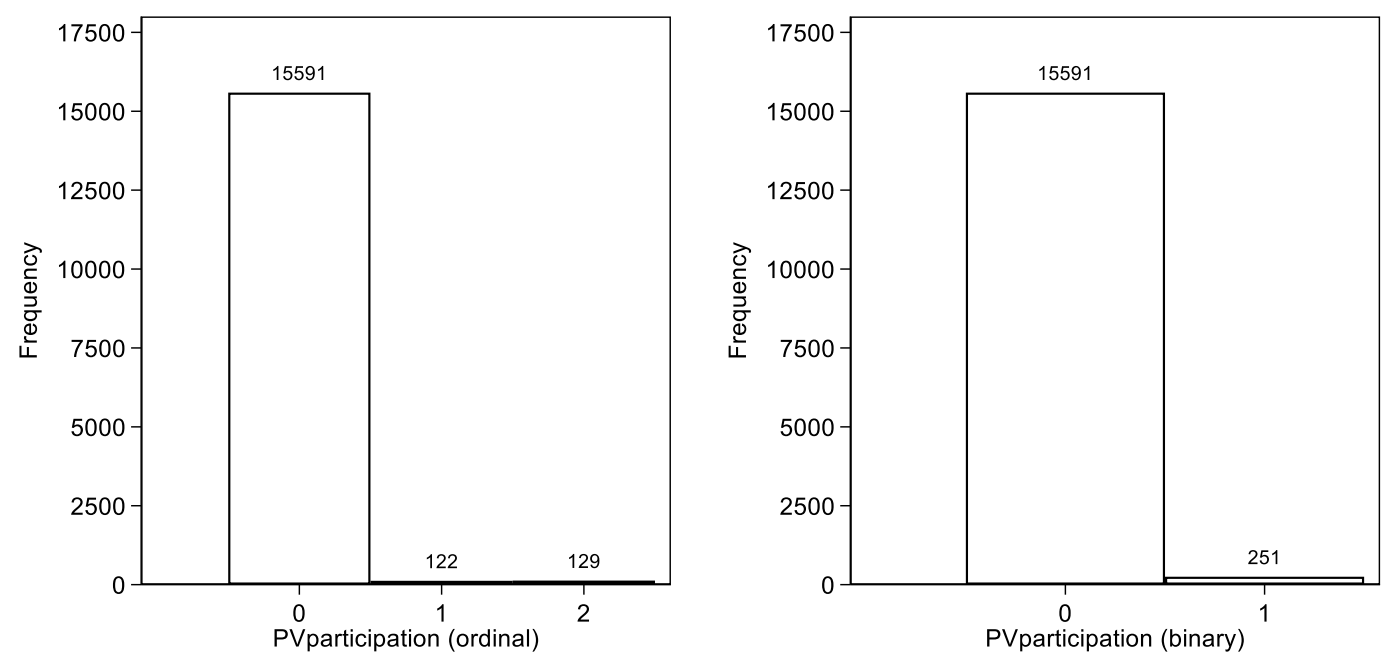

\section{Figure S9}

Histograms of outcomes (Asianbarometer Round 3). 

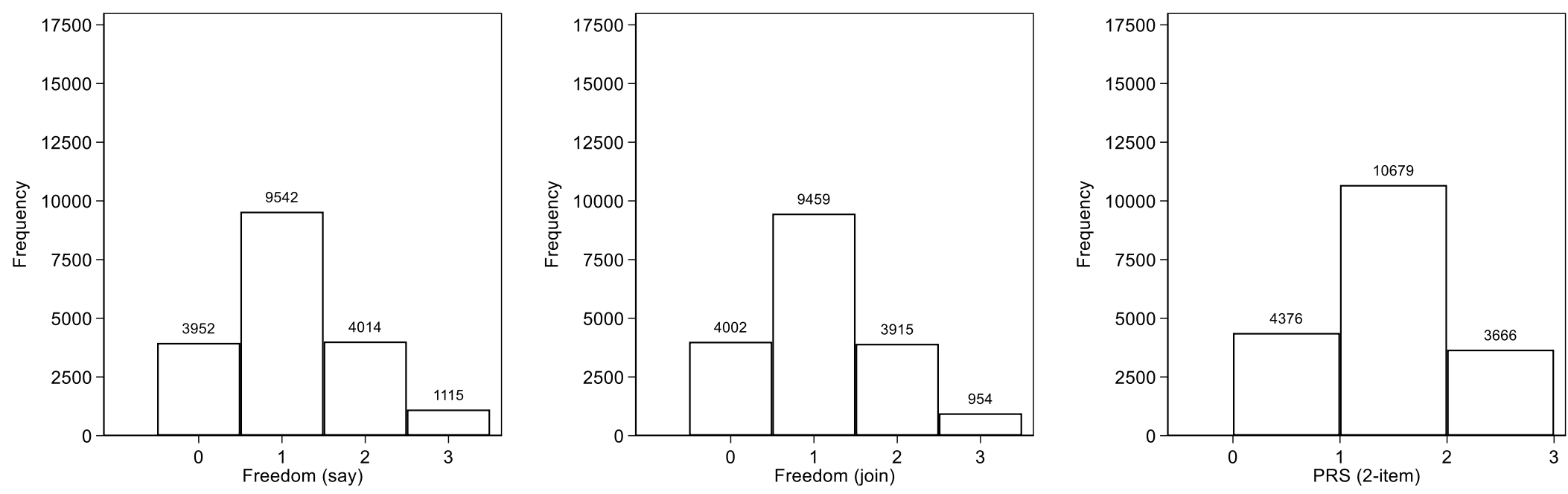

\section{Figure S10}

Histograms of items composing the perceived repression scale (PRS), and PRS (Asianbarometer Round 3). 

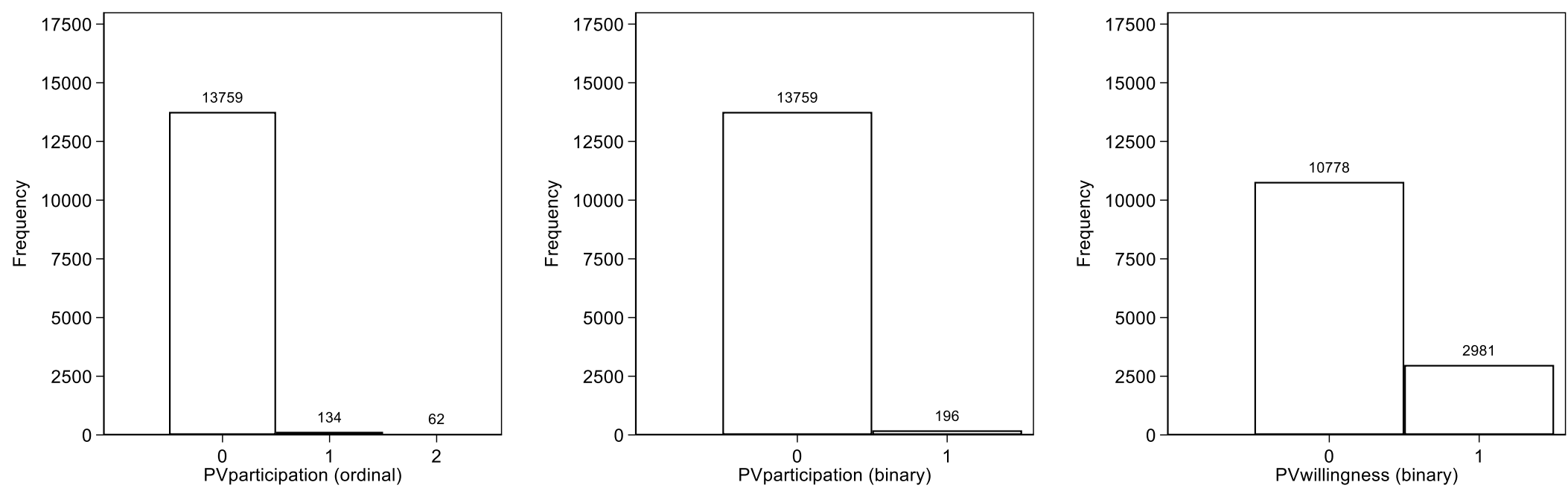

\section{Figure S11}

Histograms of outcomes (Asianbarometer Round 4). 

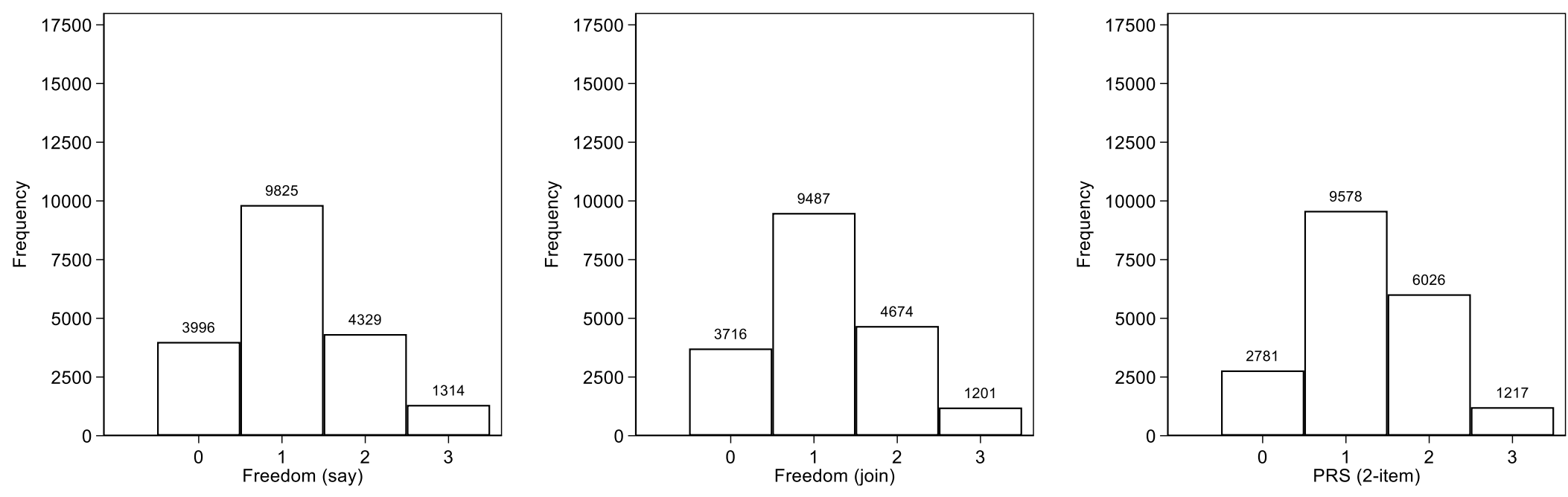

\section{Figure S12}

Histograms of items composing the perceived repression scale (PRS), and PRS (Asianbarometer Round 4). 


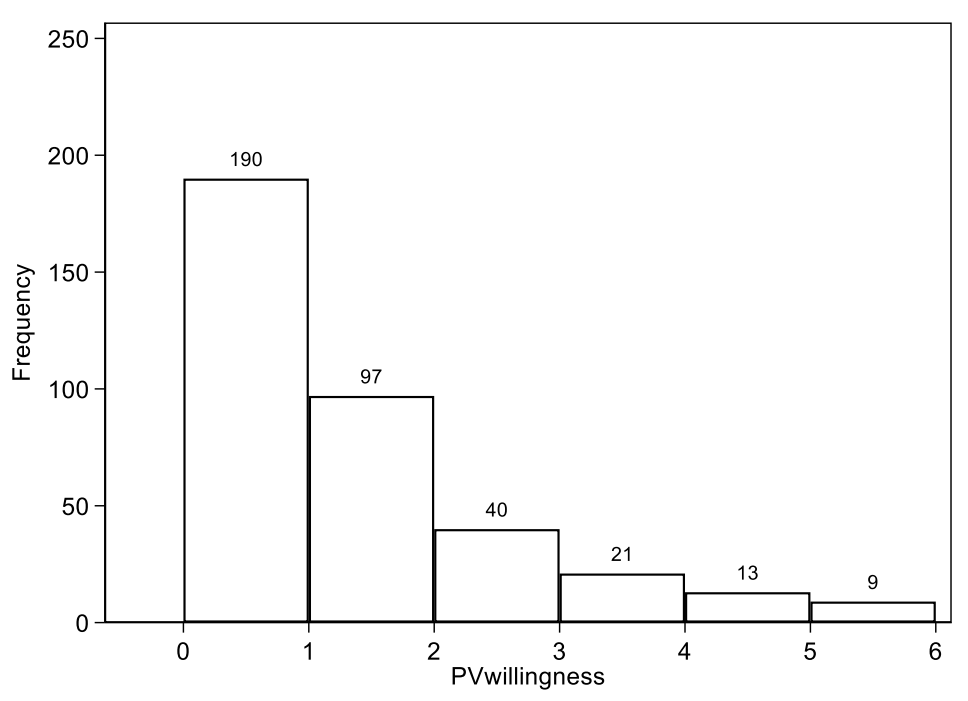

\section{Figure S13}

Histograms of outcomes (EHU). 

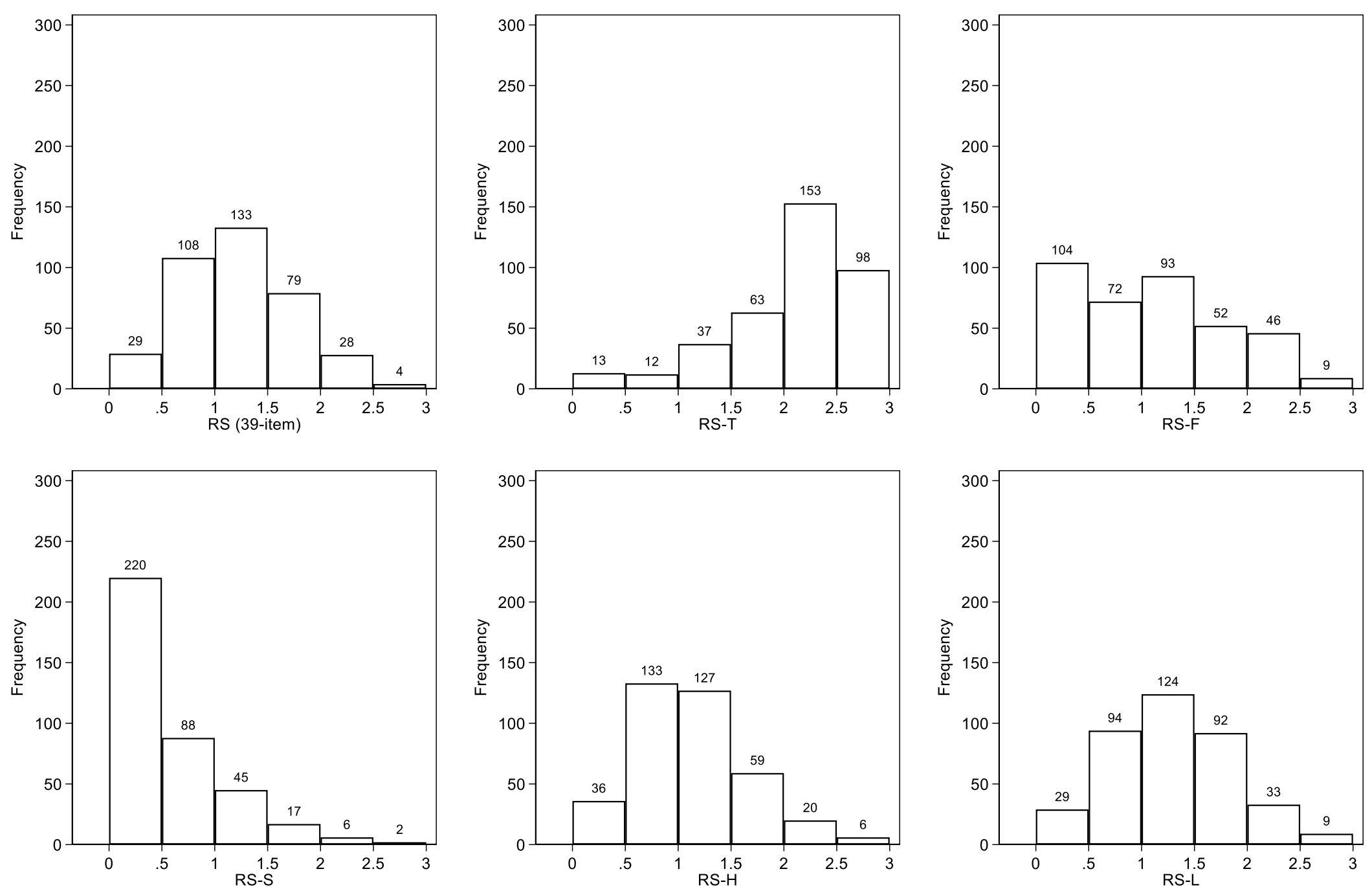

\section{Figure S14}

Histograms of repression (aggregate, typical, friends, self, high-intensity, and low-intensity) (EHU). 

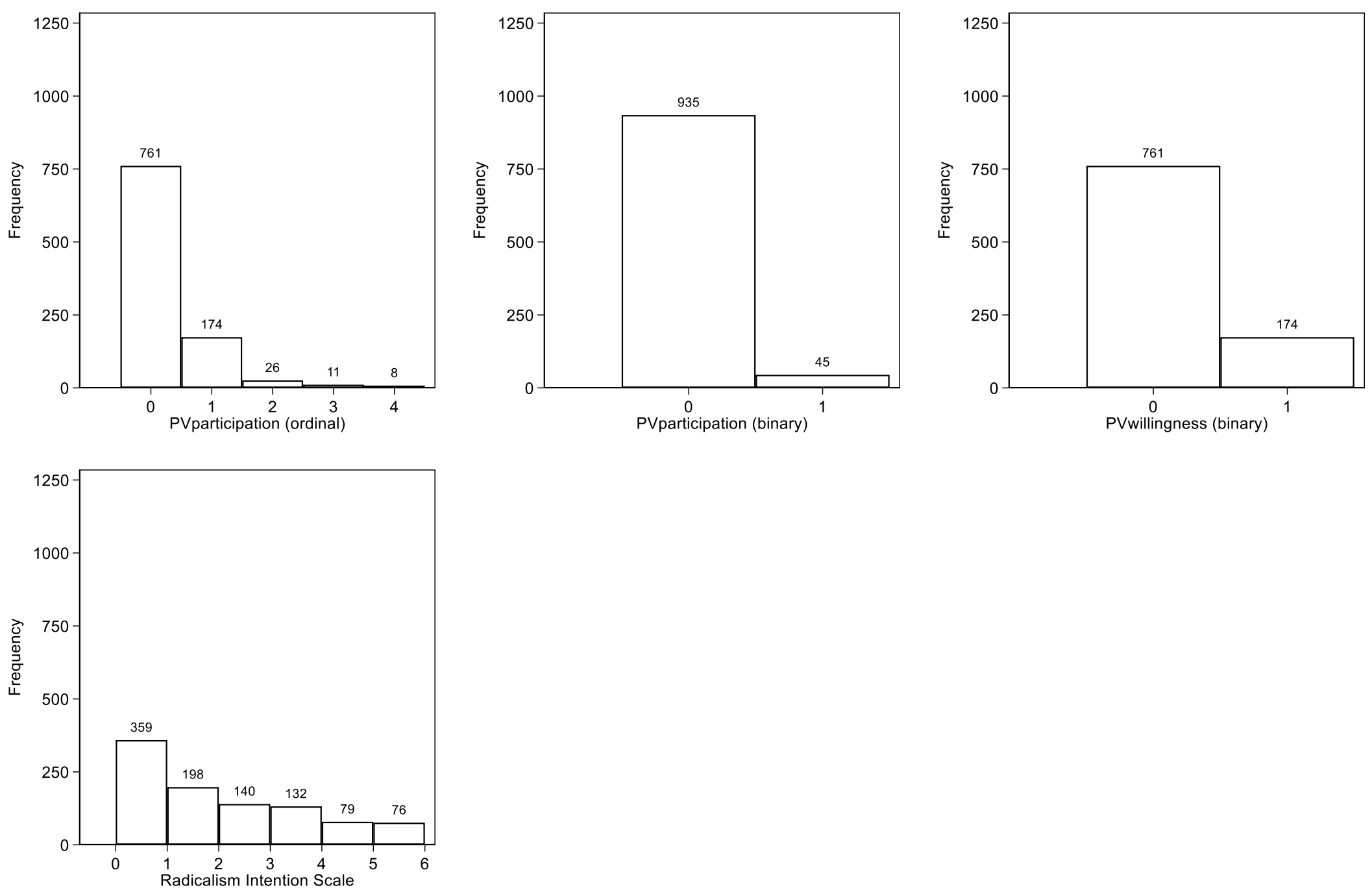

\section{Figure S15}

Histograms of outcomes (Venezuela). 

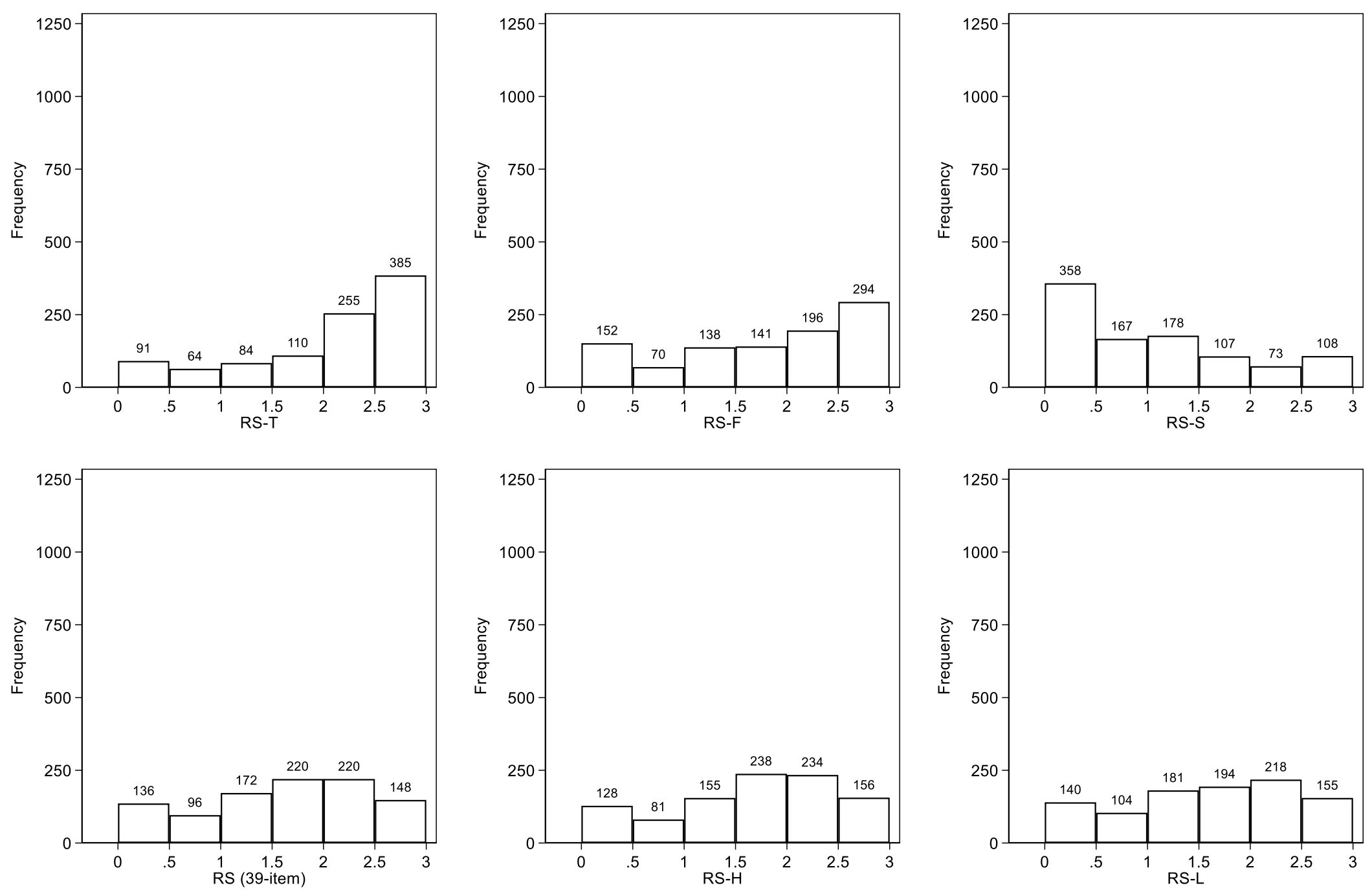

\section{Figure S16}

Histograms of repression (aggregate, typical, friends, self, high-intensity, and low-intensity) (Venezuela). 

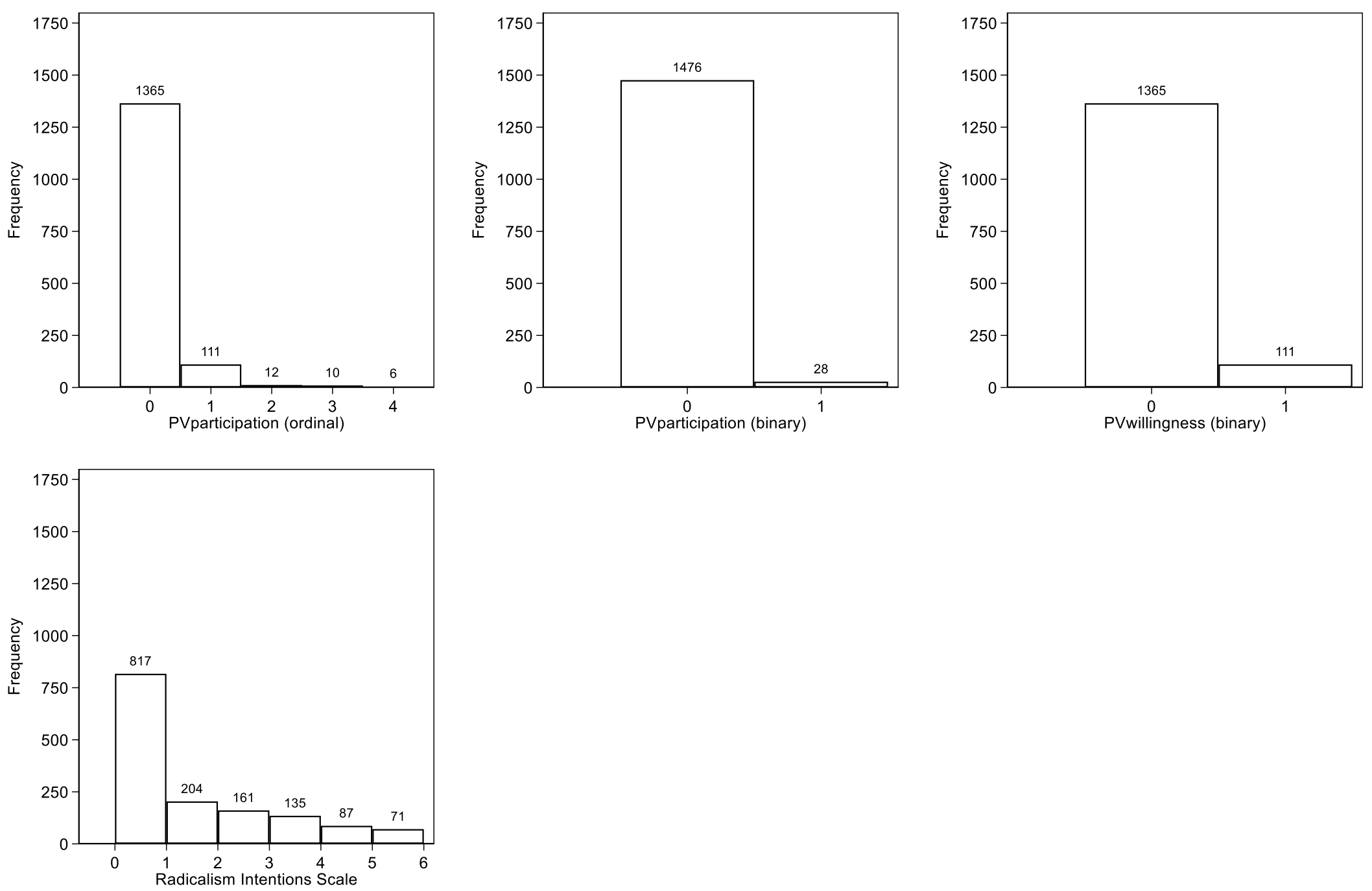

\section{Figure S17}

Histograms of outcomes (Nicaragua). 

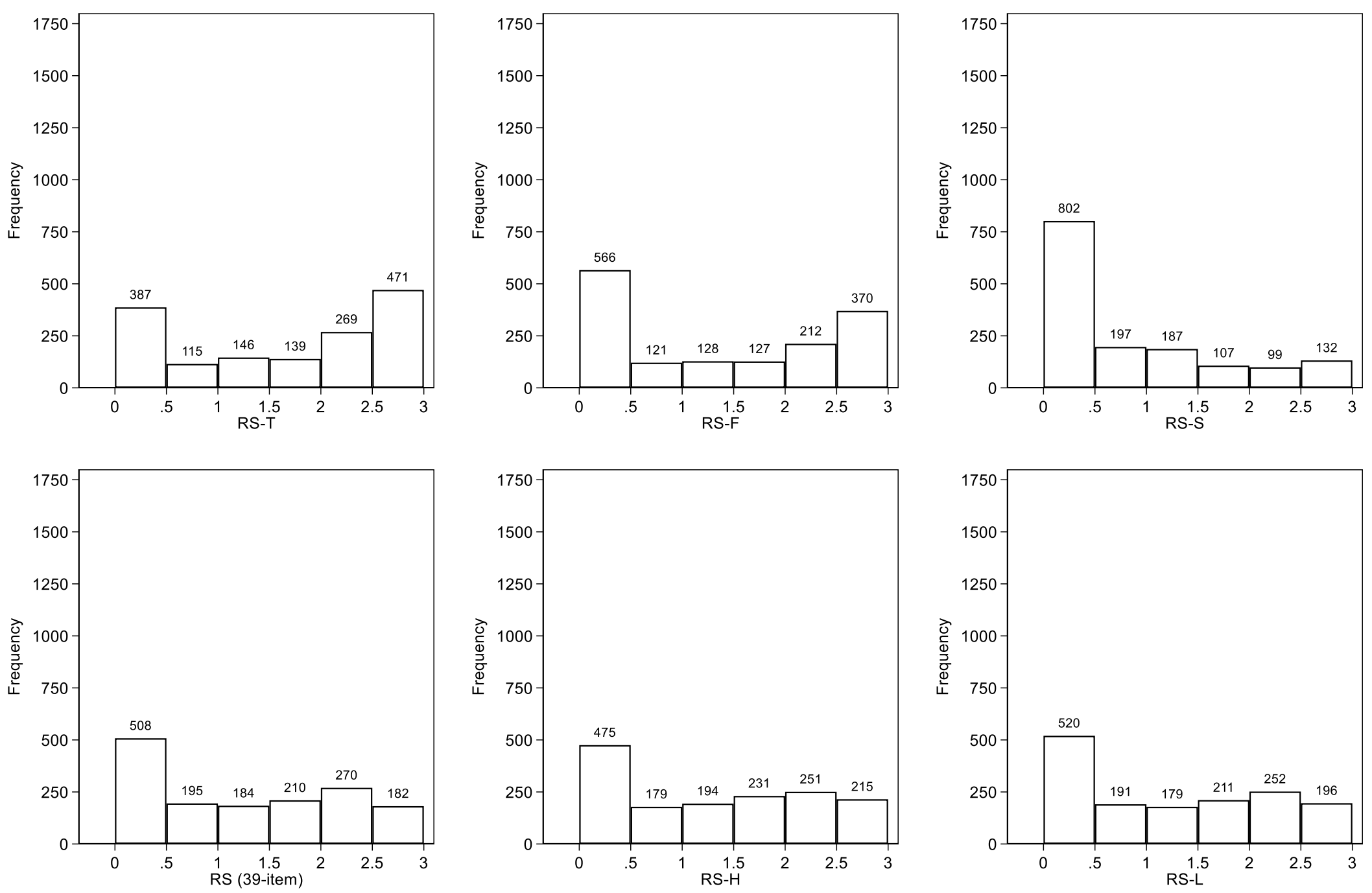

\section{Figure S18}

Histograms of repression (aggregate, typical, friends, self, high-intensity, and low-intensity) (Nicaragua). 


\begin{tabular}{|c|c|c|c|c|c|c|}
\hline & $N$ & Mean & Median & $S D$ & Min & $\operatorname{Max}$ \\
\hline PVparticipation (binary) & 50641 & .0290871 & 0 & .1680524 & 0 & 1 \\
\hline PVintentions & 49168 & .0695778 & 0 & .2544367 & 0 & 1 \\
\hline$P R S$ & 51096 & .1982021 & .1111111 & .2455211 & 0 & 1 \\
\hline Gender & 51587 & .5004555 & 1 & .5000046 & 0 & 1 \\
\hline Age & 51143 & .2206019 & .183908 & .1677482 & 0 & 1 \\
\hline Education & 51461 & .3635698 & .3333333 & .2369849 & 0 & 1 \\
\hline Economic status & 51387 & .4146574 & .5 & .2939671 & 0 & 1 \\
\hline Democratic values & 48985 & .7563336 & 1 & .4292981 & 0 & 1 \\
\hline Political Terror Scale (PTS) & 51587 & .3331976 & .3333333 & .2384279 & 0 & 1 \\
\hline Country mean PRS & 51587 & .1986419 & .1794979 & .1100916 & .0684474 & .4653794 \\
\hline Instability & 51587 & .0996875 & .0427083 & .1610027 & 0 & 1 \\
\hline Violent crime & 50388 & .2609666 & .2042733 & .2461813 & 0 & 1 \\
\hline Violent protests & 51587 & .120246 & .0458393 & .196308 & 0 & 1 \\
\hline Economic status & 51587 & .217938 & .1023108 & .2589675 & 0 & 1 \\
\hline Conflict history & 51587 & .4415957 & .4423077 & .3254404 & 0 & 1 \\
\hline Population size & 51587 & .1710034 & .1045889 & .2111677 & 0 & 1 \\
\hline
\end{tabular}

\section{Table S1}

Summary statistics for the main variables (Afrobarometer Round 5) (0-1 normalized). 


\begin{tabular}{|c|c|c|c|c|c|c|}
\hline & $N$ & Mean & Median & $S D$ & Min & $\operatorname{Max}$ \\
\hline PVparticipation (binary) & 23919 & .0426439 & 0 & .2020572 & 0 & 1 \\
\hline PVintentions & 22899 & .0921001 & 0 & .2891735 & 0 & 1 \\
\hline$P R S$ & 23973 & .2739488 & .25 & .2068992 & 0 & 1 \\
\hline Gender & 24301 & .499321 & 0 & .5000098 & 0 & 1 \\
\hline Age & 23665 & .2103446 & .1724138 & .1697962 & 0 & 1 \\
\hline Education & 24229 & .3496774 & .3333333 & .2225611 & 0 & 1 \\
\hline Economic status & 24197 & .4204034 & .5 & .2917185 & 0 & 1 \\
\hline Democratic values & 21701 & .7225473 & 1 & .4477521 & 0 & 1 \\
\hline
\end{tabular}

Table S2

Summary statistics for the main variables (Afrobarometer Round 2) (0-1 normalized). 


\begin{tabular}{|c|c|c|c|c|c|c|}
\hline & $N$ & Mean & Median & $S D$ & Min & $\operatorname{Max}$ \\
\hline PVparticipation (binary) & 19678 & .0478199 & 0 & .2133904 & 0 & 1 \\
\hline$P R S$ & 19324 & .4761178 & .3333333 & .2452673 & 0 & 1 \\
\hline Gender & 22663 & .5149362 & 1 & .4997879 & 0 & 1 \\
\hline Age & 22663 & .3023553 & .2771084 & .2022651 & 0 & 1 \\
\hline Education & 20201 & .4873934 & .5 & .2945891 & 0 & 1 \\
\hline Economic status & 20125 & .4469193 & .5 & .1915962 & 0 & 1 \\
\hline Democratic values & 20985 & .631451 & 1 & .4824228 & 0 & 1 \\
\hline
\end{tabular}

\section{Table S3}

Summary statistics for the main variables (Latinobarometero 2013) (0-1 normalized). 


\begin{tabular}{|c|c|c|c|c|c|c|}
\hline & $N$ & Mean & Median & $S D$ & Min & $\operatorname{Max}$ \\
\hline PVparticipation (binary) & 12763 & .0095589 & 0 & .0973049 & 0 & 1 \\
\hline$P R S$ & 18724 & .3740565 & .3333333 & .2323906 & 0 & 1 \\
\hline Gender & 19771 & .5035152 & 1 & .5000003 & 0 & 1 \\
\hline Age & 19722 & .347233 & .3333333 & .1992514 & 0 & 1 \\
\hline Education & 19464 & .4589156 & .4444444 & .2658829 & 0 & 1 \\
\hline Economic status & 19690 & .5310183 & .5 & .2106741 & 0 & 1 \\
\hline Democratic values & 16631 & .6692923 & 1 & .4704821 & 0 & 1 \\
\hline
\end{tabular}

\section{Table S4}

Summary statistics for the main variables (Asianbarometer Round 2) (0-1 normalized). 


\begin{tabular}{|c|c|c|c|c|c|c|}
\hline & $N$ & Mean & Median & $S D$ & Min & $\operatorname{Max}$ \\
\hline PVparticipation (binary) & 15842 & .015844 & 0 & .1248756 & 0 & 1 \\
\hline$P R S$ & 18721 & .370769 & .3333333 & .2389426 & 0 & 1 \\
\hline Gender & 19419 & .5006952 & 1 & .5000124 & 0 & 1 \\
\hline Age & 19390 & .3556499 & .3417721 & .2040335 & 0 & 1 \\
\hline Education & 19352 & .506465 & .5555556 & .273555 & 0 & 1 \\
\hline Economic status & 19362 & .4836406 & .5 & .1991512 & 0 & 1 \\
\hline Democratic values & 17409 & 6417945 & 1 & .4794867 & 0 & 1 \\
\hline
\end{tabular}

\section{Table S5}

Summary statistics for the main variables (Asianbarometer Round 3) (0-1 normalized). 


\begin{tabular}{|c|c|c|c|c|c|c|}
\hline & $N$ & Mean & Median & $S D$ & Min & $\operatorname{Max}$ \\
\hline PVparticipation (binary) & 13955 & .0140451 & 0 & .1176812 & 0 & 1 \\
\hline PVintentions & 13759 & .2166582 & 0 & .4119827 & 0 & 1 \\
\hline$P R S$ & 19602 & .3883447 & .3333333 & .2441559 & 0 & 1 \\
\hline Gender & 20663 & .5121231 & 1 & .4998651 & 0 & 1 \\
\hline Age & 20625 & .3087973 & .3076923 & .1721933 & 0 & 1 \\
\hline Education & 20604 & .4983498 & .5555556 & .2878792 & 0 & 1 \\
\hline Economic status & 20534 & .4763319 & .5 & .1924521 & 0 & 1 \\
\hline Democratic values & 18107 & .6109792 & 1 & .4875415 & 0 & 1 \\
\hline
\end{tabular}

Table S6

Summary statistics for the main variables (Asianbarometer Round 4) (0-1 normalized). 


\begin{tabular}{|c|c|c|c|c|c|c|}
\hline & $N$ & Mean & Median & $S D$ & Min & $\operatorname{Max}$ \\
\hline PVintentions & 370 & .1734234 & .0833333 & .213302 & 0 & 1 \\
\hline Repression Scale & 381 & .4564262 & .444079 & .2002723 & 0 & 1 \\
\hline Repression (typical) & 376 & .6856702 & .7435897 & .2101783 & 0 & 1 \\
\hline Repression (friends) & 376 & .3571083 & .3333333 & .2421259 & 0 & 1 \\
\hline Repression (self) & 378 & .2135117 & .1515152 & .2127112 & 0 & 1 \\
\hline High Intensity Repression Scale & 381 & .3890632 & .3844086 & .1908979 & 0 & 1 \\
\hline Low Intensity Repression Scale & 381 & .463781 & .4594595 & .2082528 & 0 & 1 \\
\hline Gender & 379 & .8153034 & 1 & .3885642 & 0 & 1 \\
\hline Age & 372 & .2245331 & .1578947 & .1774367 & 0 & 1 \\
\hline Economic status & 364 & .5100733 & .5555556 & .1868012 & 0 & 1 \\
\hline Democratic values & 367 & .6520692 & .6666667 & .2055806 & 0 & 1 \\
\hline
\end{tabular}

\section{Table S7}

Summary statistics for the main variables (EHU) (0-1 normalized). 


\begin{tabular}{|c|c|c|c|c|c|c|}
\hline & $N$ & Mean & Median & $S D$ & Min & $\operatorname{Max}$ \\
\hline PVparticipation (binary) & 980 & .0459184 & 0 & .2094149 & 0 & 1 \\
\hline PVintentions (binary) & 935 & .1860963 & 0 & .3893926 & 0 & 1 \\
\hline Radicalism Intention Scale & 984 & .3181035 & .25 & .2864408 & 0 & 1 \\
\hline Repression Scale & 992 & .5375772 & .5726495 & .2724052 & 0 & 1 \\
\hline Repression (typical) & 989 & .677451 & .7692308 & .2866876 & 0 & 1 \\
\hline Repression (friends) & 991 & .5899178 & .6410256 & .3170614 & 0 & 1 \\
\hline Repression (self) & 991 & .3486033 & .2820513 & .3033492 & 0 & 1 \\
\hline High Intensity Repression Scale & 992 & .5486323 & .5833333 & .2784689 & 0 & 1 \\
\hline Low Intensity Repression Scale & 992 & .5326216 & .5639506 & .2812879 & 0 & 1 \\
\hline Gender & 1000 & .484 & 0 & .499994 & 0 & 1 \\
\hline Age & 965 & .3066831 & .2711864 & .2113528 & 0 & 1 \\
\hline Economic status & 983 & .5721714 & .5555556 & 1955933 & 0 & 1 \\
\hline Democratic values & 989 & .8181777 & .833333 & 1921033 & 0 & 1 \\
\hline
\end{tabular}

\section{Table S8}

Summary statistics for the main variables (Venezuela) (0-1 normalized). 


\begin{tabular}{|c|c|c|c|c|c|c|}
\hline & $N$ & Mean & Median & $S D$ & Min & $\operatorname{Max}$ \\
\hline PVparticipation (binary) & 1504 & .018617 & 0 & .1352131 & 0 & 1 \\
\hline PVintentions (binary) & 1476 & .0752033 & 0 & .2638084 & 0 & 1 \\
\hline Radicalism Intention Scale & 1475 & .2209981 & .0833333 & .2767504 & 0 & 1 \\
\hline Repression Scale & 1549 & .413003 & .4017094 & .3214704 & 0 & 1 \\
\hline Repression (typical) & 1527 & .5371653 & .6410256 & .3609881 & 0 & 1 \\
\hline Repression (friends) & 1524 & .4438243 & .4102564 & .3811494 & 0 & 1 \\
\hline Repression (self) & 1524 & .2645871 & .1282051 & .3077981 & 0 & 1 \\
\hline High Intensity Repression Scale & 1545 & .4204404 & .4166667 & .329072 & 0 & 1 \\
\hline Low Intensity Repression Scale & 1549 & .4094684 & .3950617 & .3251174 & 0 & 1 \\
\hline Gender & 1550 & 6277419 & 1 & .4835627 & 0 & 1 \\
\hline Age & 1445 & 1537582 & .125 & .1180724 & 0 & 1 \\
\hline Economic status & 1467 & .4036204 & .4444444 & .2101256 & 0 & 1 \\
\hline Democratic values & 1480 & .7636833 & 0.8 & .2489852 & 0 & 1 \\
\hline
\end{tabular}

\section{Table S9}

Summary statistics for the main variables (Nicaragua) (0-1 normalized). 
(1)

PVPARTICIPATION

\begin{tabular}{|c|c|c|c|c|}
\hline & $\mathrm{b}$ & ci95 & $\mathrm{b}$ & ci95 \\
\hline PRS3 & $1.18^{* * * *}$ & $0.96,1.40$ & $0.64^{* * * *}$ & $0.48,0.79$ \\
\hline Gender & $-0.33^{* * * *}$ & $-0.44,-0.21$ & $-0.29^{* * * *}$ & $-0.37,-0.22$ \\
\hline Age & -0.11 & $-0.46,0.24$ & $-1.04^{* * * * *}$ & $-1.29,-0.80$ \\
\hline Education & -0.23 & $-0.49,0.04$ & -0.13 & $-0.31,0.05$ \\
\hline Economic status & 0.14 & $-0.05,0.33$ & -0.03 & $-0.16,0.10$ \\
\hline Democratic values & $-0.81^{* * * *}$ & $-0.92,-0.69$ & $-0.26^{* * * *}$ & $-0.35,-0.18$ \\
\hline Constant & -6.41 & $-69.48,56.66$ & -13.72 & $-58.00,30.55$ \\
\hline $\operatorname{var}\left(\_c o n s\right)$ & \multicolumn{2}{|c|}{0.38} & \multicolumn{2}{|r|}{0.19} \\
\hline Observations & 47399 & & 45989 & \\
\hline$A I C$ & 11814.3 & & 22289.8 & \\
\hline$B I C$ & 11937.1 & & 22412.1 & \\
\hline chi2 & 363.5 & & 253.9 & \\
\hline
\end{tabular}

\section{Table S10}

Repression and political violence: A multilevel analysis (Afrobarometer Round 5). Cluster means not reported. The table reports regression coefficients (logits) and the corresponding 95\% CIs. ${ }^{*} p<0.05, * * p<0.01, * * * p<0.001, * * * * p<0.0001$. 
(1)

PVPARTICIPATION

\begin{tabular}{|c|c|c|c|c|}
\hline & $\mathrm{b}$ & ci95 & $\mathrm{b}$ & ci95 \\
\hline PRS3 & $0.99^{* * * *}$ & $0.66,1.32$ & $0.69^{* * * *}$ & $0.45,0.94$ \\
\hline Gender & $-0.51^{* * * *}$ & $-0.65,-0.37$ & $-0.19^{* * *}$ & $-0.29,-0.09$ \\
\hline Age & $-0.83^{* * *}$ & $-1.28,-0.37$ & $-0.89^{* * * *}$ & $-1.22,-0.56$ \\
\hline Education & 0.14 & $-0.20,0.49$ & $0.44^{* * *}$ & $0.19,0.69$ \\
\hline Economic status & 0.18 & $-0.06,0.42$ & $-0.20^{*}$ & $-0.37,-0.03$ \\
\hline Democratic values & $-0.29^{* * * *}$ & $-0.44,-0.15$ & $-0.32^{* * * *}$ & $-0.43,-0.22$ \\
\hline Constant & $-18.33^{*}$ & $-35.87,-0.79$ & 14.36 & $-0.72,29.43$ \\
\hline $\operatorname{var}($ cons $)$ & \multicolumn{2}{|c|}{0.10} & \multicolumn{2}{|r|}{0.08} \\
\hline Observations & 20718 & & 19796 & \\
\hline$A I C$ & 7318.9 & & 12298.7 & \\
\hline$B I C$ & 7430.1 & & 12409.2 & \\
\hline chi2 & 135.1 & & 168.5 & \\
\hline
\end{tabular}

\section{Table S11}

Repression and political violence: A multilevel analysis (Afrobarometer Round 2). Cluster means not reported. The table reports regression coefficients (logits) and the corresponding 95\% CIs. ${ }^{*} p<0.05, * * p<0.01, * * * p<0.001, * * * * p<0.0001$. 
(1)

PVPARTICIPATION

\begin{tabular}{lcc} 
& b & ci95 \\
\hline PRS2 & $0.34^{*}$ & $0.04,0.63$ \\
Gender & $-0.34^{* * * *}$ & $-0.48,-0.20$ \\
Age & -0.28 & $-0.67,0.10$ \\
Education & 0.15 & $-0.12,0.42$ \\
Economic status & $-0.60^{* *}$ & $-1.00,-0.21$ \\
Democratic values & $-0.24^{* *}$ & $-0.38,-0.09$ \\
Constant & -0.77 & $-13.11,11.57$ \\
var(_cons) & & 0.21 \\
\hline Observations & 17583 & 6687.2 \\
AIC & 6796.0 & \\
BIC & 63.60 & \\
chi2 & & \\
\hline
\end{tabular}

\section{Table S12}

Repression and political violence: A multilevel analysis (Latinobarómetro 2013). Cluster means not reported. The table reports regression coefficients (logits) and the corresponding 95\% CIs. * $p<0.05, * * p<0.01$, *** $p<0.001$, **** $p<0.0001$. 
(1)

PVPARTICIPATION

(Rounds 2-4 combined)

\begin{tabular}{lcccc} 
& $\mathrm{b}$ & $\mathrm{ci95}$ & $\mathrm{b}$ & $\mathrm{ci95}$ \\
\hline PRS2 & $0.52^{* *}$ & $0.17,0.88$ & $0.34^{* *}$ & $0.12,0.57$ \\
Gender & $-0.28^{* *}$ & $-0.47,-0.10$ & $-0.23^{* * * *}$ & $-0.34,-0.12$ \\
Age & -0.34 & $-0.88,0.19$ & $-1.46^{* * * *}$ & $-1.83,-1.08$ \\
Education & -0.11 & $-0.49,0.27$ & $-0.24^{*}$ & $-0.48,-0.00$ \\
Economic status & $-0.86^{* * *}$ & $-1.32,-0.39$ & 0.12 & $-0.19,0.43$ \\
Democratic values & $-0.62^{* * * *}$ & $-0.81,-0.44$ & 0.01 & $-0.11,0.12$ \\
Constant & -2.25 & $-14.39,9.89$ & -16.24 & $-43.47,10.99$ \\
var(_cons) & & & & 2.12 \\
\hline Observations & 38195 & & & \\
AIC & 4988.0 & & & 8788.3 \\
BIC & 5176.1 & & 8892.3 & 103.3 \\
chi2 & 147.2 & & & \\
\hline
\end{tabular}

\section{Table S13}

Repression and political violence: A multilevel analysis (Asianbarometer Rounds 2-4). Cluster means and year dummies not reported. The table reports regression coefficients (logits) and the corresponding 95\% CIs. ${ }^{*} p<0.05, * * p<0.01, * * * p<0.001, * * * * p<$ 0.0001 .

\section{(2)}

PVINTENTIONS

(Round 4)

$0.17,0.88$

$0.81,-0.44$ 
(1)

PDPARTICIPATION

\begin{tabular}{|c|c|c|c|c|}
\hline & $\mathrm{b}$ & ci95 & b & ci95 \\
\hline PRS3 & $0.49^{* * * *}$ & $0.35,0.63$ & $0.21^{* * *}$ & $0.10,0.32$ \\
\hline Gender & $-0.39^{* * * *}$ & $-0.46,-0.33$ & $-0.30^{* * * *}$ & $-0.35,-0.25$ \\
\hline Age & $-0.58^{* * * *}$ & $-0.80,-0.37$ & $-1.37^{* * * * *}$ & $-1.53,-1.21$ \\
\hline Education & $1.36^{* * * *}$ & $1.21,1.51$ & $0.55^{* * * *}$ & $0.43,0.66$ \\
\hline Economic status & -0.01 & $-0.12,0.11$ & $-0.09^{*}$ & $-0.18,-0.01$ \\
\hline Democratic values & $-0.25^{* * * *}$ & $-0.33,-0.18$ & -0.04 & $-0.10,0.02$ \\
\hline Constant & -12.36 & $-56.78,32.06$ & -41.12 & $-105.87,23.62$ \\
\hline $\operatorname{var}\left(\_\right.$cons $)$ & \multicolumn{2}{|c|}{$0.20^{* * * *}$} & \multicolumn{2}{|r|}{$0.44^{* * * * *}$} \\
\hline Observations & 47364 & & 42999 & \\
\hline$A I C$ & 27731.8 & & 42493.9 & \\
\hline$B I C$ & 27854.5 & & 42615.3 & \\
\hline chi2 & 684.8 & & 638.3 & \\
\hline
\end{tabular}

\section{Table S14}

Repression and protests/demonstration: A multilevel analysis (Afrobarometer Round 5). Cluster means not reported. The table reports regression coefficients (logits) and the corresponding 95\% CIs. $* p<0.05, * * p<0.01, * * * p<0.001, * * * * p<0.0001$. 
(1)

PDPARTICIPATION

\begin{tabular}{lcccc} 
& $\mathrm{b}$ & $\mathrm{ci} 95$ & $\mathrm{~b}$ & ci95 \\
\hline PRS3 & 0.08 & $-0.13,0.28$ & 0.06 & $-0.12,0.25$ \\
Gender & $-0.41^{* * * * *}$ & $-0.48,-0.33$ & $-0.22^{* * * * *}$ & $-0.28,-0.15$ \\
Age & $-0.97^{* * * * *}$ & $-1.24,-0.70$ & $-1.41^{* * * * *}$ & $-1.64,-1.19$ \\
Education & $1.32^{* * * * *}$ & $1.12,1.52$ & $0.67^{* * * * *}$ & $0.49,0.85$ \\
Economic status & -0.11 & $-0.25,0.03$ & $-0.31^{* * * *}$ & $-0.43,-0.19$ \\
Democratic values & 0.00 & $-0.09,0.09$ & $0.11^{* *}$ & $0.03,0.18$ \\
Constant & -9.21 & $-24.75,6.33$ & -7.65 & $0.18^{* * *}$ \\
var(cons) & \multicolumn{3}{c}{$-28.75,13.45$} \\
\hline Observations & 20732 & & 17508 & \\
AIC & 17099.4 & & 20502.1 & \\
BIC & 17210.5 & & 20610.9 & \\
chi2 & 396.8 & & & \\
\hline
\end{tabular}

\section{Table S15}

Repression and protests/demonstrations: A multilevel analysis (Afrobarometer Round 2). Cluster means not reported. The table reports regression coefficients (logits) and the corresponding 95\% CIs. $* p<0.05, * * p<0.01$, *** $p<0.001, * * * *<<0.0001$. 
(1)

PDPARTICIPATION

\begin{tabular}{lcc} 
& $\mathrm{b}$ & $\mathrm{ci95}$ \\
\hline PRS2 & -0.13 & $-0.27,0.02$ \\
Gender & $-0.21^{* * * *}$ & $-0.28,-0.14$ \\
Age & $-0.31^{* *}$ & $-0.50,-0.12$ \\
Education & $1.17^{* * * *}$ & $1.04,1.31$ \\
Economic status & -0.17 & $-0.36,0.03$ \\
Democratic values & $0.12^{* *}$ & $0.05,0.19$ \\
Constant & -0.68 & $-8.84,7.48$ \\
var(_cons) & & $0.09^{* *}$ \\
\hline Observations & 17711 & \\
AIC & 19506.7 & 19615.6 \\
BIC & 428.1 & \\
chi2 & & \\
\hline
\end{tabular}

\section{Table S16}

Repression and protests/demonstrations: A multilevel analysis (Latinobarómetro 2013). Cluster means not reported. The table reports regression coefficients (logits) and the corresponding 95\% CIs. $* p<0.05$, ** $p<0.01$, *** $p<0.001$, **** $p<0.0001$. 
(1)

PDPARTICIPATION

(Rounds 2-4 combined)

\begin{tabular}{|c|c|c|c|c|}
\hline & $\mathrm{b}$ & ci95 & $\mathrm{b}$ & ci95 \\
\hline PRS2 & $0.20^{*}$ & $0.01,0.39$ & $0.34^{* * *}$ & $0.16,0.52$ \\
\hline Gender & $-0.33^{* * * *}$ & $-0.42,-0.24$ & $-0.26^{* * * * *}$ & $-0.35,-0.17$ \\
\hline Age & $-0.44^{* *}$ & $-0.72,-0.17$ & $-1.09^{* * * * *}$ & $-1.39,-0.80$ \\
\hline Education & $0.95^{* * * *}$ & $0.75,1.15$ & 0.10 & $-0.08,0.29$ \\
\hline Economic status & -0.11 & $-0.34,0.13$ & -0.15 & $-0.40,0.09$ \\
\hline Democratic values & -0.05 & $-0.15,0.04$ & $0.20^{* * * *}$ & $0.11,0.29$ \\
\hline Constant & -0.52 & $-4.23,3.20$ & -14.30 & $-38.42,9.81$ \\
\hline var(_cons) & \multicolumn{2}{|c|}{0.03} & \multicolumn{2}{|r|}{1.67} \\
\hline Observations & 38215 & & 11824 & \\
\hline$A I C$ & 15266.5 & & 12557.5 & \\
\hline$B I C$ & 15454.7 & & 12660.7 & \\
\hline chi2 & 376.2 & & 156.9 & \\
\hline
\end{tabular}

\section{Table S17}

Repression and protests/demonstrations: A multilevel analysis (Asianbarometer Rounds 2-4). Cluster means and year dummies not reported. The table reports regression coefficients (logits) and the corresponding 95\% CIs. ${ }^{*} p<0.05, * * p<0.01, * * * p<0.001$, $* * * * p<0.0001$.
(2)

PDINTENTIONS

(Round 4)

$0.01,0.39$

$0.75,1.15$

$0.15,0.04$ 
PVPARTICIPATION

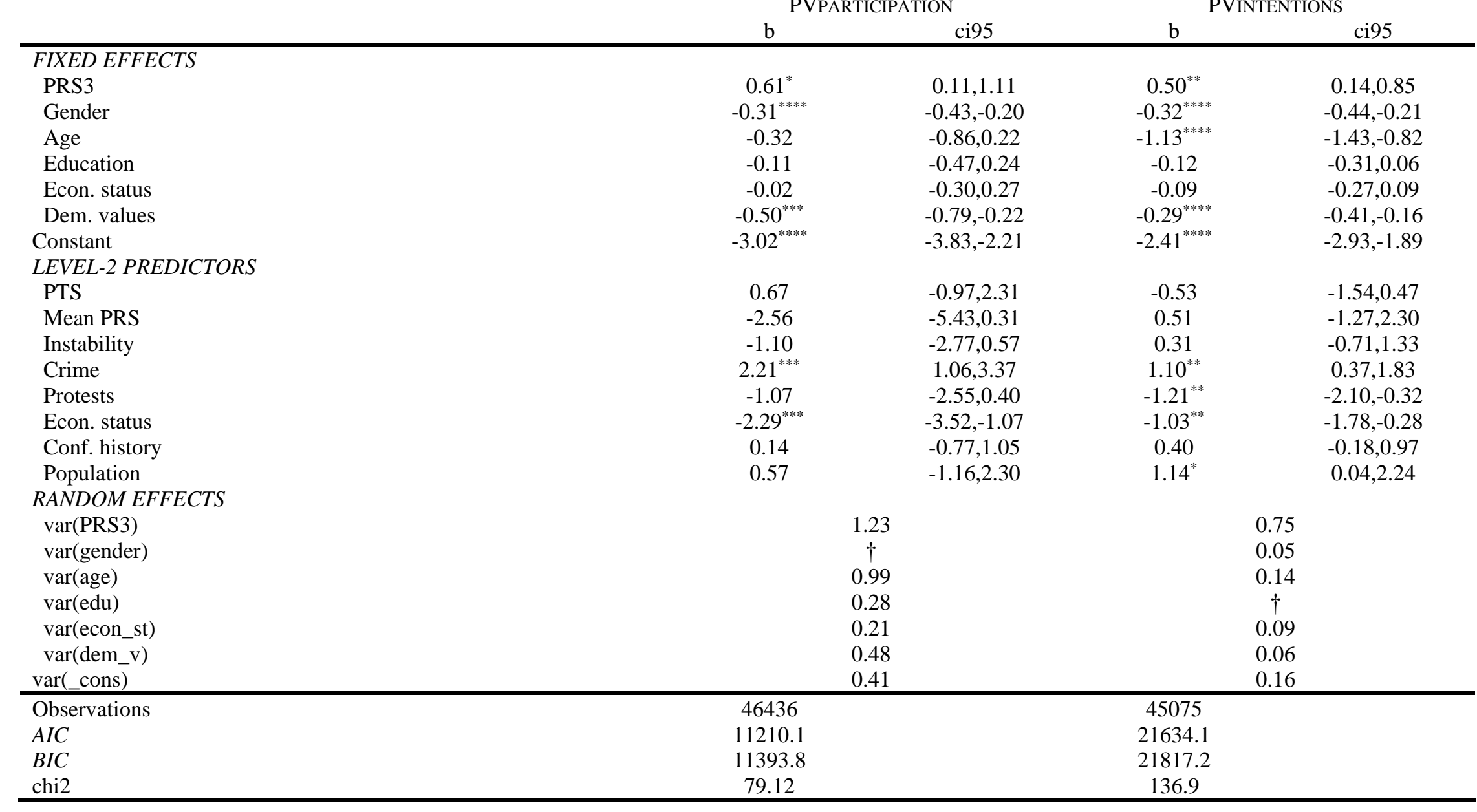

\section{Table S18}

Repression and political violence: An extended multilevel analysis (Afrobarometer Round 5). Analogous to Table S10 but with level-2 predictors and randomly varying slopes for all level-1 predictors. The table reports regression coefficients (logits) and the corresponding $95 \%$ CIs. $* p<0.05, * * p<0.01, * * * p<0.001, * * * * p<0.0001$. $\dagger$ excluded randomly varying slopes due to no significant improvement in the model fit. 


\begin{tabular}{|c|c|c|c|c|c|c|c|c|c|c|c|c|}
\hline & \multicolumn{2}{|c|}{$\begin{array}{c}(1) \\
\text { HLM } \\
\text { PVPARTICIPATION04 }\end{array}$} & \multicolumn{2}{|c|}{$\begin{array}{c}(2) \\
\text { Ologit HGLM } \\
\text { PVPARTICIPATION04 }\end{array}$} & \multicolumn{2}{|c|}{$\begin{array}{c}\text { (3) } \\
\text { FE } \\
\text { PVPARTICIPATION04 }\end{array}$} & \multicolumn{2}{|c|}{$\begin{array}{c}(4) \\
\text { HLM } \\
\text { PVPARTICIPATION03 }\end{array}$} & \multicolumn{2}{|c|}{$\begin{array}{c}(5) \\
\text { Ologit HGLM } \\
\text { PVPARTICIPATION03 }\end{array}$} & \multicolumn{2}{|c|}{$\begin{array}{c}(6) \\
\text { FE } \\
\text { PVPARTICIPATION03 }\end{array}$} \\
\hline & $\mathrm{b}$ & ci95 & $\mathrm{b}$ & ci95 & $\mathrm{b}$ & ci95 & $\mathrm{b}$ & ci95 & $\mathrm{b}$ & ci95 & $\mathrm{b}$ & ci95 \\
\hline \multicolumn{13}{|c|}{ FIXED EFFECTS } \\
\hline PRS3 & $0.10^{* *}$ & $0.04,0.17$ & $0.58^{* *}$ & $0.22,0.94$ & $0.15^{* * * * *}$ & $0.12,0.17$ & $0.04^{*}$ & $0.00,0.08$ & $0.60^{*}$ & $0.11,1.09$ & $0.07^{* * * *}$ & $0.05,0.08$ \\
\hline Gender & $-0.04^{* * * *}$ & $-0.05,-0.03$ & $-0.32^{* * * * *}$ & $-0.38,-0.25$ & $-0.04^{* * * *}$ & $-0.05,-0.03$ & $-0.01^{* * * *}$ & $-0.02,-0.01$ & $-0.31^{* * * * *}$ & $-0.42,-0.20$ & $-0.02^{* * * *}$ & $-0.02,-0.01$ \\
\hline Age & $-0.06^{* *}$ & $-0.11,-0.02$ & $-0.85^{* * * *}$ & $-1.13,-0.57$ & $-0.07^{* * * *}$ & $-0.10,-0.04$ & 0.01 & $-0.03,0.04$ & -0.32 & $-0.86,0.23$ & -0.00 & $-0.02,0.02$ \\
\hline Education & -0.02 & $-0.05,0.01$ & -0.12 & $-0.36,0.12$ & $-0.03^{*}$ & $-0.05,-0.00$ & -0.01 & $-0.03,0.01$ & -0.11 & $-0.46,0.24$ & -0.01 & $-0.03,0.00$ \\
\hline Econ. status & 0.00 & $-0.03,0.03$ & -0.05 & $-0.22,0.11$ & 0.01 & $-0.01,0.03$ & 0.00 & $-0.01,0.02$ & -0.02 & $-0.31,0.27$ & 0.01 & $-0.00,0.02$ \\
\hline Dem. values & $-0.08^{* * *}$ & $-0.13,-0.03$ & $-0.38^{* * * *}$ & $-0.56,-0.19$ & $-0.09^{* * * * *}$ & $-0.10,-0.08$ & $-0.04^{*}$ & $-0.07,-0.01$ & $-0.50^{* * *}$ & $-0.78,-0.21$ & $-0.04^{* * * *}$ & $-0.05,-0.04$ \\
\hline Constant & $0.26^{* * * * *}$ & $0.14,0.39$ & & & $0.23^{* * * * *}$ & $0.21,0.25$ & $0.11^{* *}$ & $0.04,0.19$ & & & $0.08^{* * * * *}$ & $0.07,0.09$ \\
\hline \multicolumn{13}{|c|}{ LEVEL-2 PREDICTORS } \\
\hline PTS & 0.03 & $-0.23,0.29$ & -0.25 & $-1.41,0.91$ & & & 0.03 & $-0.12,0.18$ & 0.67 & $-0.97,2.30$ & & \\
\hline Mean PRS3 & $-0.44^{*}$ & $-0.89,-0.00$ & -0.90 & $-2.93,1.13$ & & & $-0.29^{*}$ & $-0.55,-0.03$ & -2.59 & $-5.45,0.27$ & & \\
\hline Instability & -0.10 & $-0.36,0.16$ & -0.16 & $-1.32,0.99$ & & & -0.07 & $-0.22,0.09$ & -1.08 & $-2.74,0.58$ & & \\
\hline Crime & $0.28^{* *}$ & $0.10,0.47$ & $1.65^{* * * *}$ & $0.81,2.48$ & & & $0.15^{* *}$ & $0.04,0.25$ & $2.23^{* * * *}$ & $1.08,3.37$ & & \\
\hline Protests & -0.15 & $-0.36,0.06$ & $-1.45^{* *}$ & $-2.48,-0.43$ & & & -0.05 & $-0.17,0.07$ & -1.08 & $-2.55,0.39$ & & \\
\hline Econ. status & $-0.28^{* *}$ & $-0.46,-0.10$ & $-1.68^{* * * *}$ & $-2.55,-0.81$ & & & $-0.15^{* *}$ & $-0.26,-0.04$ & $-2.29^{* * *}$ & $-3.51,-1.07$ & & \\
\hline Con. history & 0.09 & $-0.06,0.24$ & 0.38 & $-0.27,1.03$ & & & 0.04 & $-0.05,0.13$ & 0.16 & $-0.74,1.06$ & & \\
\hline Population & 0.16 & $-0.12,0.45$ & 1.08 & $-0.17,2.34$ & & & 0.07 & $-0.10,0.24$ & 0.58 & $-1.14,2.30$ & & \\
\hline \multicolumn{13}{|c|}{ RANDOM EFFECTS } \\
\hline $\operatorname{var}(\mathrm{PRS} 3)$ & & 032 & & .85 & & & & 010 & & .18 & & \\
\hline $\operatorname{var}($ age $)$ & & 009 & & .21 & & & & 006 & & .02 & & \\
\hline $\operatorname{var}(\mathrm{edu})$ & & 005 & & .24 & & & & 002 & & .29 & & \\
\hline $\operatorname{var}($ econ_st) & & 004 & & 10 & & & & 001 & & .22 & & \\
\hline $\operatorname{var}\left(d e m \_v\right)$ & & 021 & & 24 & & & & 007 & & .48 & & \\
\hline $\operatorname{var}($ _cons $)$ & & 013 & & .23 & & & & 004 & & .40 & & \\
\hline Observations & 46436 & & 46436 & & 47399 & & 46436 & & 46436 & & 47399 & \\
\hline$A I C$ & 69353.4 & & 35916.6 & & 72662.3 & & 21982.9 & & 13995.9 & & 24831.0 & \\
\hline$B I C$ & 69545.8 & & 36126.5 & & 72723.7 & & 22175.3 & & 14197.1 & & 24892.3 & \\
\hline chi2 & 115.1 & & 181.3 & & & & 55.55 & & 79.36 & & & \\
\hline
\end{tabular}

\section{Table S19}

Analogous to Table S18 but using alternative outcomes and estimators. The table reports regression coefficients and the corresponding 95\% CIs. HLM = hierarchical linear model; Ologit HGLM = hierarchical generalized linear model with the cumulative logic link (ordered logit); FE $=$ fixed effects. $* p<0.05, * * p<0.01, * * * p<0.001, * * * * p<0.0001$ 
(1)

PVPARTICIPATION

Demeaned
(2)

PVINTENTIONS

Demeaned
(3)

PVPARTICIPATION

$\mathrm{FE}$
(4)

PVINTENTIONS

FE

\begin{tabular}{|c|c|c|c|c|c|c|c|c|}
\hline & $\mathrm{b}$ & ci95 & $\mathrm{b}$ & ci95 & $\mathrm{b}$ & ci95 & $\mathrm{b}$ & ci95 \\
\hline PRS3 & $1.18^{* * * *}$ & $0.96,1.40$ & $0.64^{* * * *}$ & $0.48,0.79$ & $1.18^{* * * *}$ & $0.96,1.40$ & $0.64^{* * * *}$ & $0.48,0.79$ \\
\hline Gender & $-0.33^{* * * *}$ & $-0.44,-0.21$ & $-0.29^{* * * *}$ & $-0.37,-0.22$ & $-0.32^{* * * *}$ & $-0.44,-0.21$ & $-0.29^{* * * *}$ & $-0.37,-0.22$ \\
\hline Age & -0.11 & $-0.46,0.24$ & $-1.04^{* * * *}$ & $-1.29,-0.79$ & -0.12 & $-0.46,0.23$ & $-1.04^{* * * *}$ & $-1.29,-0.79$ \\
\hline Education & -0.22 & $-0.49,0.04$ & -0.13 & $-0.30,0.05$ & -0.22 & $-0.49,0.04$ & -0.13 & $-0.31,0.05$ \\
\hline Economic status & 0.14 & $-0.05,0.33$ & -0.03 & $-0.16,0.10$ & 0.14 & $-0.05,0.33$ & -0.03 & $-0.16,0.10$ \\
\hline Democratic values & $-0.81^{* * * * *}$ & $-0.92,-0.69$ & $-0.26^{* * * *}$ & $-0.35,-0.18$ & $-0.80^{* * * *}$ & $-0.92,-0.69$ & $-0.26^{* * * *}$ & $-0.35,-0.18$ \\
\hline Constant & $-3.89^{* * * *}$ & $-4.15,-3.63$ & $-2.78^{* * * *}$ & $-2.99,-2.57$ & & & & \\
\hline $\operatorname{var}($ cons $)$ & \multicolumn{2}{|c|}{0.53} & \multicolumn{2}{|c|}{0.37} & & & & \\
\hline Observations & 47399 & & 45989 & & 47399 & & 45989 & \\
\hline$A I C$ & 11813.0 & & 22301.0 & & 11504.3 & & 21940.6 & \\
\hline$B I C$ & 11883.2 & & 22370.9 & & 11556.9 & & 21993.1 & \\
\hline chi2 & 351.4 & & 225.3 & & 332.4 & & 225.7 & \\
\hline
\end{tabular}

\section{Table S20}

Analogous to Table S10 but using alternative models to control for level-2 confounders: group demeaning and fixed effects (FE) (conditional maximum likelihood). The table reports regression coefficients (logits) and the corresponding $95 \%$ CIs. ${ }^{*} p<0.05, * * p<$ $0.01, * * * p<0.001, * * * * p<0.0001$. 


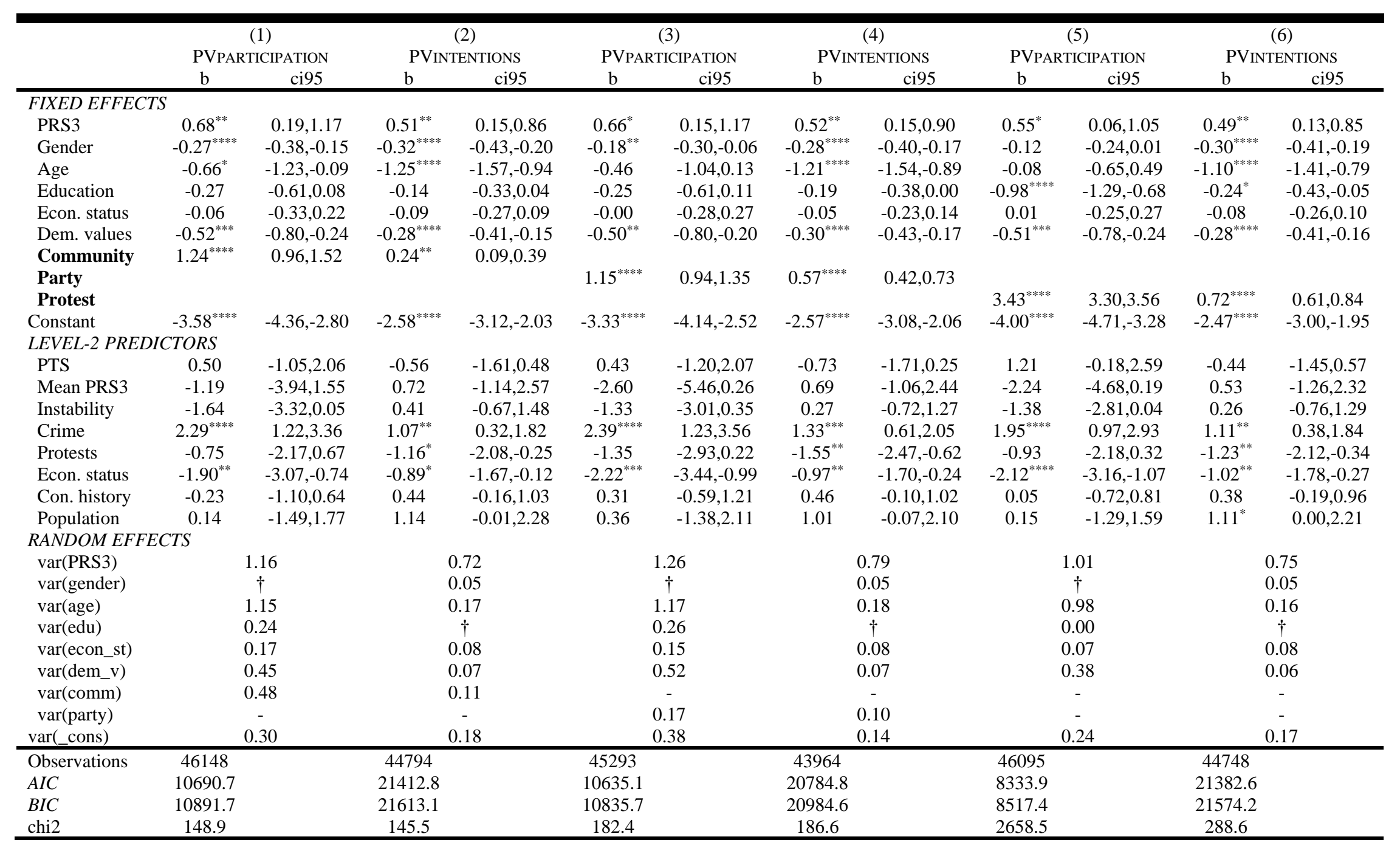

\section{Table S21}

Analogous to Table S18 but controlling for political activism/mobilization. The table reports regression coefficients (logits) and the corresponding 95\% CIs.* $p<0.05$, $* * p<0.01, * * * p<0.001$, **** $p<0.0001$. $\dagger$ excluded randomly varying slopes due to no significant improvement in the model fit. 


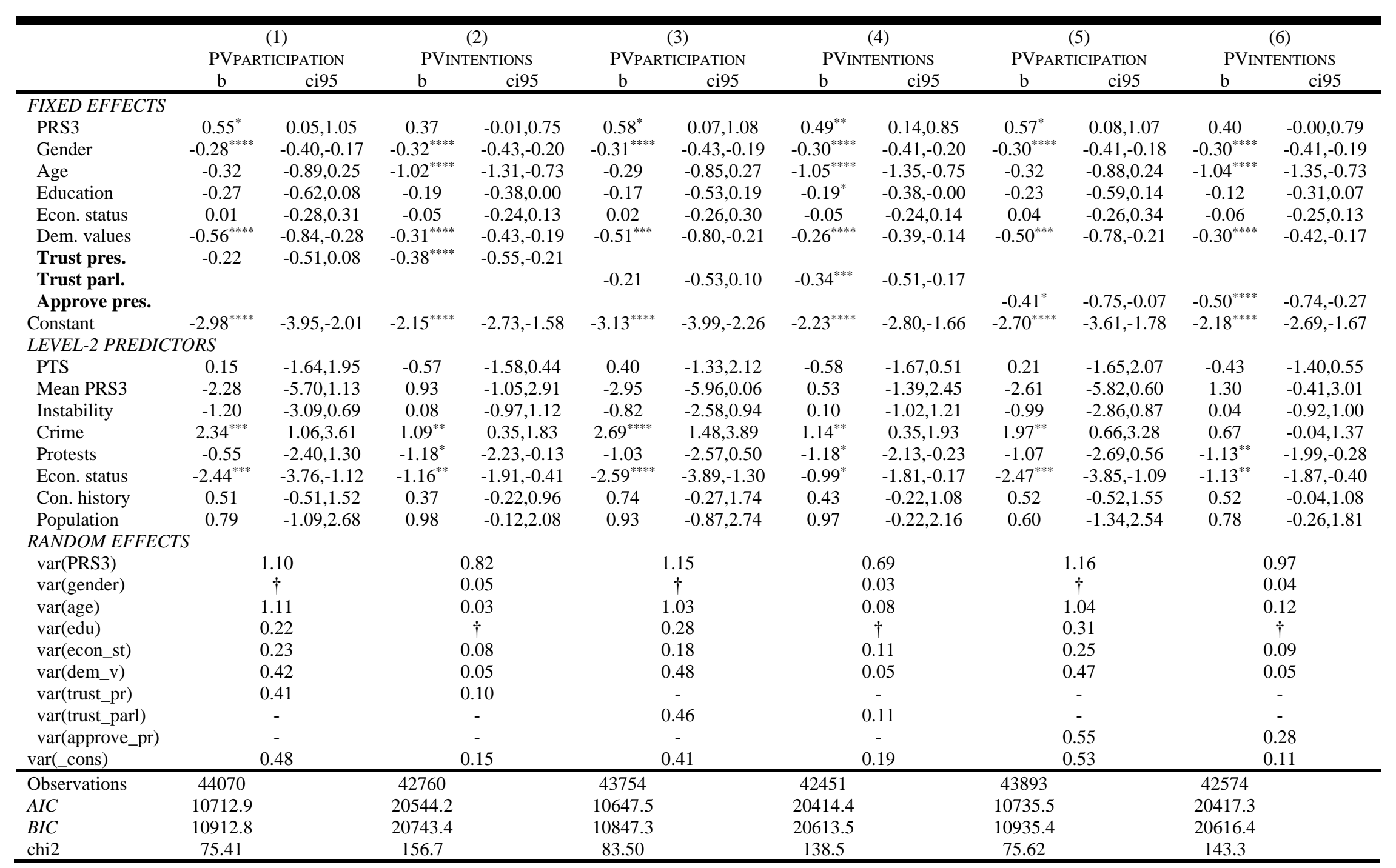

\section{Table S22}

Analogous to Table S18 but controlling for trust in and approval of government. The table reports regression coefficients (logits) and the corresponding $95 \%$ CIs. $* p<0.05, * * p<0.01$, *** $p<0.001$, **** $p<0.0001$. $\dagger$ excluded randomly varying slopes due to no significant improvement in the model fit. 


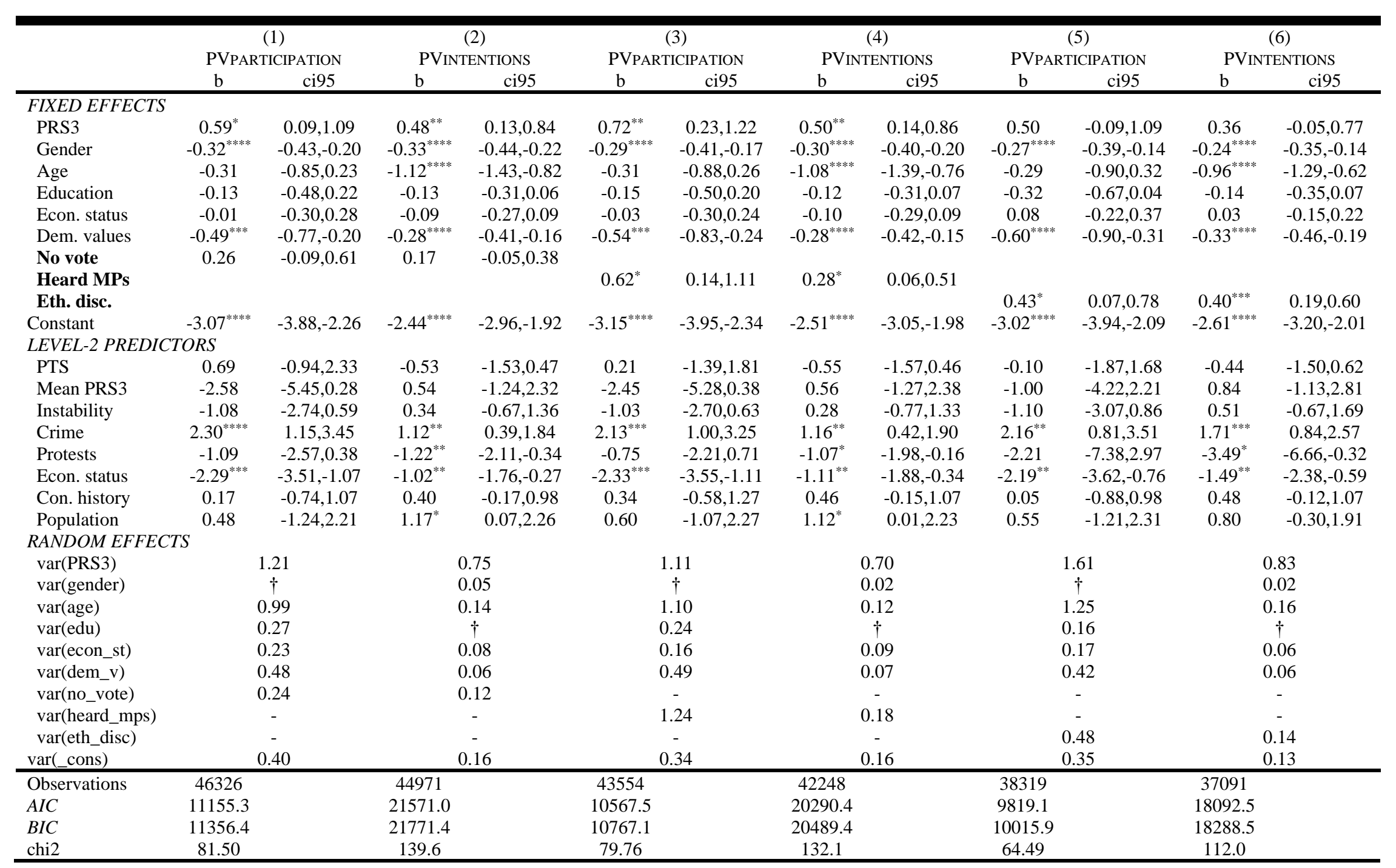

\section{Table S23}

Analogous to Table S18 but controlling for psychological predictors of political violence. The table reports regression coefficients (logits) and the corresponding 95\% CIs. * $p<0.05$, ** $p<0.01$, *** $p<0.001$, **** $p<0.0001$. $\dagger$ excluded randomly varying slopes due to no significant improvement in the model fit. 


\begin{tabular}{|c|c|c|c|c|c|c|c|c|c|c|c|c|}
\hline & \multicolumn{2}{|c|}{$(1)$} & \multicolumn{2}{|c|}{ (2) } & \multicolumn{2}{|c|}{ (3) } & \multicolumn{2}{|c|}{$(4)$} & \multicolumn{2}{|c|}{$(5)$} & \multicolumn{2}{|c|}{$\begin{array}{c}(6) \\
\text { PVINTENTIONS }\end{array}$} \\
\hline & $\mathrm{b}$ & ci95 & $\mathrm{b}$ & ci95 & $\mathrm{b}$ & ci95 & $\mathrm{b}$ & ci95 & $\mathrm{b}$ & ci95 & $\mathrm{b}$ & ci95 \\
\hline \multicolumn{13}{|c|}{ FIXED EFFECTS } \\
\hline PRS3 & $0.60^{*}$ & $0.11,1.10$ & $0.49^{* *}$ & $0.13,0.85$ & $0.60^{*}$ & $0.11,1.10$ & $0.49^{* *}$ & $0.13,0.85$ & $0.62^{*}$ & $0.12,1.12$ & $0.49^{* *}$ & $0.13,0.84$ \\
\hline Gender & $-0.31^{* * * * *}$ & $-0.43,-0.20$ & $-0.33^{* * * * *}$ & $-0.44,-0.22$ & $-0.31^{* * * * *}$ & $-0.43,-0.20$ & $-0.33^{* * * * *}$ & $-0.44,-0.22$ & $-0.31^{* * * * *}$ & $-0.42,-0.19$ & $-0.33^{* * * * *}$ & $-0.44,-0.21$ \\
\hline Age & -0.31 & $-0.86,0.23$ & $-1.13^{* * * *}$ & $-1.43,-0.82$ & -0.32 & $-0.86,0.22$ & $-1.12^{* * * * *}$ & $-1.43,-0.81$ & -0.33 & $-0.87,0.21$ & $-1.11^{* * * * *}$ & $-1.42,-0.81$ \\
\hline Education & -0.09 & $-0.45,0.26$ & -0.11 & $-0.30,0.07$ & -0.10 & $-0.46,0.25$ & -0.11 & $-0.29,0.08$ & -0.12 & $-0.48,0.23$ & -0.10 & $-0.29,0.09$ \\
\hline Econ. status & -0.01 & $-0.29,0.27$ & -0.08 & $-0.26,0.10$ & -0.02 & $-0.30,0.27$ & -0.09 & $-0.28,0.09$ & -0.02 & $-0.30,0.27$ & -0.09 & $-0.28,0.09$ \\
\hline Dem. values & $-0.50^{* * * *}$ & $-0.79,-0.21$ & $-0.29^{* * * *}$ & $-0.41,-0.16$ & $-0.50^{* * * *}$ & $-0.78,-0.21$ & $-0.28^{* * * * *}$ & $-0.41,-0.16$ & $-0.51^{* * *}$ & $-0.79,-0.22$ & $-0.28^{* * * * *}$ & $-0.41,-0.15$ \\
\hline Influenced & $0.42^{* *}$ & $0.14,0.71$ & $0.34^{* * *}$ & $0.14,0.53$ & & & & & & & & \\
\hline Suspicious & & & & & 0.12 & $-0.10,0.34$ & 0.13 & $-0.01,0.28$ & & & & \\
\hline Misleading & & & & & & & & & -0.16 & $-0.42,0.10$ & $0.22^{* *}$ & $0.06,0.39$ \\
\hline Constant & $-3.04^{* * * *}$ & $-3.85,-2.22$ & $-2.42^{* * * * *}$ & $-2.94,-1.90$ & $-3.03^{* * * *}$ & $-3.84,-2.22$ & $-2.42^{* * * * *}$ & $-2.94,-1.90$ & $-3.01^{* * * * *}$ & $-3.82,-2.20$ & $-2.43^{* * * * *}$ & $-2.94,-1.91$ \\
\hline \multicolumn{13}{|c|}{ LEVEL-2 PREDICTORS } \\
\hline PTS & 0.67 & $-0.98,2.31$ & -0.54 & $-1.54,0.46$ & 0.66 & $-0.98,2.30$ & -0.53 & $-1.53,0.46$ & 0.68 & $-0.96,2.32$ & -0.54 & $-1.54,0.46$ \\
\hline Mean PRS3 & -2.59 & $-5.47,0.28$ & 0.50 & $-1.28,2.27$ & -2.60 & $-5.47,0.27$ & 0.45 & $-1.32,2.23$ & -2.51 & $-5.39,0.36$ & 0.43 & $-1.34,2.20$ \\
\hline Instability & -1.08 & $-2.75,0.59$ & 0.32 & $-0.69,1.34$ & -1.10 & $-2.76,0.57$ & 0.32 & $-0.69,1.34$ & -1.10 & $-2.77,0.57$ & 0.33 & $-0.68,1.34$ \\
\hline Crime & $2.23^{* * *}$ & $1.07,3.38$ & $1.11^{* *}$ & $0.38,1.83$ & $2.22^{* * *}$ & $1.07,3.37$ & $1.11^{* *}$ & $0.39,1.83$ & $2.21^{* * * *}$ & $1.05,3.36$ & $1.11^{* *}$ & $0.38,1.83$ \\
\hline Protests & -1.08 & $-2.56,0.39$ & $-1.21^{* *}$ & $-2.10,-0.33$ & -1.07 & $-2.55,0.40$ & $-1.22^{* *}$ & $-2.10,-0.33$ & -1.08 & $-2.55,0.40$ & $-1.21^{* * *}$ & $-2.10,-0.33$ \\
\hline Econ. status & $-2.31^{* * *}$ & $-3.54,-1.08$ & $-1.04^{* *}$ & $-1.78,-0.29$ & $-2.31^{* * * *}$ & $-3.54,-1.09$ & $-1.04^{* *}$ & $-1.79,-0.30$ & $-2.28^{* * *}$ & $-3.51,-1.05$ & $-1.04^{* *}$ & $-1.79,-0.30$ \\
\hline Con. history & 0.14 & $-0.77,1.05$ & 0.39 & $-0.18,0.96$ & 0.14 & $-0.77,1.05$ & 0.40 & $-0.17,0.97$ & 0.15 & $-0.76,1.06$ & 0.39 & $-0.18,0.96$ \\
\hline Population & 0.59 & $-1.15,2.32$ & $1.15^{*}$ & $0.05,2.24$ & 0.58 & $-1.15,2.31$ & $1.14^{*}$ & $0.05,2.24$ & 0.56 & $-1.17,2.30$ & $1.15^{*}$ & $0.06,2.24$ \\
\hline \multicolumn{13}{|c|}{ RANDOM EFFECTS } \\
\hline $\operatorname{var}(\mathrm{PRS} 3)$ & & 1.23 & & 75 & & 23 & & 75 & & 23 & & .75 \\
\hline var(gender) & & $\dagger$ & & 05 & & $\dagger$ & & .05 & & $\dagger$ & & .05 \\
\hline $\operatorname{var}($ age $)$ & & 1.00 & & 14 & & 98 & & 14 & & 99 & & 14 \\
\hline $\operatorname{var}(\mathrm{edu})$ & & 0.28 & & $\dagger$ & & .28 & & $\dagger$ & & 28 & & $\dagger$ \\
\hline $\operatorname{var}($ econ_st $)$ & & 0.21 & & 08 & & .21 & & 09 & & 21 & & 09 \\
\hline var(dem_v) & & 0.48 & & .06 & & .48 & & .06 & & 48 & & .06 \\
\hline $\operatorname{var}($ _cons $)$ & & 0.41 & & 16 & & 41 & & 16 & & 41 & & 16 \\
\hline Observations & 46377 & & 45016 & & 46409 & & 45048 & & 46395 & & 45034 & \\
\hline$A I C$ & 11200.6 & & 21603.1 & & 11209.3 & & 21603.7 & & 11208.2 & & 21597.1 & \\
\hline$B I C$ & 11393.0 & & 21794.8 & & 11401.7 & & 21795.5 & & 11400.6 & & 21788.8 & \\
\hline $\operatorname{chi} 2$ & 87.59 & & 149.2 & & 80.23 & & 140.5 & & 80.38 & & 144.2 & \\
\hline
\end{tabular}

\section{Table S24}

Analogous to Table S18 but controlling for influenced answering and dishonesty. The table reports regression coefficients (logits) and the corresponding $95 \%$ CIs. $* p<0.05, * * p<0.01, * * * p<0.001, * * * * p<0.0001$. $\dagger$ excluded randomly varying slopes due to no significant improvement in the model fit. 


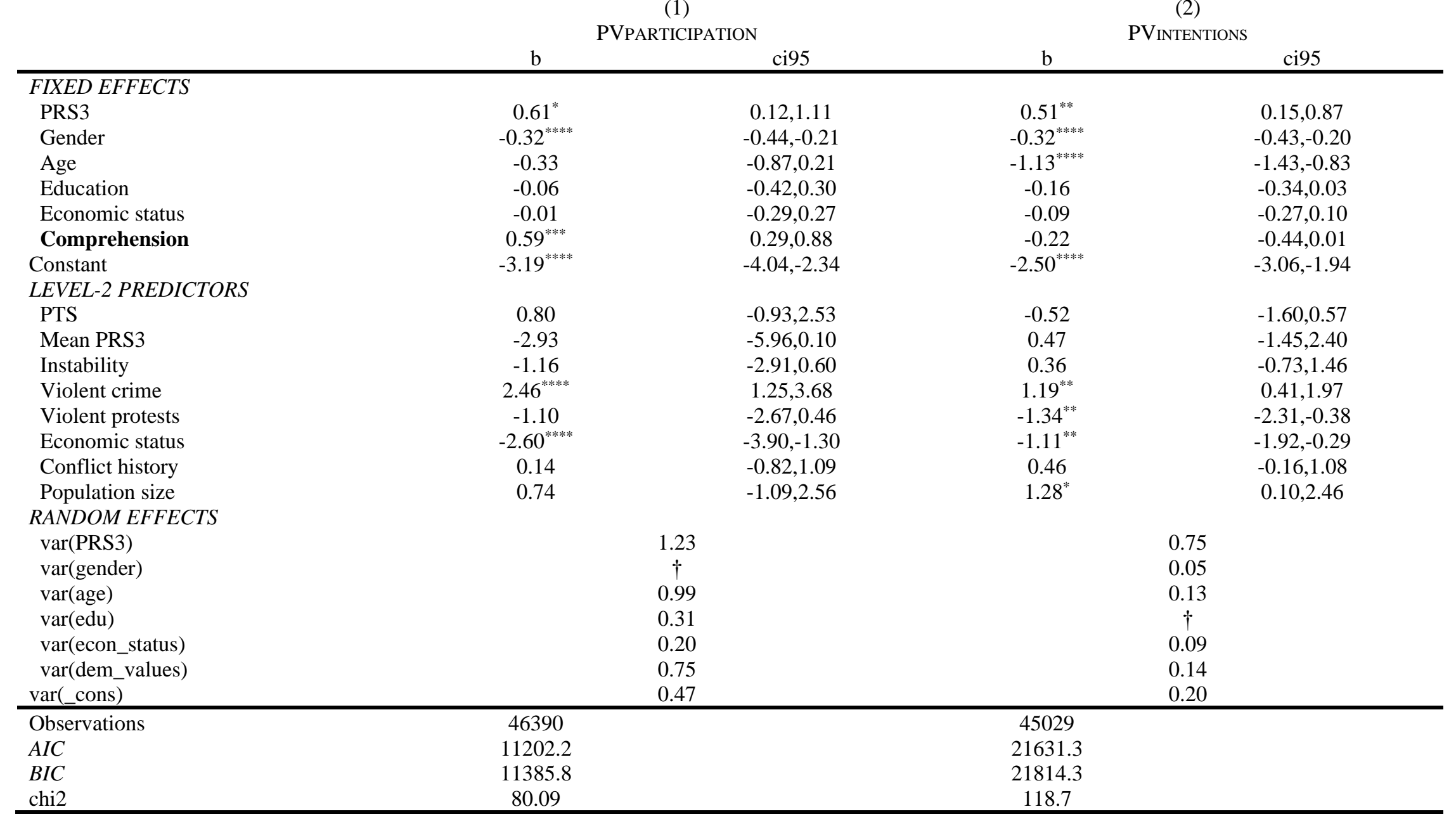

\section{Table S25}

Analogous to Table S18 but controlling for comprehension. The table reports regression coefficients (logits) and the corresponding $95 \%$ CIs. $* p<0.05, * * p<0.01, * * * p<0.001, * * * * p<0.0001$. $\dagger$ excluded randomly varying slopes due to no significant improvement in the model fit. 


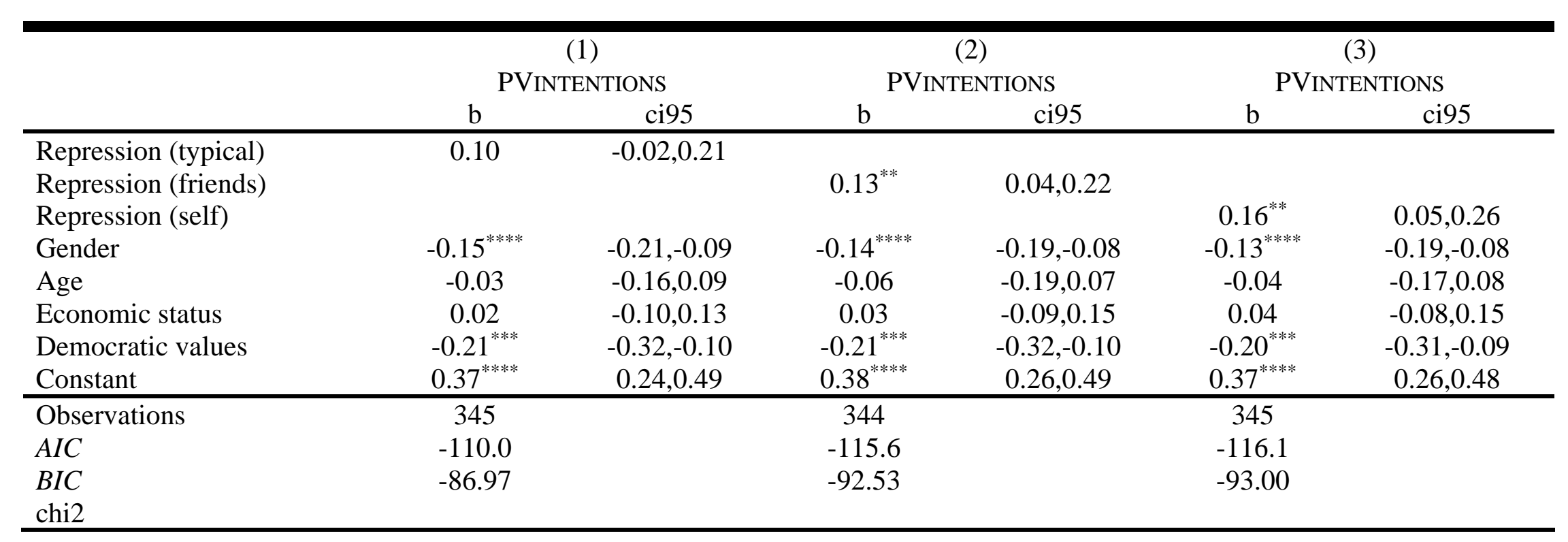

\section{Table S26}

Repression and political violence by the target of repression (Belarusian sample). The table reports regression coefficients (unstandardized betas) and the corresponding $95 \%$ CIs. $* p<0.05, * * p<0.01$, *** $p<0.001$, **** $p<0.0001$. 


\begin{tabular}{|c|c|c|c|c|c|c|}
\hline & \multicolumn{2}{|c|}{$\begin{array}{c}(1) \\
\text { PVINTENTIONS }\end{array}$} & \multicolumn{2}{|c|}{$\begin{array}{c}(2) \\
\text { PVINTENTIONS }\end{array}$} & \multicolumn{2}{|c|}{$\begin{array}{c}\text { (3) } \\
\text { PVINTENTIONS }\end{array}$} \\
\hline & $\mathrm{b}$ & ci95 & $\mathrm{b}$ & ci95 & $\mathrm{b}$ & ci95 \\
\hline Repression Scale & $0.17^{* *}$ & $0.06,0.29$ & & & & \\
\hline High Intensity Repression Scale & & & $0.21^{* * *}$ & $0.09,0.32$ & & \\
\hline Low Intensity Repression Scale & & & & & $0.14^{* *}$ & $0.03,0.25$ \\
\hline Gender & $-0.14^{* * * *}$ & $-0.20,-0.09$ & $-0.13^{* * * *}$ & $-0.19,-0.08$ & $-0.14^{* * * *}$ & $-0.20,-0.09$ \\
\hline Age & -0.04 & $-0.16,0.09$ & -0.04 & $-0.16,0.09$ & -0.04 & $-0.16,0.09$ \\
\hline Economic status & 0.04 & $-0.08,0.16$ & 0.03 & $-0.08,0.15$ & 0.03 & $-0.08,0.15$ \\
\hline Democratic values & $-0.22^{* * * *}$ & $-0.33,-0.11$ & $-0.22^{* * * * *}$ & $-0.33,-0.12$ & $-0.22^{* * *}$ & $-0.33,-0.11$ \\
\hline Constant & $0.35^{* * * *}$ & $0.23,0.46$ & $0.34^{* * * *}$ & $0.22,0.46$ & $0.36^{* * * *}$ & $0.24,0.47$ \\
\hline Observations & 346 & & 346 & & 346 & \\
\hline$A I C$ & -117.3 & & -120.2 & & -115.0 & \\
\hline$B I C$ & -94.19 & & -97.13 & & -91.96 & \\
\hline chi2 & & & & & & \\
\hline
\end{tabular}

\section{Table S27}

Aggregate, high-intensity, and low-intensity repression and political violence (Belarusian sample). The table reports regression coefficients (unstandardized betas) and the corresponding 95\% CIs. * $p<0.05, * * p<0.01$, *** $p<0.001, * * * * p<0.0001$. 


\begin{tabular}{|c|c|c|c|c|c|c|}
\hline & \multicolumn{2}{|c|}{$\begin{array}{l}\text { (1) } \\
\text { RIS }\end{array}$} & \multicolumn{2}{|c|}{$\begin{array}{l}(2) \\
\text { RIS }\end{array}$} & \multicolumn{2}{|c|}{$\begin{array}{l}(3) \\
\text { RIS }\end{array}$} \\
\hline & $\mathrm{b}$ & ci95 & $\mathrm{b}$ & ci95 & $\mathrm{b}$ & ci95 \\
\hline Repression (typical) & $0.36^{* * * *}$ & $0.30,0.43$ & & & & \\
\hline Repression (friends) & & & $0.30^{* * * * *}$ & $0.25,0.36$ & & \\
\hline Repression (self) & & & & & $0.30^{* * * * *}$ & $0.24,0.35$ \\
\hline Gender & $-0.09^{* * * *}$ & $-0.13,-0.06$ & $-0.08^{* * * *}$ & $-0.12,-0.05$ & $-0.06^{* * *}$ & $-0.10,-0.03$ \\
\hline Age & $-0.09^{*}$ & $-0.17,-0.01$ & $-0.10^{*}$ & $-0.18,-0.01$ & -0.06 & $-0.14,0.02$ \\
\hline Economic status & $-0.12^{* *}$ & $-0.21,-0.04$ & $-0.14^{* *}$ & $-0.22,-0.05$ & $-0.13^{* *}$ & $-0.22,-0.05$ \\
\hline Democratic values & $0.10^{*}$ & $0.01,0.20$ & $0.13^{* * *}$ & $0.03,0.22$ & $0.17^{* * * *}$ & $0.07,0.27$ \\
\hline Constant & $0.13^{* *}$ & $0.03,0.23$ & $0.18^{* * *}$ & $0.09,0.28$ & $0.20^{* * * *}$ & $0.11,0.30$ \\
\hline Observations & 929 & & 930 & & 930 & \\
\hline$A I C$ & 160.9 & & 176.9 & & 184.8 & \\
\hline$B I C$ & 189.9 & & 205.9 & & 213.8 & \\
\hline
\end{tabular}

\section{Table S28}

Repression and radicalism intentions (RIS) by the target of repression (Venezuelan sample). The table reports regression coefficients (unstandardized betas) and the corresponding 95\% CIs. * $p<0.05, * * p<0.01, * * * p<0.001$, **** $p<0.0001$. 


\begin{tabular}{|c|c|c|c|c|c|c|}
\hline & \multicolumn{2}{|c|}{$\begin{array}{l}\text { (1) } \\
\text { RIS }\end{array}$} & \multicolumn{2}{|c|}{$\begin{array}{l}(2) \\
\text { RIS }\end{array}$} & \multicolumn{2}{|c|}{$\begin{array}{c}(3) \\
\text { RIS }\end{array}$} \\
\hline & $b$ & ci95 & $b$ & ci95 & $\mathrm{b}$ & ci95 \\
\hline Repression Scale & $0.40^{* * * *}$ & $0.33,0.46$ & & & & \\
\hline High Intensity Repression Scale & & & $0.35^{* * * *}$ & $0.29,0.42$ & & \\
\hline Low Intensity Repression Scale & & & & & $0.38^{* * * *}$ & $0.32,0.44$ \\
\hline Gender & $-0.08^{* * * *}$ & $-0.11,-0.05$ & $-0.08^{* * * *}$ & $-0.11,-0.04$ & $-0.08^{* * * *}$ & $-0.12,-0.05$ \\
\hline Age & -0.08 & $-0.16,0.00$ & -0.07 & $-0.15,0.01$ & $-0.08^{*}$ & $-0.17,-0.00$ \\
\hline Economic status & $-0.14^{* *}$ & $-0.22,-0.05$ & $-0.14^{* *}$ & $-0.23,-0.05$ & $-0.14^{* *}$ & $-0.22,-0.05$ \\
\hline Democratic values & $0.11^{*}$ & $0.02,0.21$ & $0.11^{*}$ & $0.02,0.21$ & $0.12^{*}$ & $0.03,0.21$ \\
\hline Constant & $0.16^{* *}$ & $0.06,0.25$ & $0.17^{* * *}$ & $0.07,0.27$ & $0.16^{* *}$ & $0.06,0.26$ \\
\hline Observations & 930 & & 930 & & 930 & \\
\hline$A I C$ & 145.0 & & 172.4 & & 144.8 & \\
\hline$B I C$ & 174.0 & & 201.4 & & 173.8 & \\
\hline chi2 & & & & & & \\
\hline
\end{tabular}

\section{Table S29}

Aggregate, high-intensity, and low-intensity repression and radicalism intentions (RIS) (Venezuelan sample). The table reports regression coefficients (unstandardized betas) and the corresponding 95\% CIs. $* p<0.05, * * p<0.01, * * * p<0.001, * * * * p<0.0001$. 


\begin{tabular}{|c|c|c|c|c|c|c|}
\hline & \multicolumn{2}{|c|}{$\begin{array}{c}(1) \\
\text { PVINTENTIONS }\end{array}$} & \multicolumn{2}{|c|}{$\begin{array}{c}(2) \\
\text { PVINTENTIONS }\end{array}$} & \multicolumn{2}{|c|}{$\begin{array}{c}(3) \\
\text { PVINTENTIONS }\end{array}$} \\
\hline & $\mathrm{b}$ & ci95 & $\mathrm{b}$ & ci95 & $\mathrm{b}$ & ci95 \\
\hline Repression (typical) & $2.58^{* * * *}$ & $1.74,3.41$ & & & & \\
\hline Repression (friends) & & & $1.85^{* * * *}$ & $1.22,2.49$ & & \\
\hline Repression (self) & & & & & $1.68^{* * * *}$ & $1.13,2.23$ \\
\hline Gender & $-0.57^{* *}$ & $-0.93,-0.22$ & $-0.48^{* *}$ & $-0.83,-0.13$ & $-0.35^{*}$ & $-0.70,-0.00$ \\
\hline Age & -0.36 & $-1.18,0.46$ & -0.43 & $-1.25,0.39$ & -0.22 & $-1.03,0.60$ \\
\hline Economic status & -0.81 & $-1.71,0.09$ & -0.88 & $-1.76,0.00$ & $-0.89^{*}$ & $-1.77,-0.00$ \\
\hline Democratic values & 0.04 & $-1.02,1.11$ & 0.29 & $-0.74,1.32$ & 0.55 & $-0.46,1.56$ \\
\hline Constant & $-2.53^{* * * *}$ & $-3.68,-1.38$ & $-2.02^{* * *}$ & $-3.09,-0.96$ & $-1.82^{* * *}$ & $-2.86,-0.79$ \\
\hline Observations & 878 & & 880 & & 880 & \\
\hline$A I C$ & 814.5 & & 825.0 & & 826.0 & \\
\hline$B I C$ & 843.2 & & 853.7 & & 854.6 & \\
\hline chi2 & 57.58 & & 47.92 & & 46.99 & \\
\hline
\end{tabular}

\section{Table S30}

Repression and political violence (PVINTENTIONS) by the target of repression (Venezuelan sample). The table reports regression coefficients (logits) and the corresponding 95\% CIs. * $p<0.05, * * p<0.01, * * * p<0.001, * * * * p<0.0001$. 


\begin{tabular}{|c|c|c|c|c|c|c|}
\hline & \multicolumn{2}{|c|}{$\begin{array}{c}(1) \\
\text { PVINTENTIONS }\end{array}$} & \multicolumn{2}{|c|}{$\begin{array}{c}(2) \\
\text { PVINTENTIONS }\end{array}$} & \multicolumn{2}{|c|}{$\begin{array}{c}(3) \\
\text { PVINTENTIONS }\end{array}$} \\
\hline & $\mathrm{b}$ & ci95 & $\mathrm{b}$ & ci95 & $\mathrm{b}$ & ci95 \\
\hline Repression Scale & $2.50^{* * * * *}$ & $1.76,3.24$ & & & & \\
\hline High Intensity Repression Scale & & & $2.04^{* * * * *}$ & $1.33,2.75$ & & \\
\hline Low Intensity Repression Scale & & & & & $2.47^{* * * * *}$ & $1.75,3.18$ \\
\hline Gender & $-0.47^{* *}$ & $-0.82,-0.11$ & $-0.42^{*}$ & $-0.77,-0.07$ & $-0.49^{* *}$ & $-0.84,-0.13$ \\
\hline Age & -0.33 & $-1.15,0.50$ & -0.26 & $-1.08,0.55$ & -0.36 & $-1.19,0.46$ \\
\hline Economic status & $-0.91^{*}$ & $-1.80,-0.01$ & $-0.91^{*}$ & $-1.80,-0.03$ & -0.88 & $-1.77,0.02$ \\
\hline Democratic values & 0.18 & $-0.87,1.22$ & 0.27 & $-0.77,1.30$ & 0.22 & $-0.82,1.26$ \\
\hline Constant & $-2.23^{* * * * *}$ & $-3.32,-1.14$ & $-2.08^{* * *}$ & $-3.15,-1.01$ & $-2.24^{* * * *}$ & $-3.33,-1.15$ \\
\hline Observations & 880 & & 880 & & 880 & \\
\hline$A I C$ & 812.3 & & 827.0 & & 809.6 & \\
\hline$B I C$ & 841.0 & & 855.7 & & 838.3 & \\
\hline chi2 & 60.66 & & 45.91 & & 63.38 & \\
\hline
\end{tabular}

\section{Table S31}

Aggregate, high-intensity, and low-intensity repression and political violence (PVINTENTIONS) (Venezuelan sample). The table reports regression coefficients (logits) and the corresponding 95\% CIs. $* p<0.05, * * p<0.01, * * * p<0.001, * * * * p<0.0001$. 
(1)

PDINTENTIONS

\begin{tabular}{|c|c|c|c|c|c|c|}
\hline & \multicolumn{2}{|c|}{$(1)$} & \multicolumn{2}{|c|}{$(2)$} & \multicolumn{2}{|c|}{$(3)$} \\
\hline & $\mathrm{b}$ & ci95 & $\mathrm{b}$ & ci95 & $\mathrm{b}$ & ci95 \\
\hline Repression (typical) & $2.46^{* * * * *}$ & $1.70,3.23$ & & & & \\
\hline Repression (friends) & & & $2.07^{* * * * *}$ & $1.39,2.76$ & & \\
\hline Repression (self) & & & & & $1.93^{* * * * *}$ & $1.09,2.77$ \\
\hline Gender & 0.31 & $-0.12,0.74$ & $0.46^{*}$ & $0.04,0.88$ & $0.58^{* *}$ & $0.16,0.99$ \\
\hline Age & $1.33^{*}$ & $0.27,2.38$ & $1.27^{*}$ & $0.22,2.31$ & $1.44^{* *}$ & $0.41,2.47$ \\
\hline Economic status & -0.51 & $-1.59,0.58$ & -0.52 & $-1.60,0.56$ & -0.43 & $-1.48,0.63$ \\
\hline Democratic values & 0.82 & $-0.29,1.93$ & 0.96 & $-0.12,2.05$ & $1.22^{*}$ & $0.15,2.28$ \\
\hline Constant & $-2.25^{* * *}$ & $-3.42,-1.08$ & $-1.95^{* * *}$ & $-3.08,-0.82$ & $-1.79^{* *}$ & $-2.91,-0.68$ \\
\hline Observations & 409 & & 410 & & 410 & \\
\hline$A I C$ & 510.5 & & 517.6 & & 533.3 & \\
\hline$B I C$ & 534.6 & & 541.7 & & 557.4 & \\
\hline chi2 & 67.22 & & 61.62 & & 45.93 & \\
\hline
\end{tabular}

\section{Table S32}

Repression and protests/demonstrations (PDINTENTIONS) by the target of repression (Venezuelan sample). The table reports regression

coefficients (logits) and the corresponding 95\% CIs. $* p<0.05, * * p<0.01, * * * p<0.001, * * * * p<0.0001$.

(3)

PDINTENTIONS

PDINTENTIONS 
(1)

\begin{tabular}{|c|c|c|c|c|c|c|}
\hline & \multicolumn{2}{|c|}{ PDINTENTIONS } & \multicolumn{2}{|c|}{ PDINTENTIONS } & \multicolumn{2}{|c|}{ PDINTENTIONS } \\
\hline & $\mathrm{b}$ & $\mathrm{ci95}$ & $\mathrm{b}$ & ci95 & $\mathrm{b}$ & ci95 \\
\hline Repression Scale & $2.81^{* * * * *}$ & $1.94,3.68$ & & & & \\
\hline High Intensity Repression Scale & & & $2.28^{* * * * *}$ & $1.46,3.11$ & & \\
\hline Low Intensity Repression Scale & & & & & $2.76^{* * * *}$ & $1.92,3.61$ \\
\hline Gender & $0.45^{*}$ & $0.02,0.88$ & $0.47^{*}$ & $0.05,0.89$ & $0.45^{*}$ & $0.02,0.87$ \\
\hline Age & $1.38^{*}$ & $0.33,2.43$ & $1.35^{*}$ & $0.32,2.39$ & $1.38^{*}$ & $0.33,2.44$ \\
\hline Economic status & -0.56 & $-1.65,0.53$ & -0.50 & $-1.57,0.57$ & -0.55 & $-1.64,0.54$ \\
\hline Democratic values & 0.93 & $-0.17,2.03$ & 0.87 & $-0.23,1.96$ & 1.02 & $-0.08,2.12$ \\
\hline Constant & $-2.16^{* * *}$ & $-3.32,-1.00$ & $-1.96^{* * *}$ & $-3.10,-0.82$ & $-2.19^{* * *}$ & $-3.35,-1.03$ \\
\hline Observations & 410 & & 410 & & 410 & \\
\hline$A I C$ & 510.7 & & 524.2 & & 508.6 & \\
\hline$B I C$ & 534.8 & & 548.3 & & 532.7 & \\
\hline chi2 & 68.48 & & 54.99 & & 70.58 & \\
\hline
\end{tabular}

\section{Table S33}

Aggregate, high-intensity, and low-intensity repression and protests/demonstrations (PDINTENTIONS) (Venezuelan sample). The table reports regression coefficients (logits) and the corresponding 95\% CIs. $* p<0.05$, ** $p<0.01$, *** $p<0.001$, **** $p<0.0001$. 


\begin{tabular}{|c|c|c|c|c|c|c|}
\hline & \multicolumn{2}{|c|}{$\begin{array}{c}(1) \\
\text { PVPARTICIPATION }\end{array}$} & \multicolumn{2}{|c|}{$\begin{array}{c}(2) \\
\text { PVPARTICIPATION }\end{array}$} & \multicolumn{2}{|c|}{$\begin{array}{c}(3) \\
\text { PVPARTICIPATION }\end{array}$} \\
\hline & $\mathrm{b}$ & ci95 & $\mathrm{b}$ & ci95 & $\mathrm{b}$ & ci95 \\
\hline Repression (typical) & $3.37^{* * *}$ & $1.51,5.24$ & & & & \\
\hline Repression (friends) & & & $2.91^{* * * *}$ & $1.48,4.34$ & & \\
\hline Repression (self) & & & & & $2.34^{* * * * *}$ & $1.36,3.33$ \\
\hline Gender & -0.64 & $-1.28,0.00$ & -0.56 & $-1.21,0.08$ & -0.45 & $-1.09,0.20$ \\
\hline Age & $-1.73^{*}$ & $-3.34,-0.11$ & $-1.76^{*}$ & $-3.35,-0.16$ & -1.45 & $-3.05,0.14$ \\
\hline Economic status & 0.48 & $-1.13,2.08$ & 0.38 & $-1.19,1.95$ & 0.35 & $-1.20,1.90$ \\
\hline Democratic values & 0.22 & $-1.73,2.17$ & 0.30 & $-1.60,2.20$ & 0.51 & $-1.35,2.36$ \\
\hline Constant & $-5.33^{* * * *}$ & $-7.66,-2.99$ & $-4.81^{* * * *}$ & $-6.91,-2.71$ & $-4.14^{* * * *}$ & $-6.04,-2.24$ \\
\hline Observations & 921 & & 923 & & 923 & \\
\hline$A I C$ & 333.1 & & 330.3 & & 328.9 & \\
\hline$B I C$ & 362.1 & & 359.2 & & 357.8 & \\
\hline chi2 & 26.35 & & 29.41 & & 30.79 & \\
\hline
\end{tabular}

\section{Table S34}

Repression and political violence (PVPARTICIPATION) by the target of repression (Venezuelan sample). The table reports regression coefficients (logits) and the corresponding 95\% CIs. $* p<0.05, * * p<0.01, * * * p<0.001, * * * * p<0.0001$. 


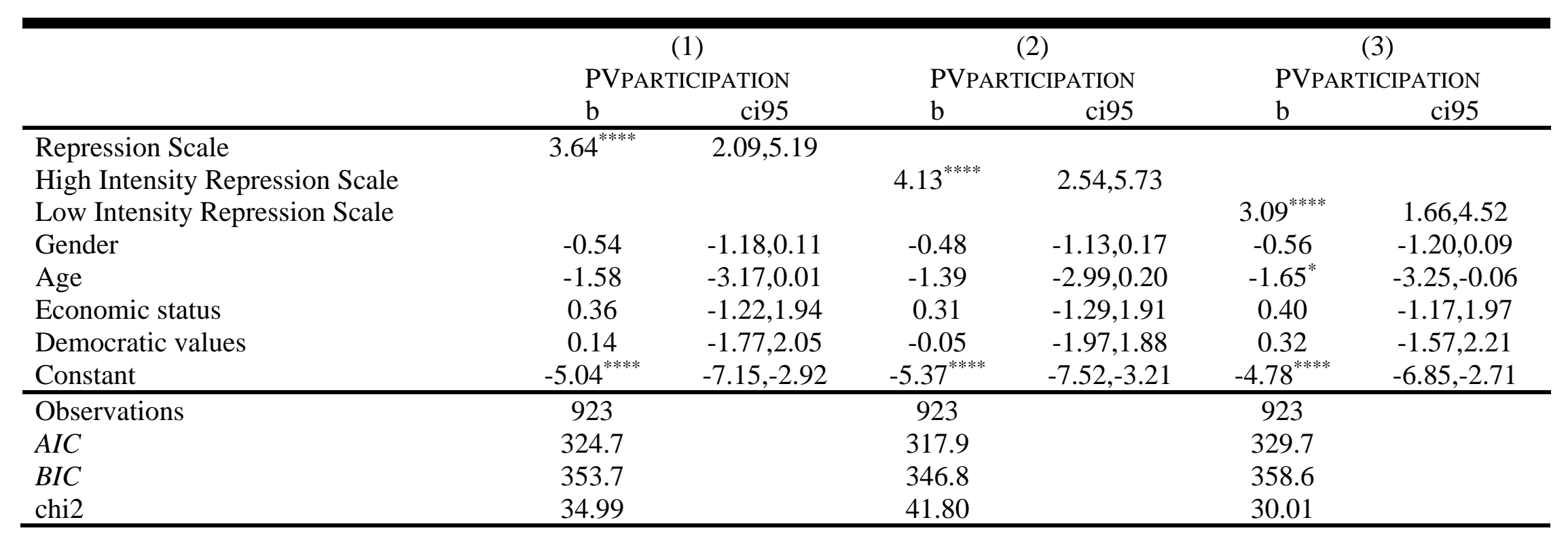

\section{Table S35}

Aggregate, high-intensity, and low-intensity repression and political violence (PVPARTICIPATION) (Venezuelan sample). The table reports regression coefficients (logits) and the corresponding 95\% CIs. $* p<0.05$, ** $p<0.01$, *** $p<0.001, * * * * p<0.0001$. 


\begin{tabular}{|c|c|c|c|c|c|c|}
\hline & \multicolumn{2}{|c|}{$(1)$} & \multicolumn{2}{|c|}{$(2)$} & \multicolumn{2}{|c|}{$(3)$} \\
\hline & $\mathrm{b}$ & ci95 & $\mathrm{b}$ & ci95 & $\mathrm{b}$ & ci95 \\
\hline Repression (typical) & $2.66^{* * * *}$ & $2.11,3.22$ & & & & \\
\hline Repression (friends) & & & $2.43^{* * * *}$ & $1.95,2.92$ & & \\
\hline Repression (self) & & & & & $2.53^{* * * *}$ & $2.02,3.05$ \\
\hline Gender & $-0.38^{* *}$ & $-0.67,-0.10$ & $-0.31^{*}$ & $-0.59,-0.02$ & -0.15 & $-0.43,0.13$ \\
\hline Age & -0.45 & $-1.12,0.22$ & -0.54 & $-1.22,0.14$ & -0.25 & $-0.92,0.43$ \\
\hline Economic status & $-0.73^{*}$ & $-1.45,-0.01$ & $-0.85^{*}$ & $-1.58,-0.13$ & $-0.85^{*}$ & $-1.58,-0.12$ \\
\hline Democratic values & 0.69 & $-0.11,1.50$ & 0.75 & $-0.05,1.54$ & $1.10^{* *}$ & $0.32,1.88$ \\
\hline Constant & $-1.45^{* * *}$ & $-2.28,-0.61$ & $-1.04^{*}$ & $-1.85,-0.23$ & $-0.90^{*}$ & $-1.71,-0.10$ \\
\hline Observations & 917 & & 919 & & 919 & \\
\hline$A I C$ & 1149.2 & & 1143.8 & & 1146.3 & \\
\hline$B I C$ & 1178.1 & & 1172.8 & & 1175.2 & \\
\hline chi2 & 123.3 & & 131.5 & & 129.1 & \\
\hline
\end{tabular}

\section{Table S36}

Repression and protests/demonstrations (PDPARTICIPATION) by the target of repression (Venezuelan sample). The table reports regression coefficients (logits) and the corresponding 95\% CIs. * $p<0.05$, ** $p<0.01$, *** $p<0.001$, **** $p<0.0001$. 
(1)

\begin{tabular}{|c|c|c|c|c|c|c|}
\hline & \multicolumn{2}{|c|}{$\begin{array}{c}(1) \\
\text { PDPARTICIPATION }\end{array}$} & \multicolumn{2}{|c|}{$\begin{array}{c}(2) \\
\text { PDPARTICIPATION }\end{array}$} & \multicolumn{2}{|c|}{$\begin{array}{c}(3) \\
\text { PDPARTICIPATION }\end{array}$} \\
\hline & $\mathrm{b}$ & ci95 & $\mathrm{b}$ & ci95 & $\mathrm{b}$ & ci95 \\
\hline Repression Scale & $3.21^{* * * *}$ & $2.62,3.80$ & & & & \\
\hline High Intensity Repression Scale & & & $3.01^{* * * *}$ & $2.43,3.59$ & & \\
\hline Low Intensity Repression Scale & & & & & $3.00^{* * * * *}$ & $2.44,3.56$ \\
\hline Gender & $-0.31^{*}$ & $-0.59,-0.02$ & -0.26 & $-0.54,0.02$ & $-0.32^{*}$ & $-0.60,-0.03$ \\
\hline Age & -0.41 & $-1.10,0.28$ & -0.33 & $-1.01,0.36$ & -0.45 & $-1.13,0.24$ \\
\hline Economic status & $-0.89^{*}$ & $-1.63,-0.15$ & $-0.90^{*}$ & $-1.64,-0.17$ & $-0.85^{*}$ & $-1.59,-0.12$ \\
\hline Democratic values & 0.64 & $-0.17,1.45$ & 0.59 & $-0.21,1.40$ & 0.75 & $-0.05,1.55$ \\
\hline Constant & $-1.26^{* *}$ & $-2.09,-0.43$ & $-1.20^{* *}$ & $-2.03,-0.37$ & $-1.22^{* *}$ & $-2.05,-0.40$ \\
\hline Observations & 919 & & 919 & & 919 & \\
\hline$A I C$ & 1119.7 & & 1132.3 & & 1125.8 & \\
\hline$B I C$ & 1148.7 & & 1161.2 & & 1154.8 & \\
\hline chi2 & 155.6 & & 143.0 & & 149.5 & \\
\hline
\end{tabular}

\section{Table S37}

Aggregate, high-intensity, and low-intensity repression and protests/demonstrations (PDPARTICIPATION) (Venezuelan sample). The table reports regression coefficients (logits) and the corresponding 95\% CIs. $* p<0.05, * * p<0.01, * * * p<0.001, * * * * p<0.0001$. 


\begin{tabular}{|c|c|c|c|c|c|c|}
\hline & \multicolumn{2}{|c|}{$\begin{array}{l}(1) \\
\text { RIS }\end{array}$} & \multicolumn{2}{|c|}{$\begin{array}{l}(2) \\
\text { RIS }\end{array}$} & \multicolumn{2}{|c|}{$\begin{array}{l}(3) \\
\text { RIS }\end{array}$} \\
\hline & $\mathrm{b}$ & ci95 & $\mathrm{b}$ & ci95 & $\mathrm{b}$ & ci95 \\
\hline Repression (typical) & $0.30^{* * * *}$ & $0.26,0.34$ & & & & \\
\hline Repression (friends) & & & $0.31^{* * * * *}$ & $0.27,0.34$ & & \\
\hline Repression (self) & & & & & $0.34^{* * * *}$ & $0.30,0.39$ \\
\hline Gender & -0.03 & $-0.06,0.00$ & -0.01 & $-0.04,0.02$ & -0.01 & $-0.04,0.02$ \\
\hline Age & $-0.16^{* *}$ & $-0.28,-0.05$ & $-0.18^{* *}$ & $-0.30,-0.07$ & $-0.15^{*}$ & $-0.27,-0.04$ \\
\hline Economic status & 0.01 & $-0.06,0.08$ & 0.01 & $-0.06,0.08$ & 0.01 & $-0.06,0.08$ \\
\hline Democratic values & 0.05 & $-0.02,0.11$ & $0.06^{*}$ & $0.00,0.13$ & $0.11^{* * *}$ & $0.05,0.17$ \\
\hline Constant & 0.06 & $-0.00,0.11$ & $0.07^{*}$ & $0.01,0.12$ & $0.07^{*}$ & $0.01,0.13$ \\
\hline Observations & 1269 & & 1272 & & 1271 & \\
\hline$A I C$ & 155.0 & & 109.4 & & 133.2 & \\
\hline$B I C$ & 185.9 & & 140.3 & & 164.1 & \\
\hline chi2 & & & & & & \\
\hline
\end{tabular}

\section{Table S38}

Repression and radicalism intentions (RIS) by the target of repression (Nicaraguan sample). The table reports regression coefficients (unstandardized betas) and the corresponding 95\% CIs. * $p<0.05, * * p<0.01, * * * p<0.001$, **** $p<0.0001$. 


\begin{tabular}{|c|c|c|c|c|c|c|}
\hline & \multicolumn{2}{|c|}{$\begin{array}{l}(1) \\
\text { RIS }\end{array}$} & \multicolumn{2}{|c|}{$\begin{array}{l}(2) \\
\text { RIS }\end{array}$} & \multicolumn{2}{|c|}{$\begin{array}{l}(3) \\
\text { RIS }\end{array}$} \\
\hline & $\mathrm{b}$ & ci95 & $\mathrm{b}$ & ci95 & $\mathrm{b}$ & ci95 \\
\hline Repression Scale & $0.39^{* * * *}$ & $0.34,0.43$ & & & & \\
\hline High Intensity Repression Scale & & & $0.35^{* * * *}$ & $0.31,0.39$ & & \\
\hline Low Intensity Repression Scale & & & & & $0.39^{* * * *}$ & $0.34,0.43$ \\
\hline Gender & -0.01 & $-0.04,0.02$ & -0.01 & $-0.04,0.02$ & -0.01 & $-0.04,0.01$ \\
\hline Age & $-0.16^{* *}$ & $-0.27,-0.04$ & $-0.16^{* *}$ & $-0.28,-0.04$ & $-0.16^{* *}$ & $-0.28,-0.05$ \\
\hline Economic status & 0.01 & $-0.06,0.08$ & 0.01 & $-0.06,0.08$ & 0.01 & $-0.06,0.07$ \\
\hline Democratic values & 0.04 & $-0.02,0.11$ & 0.06 & $-0.00,0.12$ & 0.05 & $-0.02,0.11$ \\
\hline Constant & 0.05 & $-0.01,0.11$ & 0.05 & $-0.00,0.11$ & 0.05 & $-0.00,0.11$ \\
\hline Observations & 1277 & & 1276 & & 1277 & \\
\hline$A I C$ & 77.25 & & 121.2 & & 71.26 & \\
\hline $\begin{array}{l}B I C \\
\text { chi? }\end{array}$ & 108.2 & & 152.1 & & 102.2 & \\
\hline
\end{tabular}

\section{Table S39}

Aggregate, high-intensity, and low-intensity repression and radicalism intentions (RIS) (Nicaraguan sample). The table reports regression coefficients (unstandardized betas) and the corresponding 95\% CIs. $* p<0.05, * * p<0.01$, *** $p<0.001, * * * * p<0.0001$. 


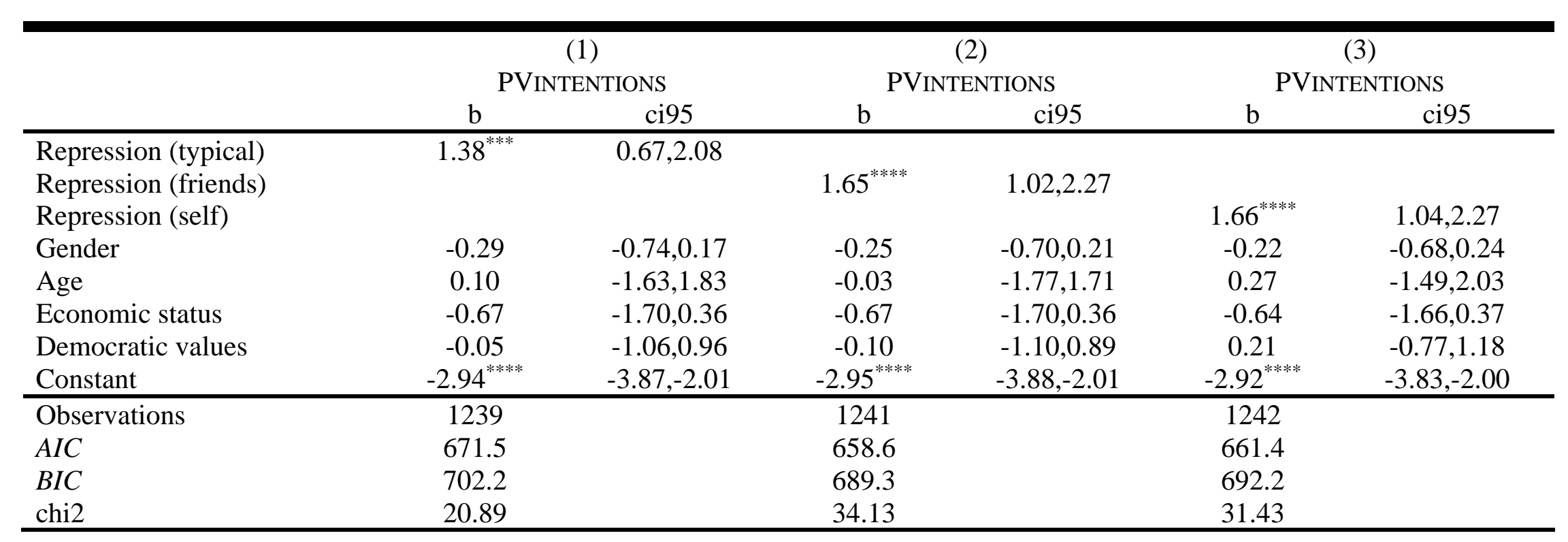

\section{Table S40}

Repression and political violence (PVINTENTIONS) by the target of repression (Nicaraguan sample). The table reports regression coefficients (logits) and the corresponding 95\% CIs. * $p<0.05, * * p<0.01, * * * p<0.001, * * * * p<0.0001$. 
(1)

\begin{tabular}{|c|c|c|c|c|c|c|}
\hline & \multicolumn{2}{|c|}{ PVINTENTIONS } & \multicolumn{2}{|c|}{ PVINTENTIONS } & \multicolumn{2}{|c|}{ PVINTENTIONS } \\
\hline & $\mathrm{b}$ & ci95 & $\mathrm{b}$ & ci95 & $\mathrm{b}$ & ci95 \\
\hline Repression Scale & $1.97^{* * * *}$ & $1.23,2.70$ & & & & \\
\hline High Intensity Repression Scale & & & $1.71^{* * * * *}$ & $1.01,2.42$ & & \\
\hline Low Intensity Repression Scale & & & & & $1.96^{* * * * *}$ & $1.25,2.68$ \\
\hline Gender & -0.23 & $-0.69,0.22$ & -0.23 & $-0.69,0.22$ & -0.24 & $-0.70,0.22$ \\
\hline Age & 0.13 & $-1.61,1.87$ & 0.18 & $-1.57,1.92$ & 0.11 & $-1.63,1.85$ \\
\hline Economic status & -0.67 & $-1.70,0.35$ & -0.64 & $-1.66,0.39$ & -0.68 & $-1.71,0.35$ \\
\hline Democratic values & -0.12 & $-1.12,0.88$ & -0.05 & $-1.05,0.95$ & -0.13 & $-1.12,0.87$ \\
\hline Constant & $-3.05^{* * * *}$ & $-3.99,-2.12$ & $-3.01^{* * * *}$ & $-3.94,-2.07$ & $-3.04^{* * * *}$ & $-3.97,-2.10$ \\
\hline Observations & 1248 & & 1247 & & 1248 & \\
\hline$A I C$ & 659.3 & & 665.0 & & 658.3 & \\
\hline$B I C$ & 690.1 & & 695.7 & & 689.0 & \\
\hline chi2 & 34.51 & & 28.71 & & 35.58 & \\
\hline
\end{tabular}

\section{Table S41}

Aggregate, high-intensity, and low-intensity repression and political violence (PVINTENTIONS) (Nicaraguan sample). The table reports regression coefficients (logits) and the corresponding 95\% CIs. $* p<0.05, * * p<0.01, * * * p<0.001, * * * * p<0.0001$. 
(1)

\begin{tabular}{|c|c|c|c|c|c|c|}
\hline & \multicolumn{2}{|c|}{$\begin{array}{c}(1) \\
\text { PDINTENTIONS }\end{array}$} & \multicolumn{2}{|c|}{$\begin{array}{c}(2) \\
\text { PDINTENTIONS }\end{array}$} & \multicolumn{2}{|c|}{$\begin{array}{c}(3) \\
\text { PDINTENTIONS }\end{array}$} \\
\hline & $\mathrm{b}$ & ci95 & $\mathrm{b}$ & ci95 & $\mathrm{b}$ & ci95 \\
\hline Repression (typical) & $2.88^{* * * *}$ & $2.36,3.39$ & & & & \\
\hline Repression (friends) & & & $2.77^{* * * *}$ & $2.29,3.25$ & & \\
\hline Repression (self) & & & & & $3.15^{* * * * *}$ & $2.48,3.83$ \\
\hline Gender & -0.08 & $-0.41,0.26$ & 0.00 & $-0.34,0.34$ & -0.01 & $-0.34,0.32$ \\
\hline Age & -0.43 & $-1.81,0.95$ & -0.55 & $-1.94,0.85$ & -0.55 & $-1.88,0.79$ \\
\hline Economic status & $0.91^{*}$ & $0.10,1.72$ & $0.98^{*}$ & $0.15,1.80$ & $0.90^{*}$ & $0.10,1.70$ \\
\hline Democratic values & $1.76^{* * * *}$ & $0.96,2.55$ & $2.07^{* * * *}$ & $1.27,2.86$ & $2.40^{* * * *}$ & $1.64,3.17$ \\
\hline Constant & $-3.43^{* * * *}$ & $-4.23,-2.64$ & $-3.30^{* * * *}$ & $-4.09,-2.51$ & $-3.06^{* * * *}$ & $-3.81,-2.31$ \\
\hline Observations & 788 & & 789 & & 793 & \\
\hline$A I C$ & 878.6 & & 869.6 & & 918.5 & \\
\hline$B I C$ & 906.6 & & 897.7 & & 946.6 & \\
\hline chi2 & 206.8 & & 216.3 & & 171.7 & \\
\hline
\end{tabular}

\section{Table S42}

Repression and protests/demonstrations (PDINTENTIONS) by the target of repression (Nicaraguan sample). The table reports regression coefficients (logits) and the corresponding 95\% CIs. $* p<0.05, * * p<0.01, * * * p<0.001, * * * * p<0.0001$. 
(1)

PDINTENTIONS

Repression Scale

High Intensity Repression Scale

Low Intensity Repression Scale

Gender

Age

Economic status

Democratic values

Constant

Observations

AIC

$B I C$

chi2

\section{Table S43}

Aggregate, high-intensity, and low-intensity repression and protests/demonstrations (PDINTENTIONS) (Nicaraguan sample). The table reports regression coefficients (logits) and the corresponding 95\% CIs. $* p<0.05, * * p<0.01$, *** $p<0.001, * * * * p<0.0001$.

(3)

\section{(2)}

PDINTENTIONS

ci95

b

ci95

b

ci95

\begin{tabular}{cccccc}
$\mathrm{b}$ & $\mathrm{ci95}$ & $\mathrm{b}$ & $\mathrm{ci95}$ & $\mathrm{b}$ & $\mathrm{ci95}$ \\
\hline $3.86^{* * * *}$ & $3.23,4.50$ & & & & \\
& & $3.41^{* * * *}$ & $2.80,4.01$ & & \\
& & & & $3.84^{* * * *}$ & $3.21,4.46$ \\
0.01 & $-0.33,0.36$ & -0.02 & $-0.35,0.32$ & 0.02 & $-0.32,0.37$ \\
-0.37 & $-1.78,1.04$ & -0.52 & $-1.91,0.86$ & -0.33 & $-1.74,1.08$ \\
$1.09^{*}$ & $0.25,1.93$ & $1.04^{*}$ & $0.22,1.87$ & $1.07^{*}$ & $0.23,1.92$ \\
$1.85^{* * * *}$ & $1.05,2.65$ & $1.92^{* * * *}$ & $1.13,2.71$ & $1.87^{* * * *}$ & $1.07,2.66$ \\
$-3.55^{* * * *}$ & $-4.36,-2.75$ & $-3.43^{* * * *}$ & $-4.22,-2.64$ & $-3.54^{* * * *}$ & $-4.34,-2.73$ \\
\hline 797 & & 797 & & 797 & \\
852.6 & & 882.1 & & 849.0 & \\
880.7 & & 910.2 & & 877.1 & \\
242.6 & & 213.1 & & 246.2 & \\
\hline
\end{tabular}

\footnotetext{
reports regression coefficients (logits) and the corresponding $95 \%$ Cls. $p<0.05, * p<0.01, * * *<0.001, * * * p<0.0001$
} 


\begin{tabular}{|c|c|c|c|c|c|c|}
\hline & \multicolumn{2}{|c|}{$\begin{array}{c}(1) \\
\text { PVPARTICIPATION }\end{array}$} & \multicolumn{2}{|c|}{$\begin{array}{c}(2) \\
\text { PVPARTICIPATION }\end{array}$} & \multicolumn{2}{|c|}{$\begin{array}{c}(3) \\
\text { PVPARTICIPATION }\end{array}$} \\
\hline & $\mathrm{b}$ & ci95 & $\mathrm{b}$ & ci95 & $\mathrm{b}$ & ci95 \\
\hline Repression (typical) & $2.44^{* *}$ & $0.86,4.02$ & & & & \\
\hline Repression (friends) & & & $2.66^{* * *}$ & $1.26,4.05$ & & \\
\hline Repression (self) & & & & & $1.81^{* *}$ & $0.69,2.93$ \\
\hline Gender & -0.43 & $-1.31,0.45$ & -0.38 & $-1.26,0.51$ & -0.34 & $-1.22,0.54$ \\
\hline Age & 1.33 & $-1.61,4.28$ & 1.08 & $-1.89,4.04$ & 1.50 & $-1.48,4.49$ \\
\hline Economic status & 0.34 & $-1.59,2.27$ & 0.36 & $-1.55,2.26$ & 0.32 & $-1.56,2.19$ \\
\hline Democratic values & -0.70 & $-2.55,1.14$ & -0.68 & $-2.51,1.15$ & -0.09 & $-1.86,1.68$ \\
\hline Constant & $-5.19^{* * * *}$ & $-7.06,-3.32$ & $-5.20^{* * * *}$ & $-7.07,-3.34$ & $-4.73^{* * * *}$ & $-6.44,-3.03$ \\
\hline Observations & 1265 & & 1267 & & 1268 & \\
\hline$A I C$ & 251.5 & & 245.2 & & 254.0 & \\
\hline$B I C$ & 282.3 & & 276.1 & & 284.9 & \\
\hline chi2 & 14.00 & & 20.34 & & 11.61 & \\
\hline
\end{tabular}

\section{Table S44}

Repression and political violence (PVPARTICIPATION) by the target of repression (Nicaraguan sample). The table reports regression coefficients (logits) and the corresponding 95\% CIs. $* p<0.05, * * p<0.01, * * * p<0.001, * * * * p<0.0001$. 


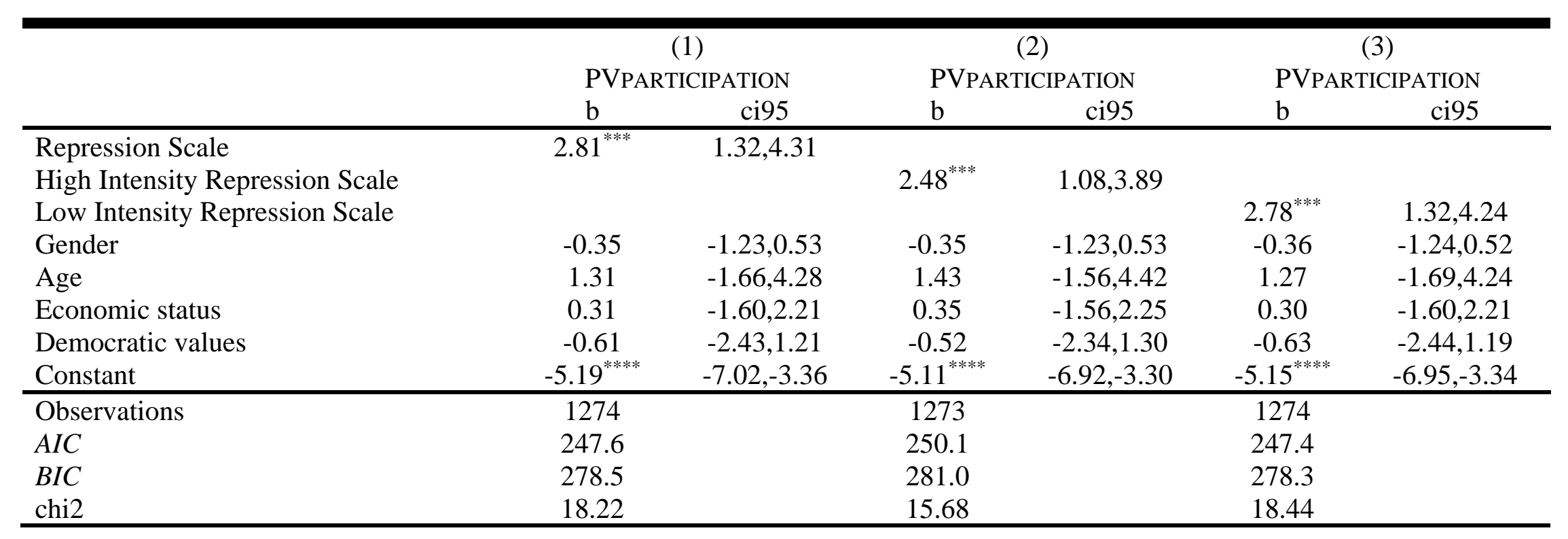

\section{Table S45}

Aggregate, high-intensity, and low-intensity repression and political violence (PVPARTICIPATION) (Nicaraguan sample). The table reports regression coefficients (logits) and the corresponding 95\% CIs. $* p<0.05, * * p<0.01$, *** $p<0.001$, **** $p<0.0001$. 
(1)

PDPARTICIPATION

Repression (typical)

Repression (friends)

Repression (self)

Gender

Age

Economic status

Democratic values

Constant

Observations

AIC

$B I C$

chi2

Repression and protests/demonstrations (PDPARTICIPATION) by the target of repression (Nicaraguan sample). The table reports regres-

sion coefficients (logits) and the corresponding 95\% CIs. * $p<0.05$, ** $p<0.01$, *** $p<0.001$, **** $p<0.0001$.
(3)

PDPARTICIPATION

PDPARTICIPATION

ci95

$\mathrm{b}$

ci95

$\frac{\operatorname{ci} 95}{21,2.00}$

$1.87^{* * * * *} \quad 1.51,2.23$

$2.27^{* * * *} \quad 1.85,2.70$

$-0.46,0.06$

$-1.34,0.76$

$0.82,2.08$

$0.24,1.48$

$-0.15$

$-0.44$

$1.49^{* * * *}$

$0.86^{* *}$

$-3.35,-2.14$

$-2.75^{* * * *}$

$-0.42,0.11$

$-1.52,0.63$

$0.85,2.13$

$0.23,1.48$

$-3.36,-2.14$

1408.0

1438.6

163.5

$-0.13$

$-0.23$

$1.50^{* * * *}$

$1.13^{* * *}$

$-2.74^{* * * *}$

1211

1402.3

1432.9

170.5

$-0.40,0.14$

$-1.31,0.85$

$0.86,2.14$

$0.52,1.74$

$-3.35,-2.14$

1480.5

120.7

\section{Table S46}


(1)

\begin{tabular}{|c|c|c|c|c|c|c|}
\hline & \multicolumn{2}{|c|}{ PDPARTICIPATION } & \multicolumn{2}{|c|}{ PDPARTICIPATION } & \multicolumn{2}{|c|}{ PDPARTICIPATION } \\
\hline & $\mathrm{b}$ & ci95 & $\mathrm{b}$ & ci95 & $\mathrm{b}$ & ci95 \\
\hline Repression Scale & $2.39^{* * * * *}$ & $1.95,2.82$ & & & & \\
\hline High Intensity Repression Scale & & & $2.10^{* * * *}$ & $1.67,2.52$ & & \\
\hline Low Intensity Repression Scale & & & & & $2.38^{* * * *}$ & $1.95,2.81$ \\
\hline Gender & -0.15 & $-0.42,0.12$ & -0.15 & $-0.42,0.11$ & -0.16 & $-0.42,0.11$ \\
\hline Age & -0.29 & $-1.37,0.79$ & -0.30 & $-1.36,0.77$ & -0.28 & $-1.37,0.80$ \\
\hline Economic status & $1.51^{* * * *}$ & $0.87,2.15$ & $1.51^{* * * *}$ & $0.87,2.14$ & $1.51^{* * * *}$ & $0.87,2.15$ \\
\hline Democratic values & $0.78^{*}$ & $0.15,1.40$ & $0.87^{* *}$ & $0.25,1.48$ & $0.78^{*}$ & $0.16,1.40$ \\
\hline Constant & $-2.90^{* * * *}$ & $-3.51,-2.28$ & $-2.84^{* * * *}$ & $-3.44,-2.23$ & $-2.89^{* * * *}$ & $-3.50,-2.27$ \\
\hline Observations & 1216 & & 1216 & & 1216 & \\
\hline$A I C$ & 1400.5 & & 1423.4 & & 1396.7 & \\
\hline$B I C$ & 1431.1 & & 1454.0 & & 1427.3 & \\
\hline chi2 & 177.8 & & 154.9 & & 181.6 & \\
\hline
\end{tabular}

\section{Table S47}

Aggregate, high-intensity, and low-intensity repression and protests/demonstrations (PDPARTICIPATION) (Nicaraguan sample). The table reports regression coefficients (logits) and the corresponding 95\% CIs.* $p<0.05, * * p<0.01, * * * p<0.001, * * * * p<0.0001$. 
Here is a list of actions that people sometimes take as citizens. For each of these, please tell me whether you, personally, have done any of these things during the past year. If not, would you do this if you had the chance?"

\begin{tabular}{lcc} 
& "Used force or violence for a political cause" & "Attended a demonstration or a protest march" \\
\hline Afrobarometer 5 & $1.76 \%$ & $\mathbf{1 . 8 7 \%}$ \\
Afrobarometer 2 & $1.57 \%$ & $\mathbf{1 . 6 3 \%}$ \\
Latinobarómetro 2013 & $\mathbf{2 . 6 0 \%}$ & $1.75 \%$ \\
Asianbarometer 4 & $\mathbf{2 . 8 2 \%}$ & $2.45 \%$ \\
Asianbarometer 3 & $0.76 \%$ & $\mathbf{0 . 9 7 \%}$ \\
Asianbarometer 2 & $\mathbf{0 . 6 8 \%}$ & $0.61 \%$ \\
Venezuela & $2.00 \%$ & $\mathbf{2 . 7 0 \%}$ \\
Nicaragua & $4.26 \%$ & $\mathbf{9 . 2 1 \%}$ \\
\hline
\end{tabular}

\section{Table S48}

A comparison of nonresponse rates to the questions about violence (PVPARTICIPATION) and protests/demonstrations. The table reports percentages of interviewees who replied "prefer not to say" or "don't know". In the EHU survey, we did not measure PVPARTICIPATION. The nonresponse to the question about PVINTENTIONS in the EHU survey is $4.15 \%$. 
PVPARTICIPATION $=1$

Afrobarometer 5

Afrobarometer 2

Latinobarómetro 2013

Asianbarometer 4

Asianbarometer 3

Asianbarometer 2

Venezuela

Nicaragua

Table S49

A comparison of repression levels among participants in violence and nonresponders. The table reports average perceived repression scale, PRS (Afrobarometers 2 and 5, Latinobarómetro 2013, Asianbarometers 2-4) and repression scale, RS (Venezuela and Nicaragua) for two sub-samples: interviewees who reported participation in violence (PVPARTICIPATION $=1)$ and interviewees who replied "prefer not to say"/ "don't know" to the question about violence (nonresponders). In the EHU survey, we did not measure PVPARTICIPATION.
Nonresponders

.24

.27

.51

.40

.39

.393

.52

.74

.69 


\begin{tabular}{|c|c|c|c|}
\hline \multirow[b]{2}{*}{ List } & \multirow[b]{2}{*}{ Condition } & \multicolumn{2}{|c|}{$R S$} \\
\hline & & $\begin{array}{c}\text { low } \\
n=185\end{array}$ & $\begin{array}{c}\text { high } \\
n=183\end{array}$ \\
\hline \multirow[t]{8}{*}{$A$} & Baseline & 1.84 & 1.72 \\
\hline & & $(0.68)$ & $(0.68)$ \\
\hline & & $\mathrm{n}=99$ & $\mathrm{n}=88$ \\
\hline & Treatment & 1.86 & 1.94 \\
\hline & & $(0.86)$ & $(0.90)$ \\
\hline & & $\mathrm{n}=86$ & $\mathrm{n}=95$ \\
\hline & Estimated proportion supporting political violence (Treatment-Base- & & \\
\hline & line) & 0.02 & 0.22 \\
\hline \multirow[t]{8}{*}{$B$} & Baseline & 1.46 & 1.33 \\
\hline & & $(0.70)$ & $(0.71)$ \\
\hline & & $\mathrm{n}=85$ & $\mathrm{n}=99$ \\
\hline & Treatment & 1.56 & 1.55 \\
\hline & & $(0.87)$ & $(0.66)$ \\
\hline & & $\mathrm{n}=95$ & $\mathrm{n}=88$ \\
\hline & Estimated proportion supporting political violence (Treatment-Base- & & \\
\hline & line) & 0.10 & 0.21 \\
\hline \multirow[t]{2}{*}{ Overall } & Average estimated proportion supporting political violence & 0.06 & 0.22 \\
\hline & & $(0.53)$ & $(0.61)$ \\
\hline
\end{tabular}

\section{Table S50}

List experiment, EHU: Estimated proportions of support for violence among respondents with high and low scores on the repression scale, RS. The table reports means with standard deviations in parentheses. 


\begin{tabular}{|c|c|c|c|c|}
\hline \multirow[b]{2}{*}{ List } & \multirow[b]{2}{*}{ Condition } & \multicolumn{3}{|c|}{$R S$} \\
\hline & & $\begin{array}{l}\text { lowest third } \\
\quad n=321\end{array}$ & $\begin{array}{c}\text { middle } \\
\text { third } \\
n=332\end{array}$ & $\begin{array}{l}\text { highest third } \\
\quad n=339\end{array}$ \\
\hline \multirow[t]{7}{*}{$A$} & Baseline & 1.91 & 1.96 & 1.99 \\
\hline & & $(0.85)$ & $(0.83)$ & $(0.82)$ \\
\hline & & $\mathrm{n}=156$ & $\mathrm{n}=175$ & $\mathrm{n}=164$ \\
\hline & Treatment & 1.92 & 2.34 & 2.32 \\
\hline & & $(1.01)$ & $(0.95)$ & (1.06) \\
\hline & & $\mathrm{n}=165$ & $\mathrm{n}=157$ & $\mathrm{n}=175$ \\
\hline & $\begin{array}{l}\text { Estimated proportion supporting political violence (Treatment-Base- } \\
\text { line) }\end{array}$ & 0.005 & 0.38 & 0.33 \\
\hline \multirow[t]{7}{*}{$B$} & Baseline & 1.58 & 1.91 & 1.95 \\
\hline & & $(0.82)$ & $(0.75)$ & $(0.82)$ \\
\hline & & $\mathrm{n}=165$ & $\mathrm{n}=157$ & $\mathrm{n}=175$ \\
\hline & Treatment & 1.92 & 2.04 & 2.09 \\
\hline & & $(0.92)$ & $(0.83)$ & $(0.90)$ \\
\hline & & $\mathrm{n}=156$ & $\mathrm{n}=175$ & $\mathrm{n}=164$ \\
\hline & $\begin{array}{l}\text { Estimated proportion supporting political violence (Treatment-Base- } \\
\text { line) }\end{array}$ & 0.35 & 0.13 & 0.14 \\
\hline Overall & Average estimated proportion supporting political violence & $\begin{array}{c}0.18 \\
(0.61)\end{array}$ & $\begin{array}{c}0.25 \\
(0.57)\end{array}$ & $\begin{array}{c}0.23 \\
(0.60)\end{array}$ \\
\hline
\end{tabular}

\section{Table S51}

List experiment, Venezuela: Estimated proportions of support for violence among respondents with high and low scores on the repression scale, RS. The table reports means with standard deviations in parentheses. 


\begin{tabular}{|c|c|c|c|c|}
\hline \multirow[b]{2}{*}{ List } & \multirow[b]{2}{*}{ Condition } & \multicolumn{3}{|c|}{$R S$} \\
\hline & & $\begin{array}{l}\text { lowest third } \\
n=512\end{array}$ & $\begin{array}{c}\text { middle } \\
\text { third } \\
n=518\end{array}$ & $\begin{array}{l}\text { highest third } \\
\quad n=519\end{array}$ \\
\hline \multirow[t]{7}{*}{$A$} & Baseline & 1.85 & 1.90 & 2.00 \\
\hline & & $(0.94)$ & $(0.90)$ & $(0.86)$ \\
\hline & & $\mathrm{n}=259$ & $\mathrm{n}=265$ & $\mathrm{n}=282$ \\
\hline & Treatment & 1.61 & 1.93 & 2.11 \\
\hline & & $(0.99)$ & $(1.00)$ & $(0.96)$ \\
\hline & & $\mathrm{n}=253$ & $\mathrm{n}=253$ & $\mathrm{n}=237$ \\
\hline & $\begin{array}{l}\text { Estimated proportion supporting political violence (Treatment - Base- } \\
\text { line) }\end{array}$ & $0.00^{\mathrm{C}}$ & 0.03 & 0.11 \\
\hline \multirow[t]{7}{*}{$B$} & Baseline & 1.46 & 1.70 & 1.82 \\
\hline & & $(0.87)$ & $(0.75)$ & $(0.80)$ \\
\hline & & $\mathrm{n}=253$ & $\mathrm{n}=253$ & $\mathrm{n}=237$ \\
\hline & Treatment & 1.62 & 1.84 & 2.02 \\
\hline & & $(0.96)$ & $(0.86)$ & $(1.03)$ \\
\hline & & $\mathrm{n}=259$ & $\mathrm{n}=265$ & $\mathrm{n}=282$ \\
\hline & $\begin{array}{l}\text { Estimated proportion supporting political violence (Treatment-Base- } \\
\text { line) }\end{array}$ & 0.16 & 0.13 & 0.20 \\
\hline Overall & Average estimated proportion supporting political violence & $\begin{array}{c}0.08 \\
(0.62)\end{array}$ & $\begin{array}{c}0.08 \\
(0.60)\end{array}$ & $\begin{array}{c}0.16 \\
(0.58)\end{array}$ \\
\hline
\end{tabular}

\section{Table S52}

List experiment, Nicaragua: Estimated proportions of support for violence among respondents with high and low scores on the repression scale, RS. The table reports means with standard deviations in parentheses. Superscript C indicates that this value was set to zero because the difference-in-means estimator was negative. 